\title{
EUTROPHICATION TRENDS INFERRED FROM HYPOLIMNETIC DISSOLVED-OXYGEN DYNAMICS WITHIN SELECTED WHITE RIVER RESERVOIRS, NORTHERN ARKANSAS - SOUTHERN MISSOURI, 1974-94
}

By W. Reed Green

U.S. GEOLOGICAL SURVEY

Water-Resources Investigations Report 96-4096

Prepared in cooperation with the ARKANSAS GAME AND FISH COMMISSION

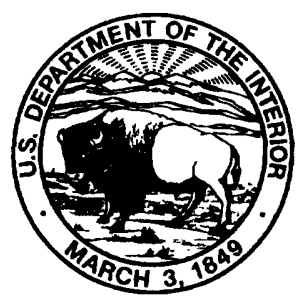




\section{U.S. DEPARTMENT OF THE INTERIOR \\ BRUCE BABBITT, Secretary}

U.S. GEOLOGICAL SURVEY

Gordon P. Eaton, Director

-For addtional information write to:

District Chief

U.S. Geological Survey

401 Hardin Road

Little Rock, AR 72211
Copies of this report can be purchased from:

U.S. Geological Survey

Earth Science Information Center

Box 25286, Mail Stop 517

Denver Federal Center

Denver, CO 80225 


\section{CONTENTS}

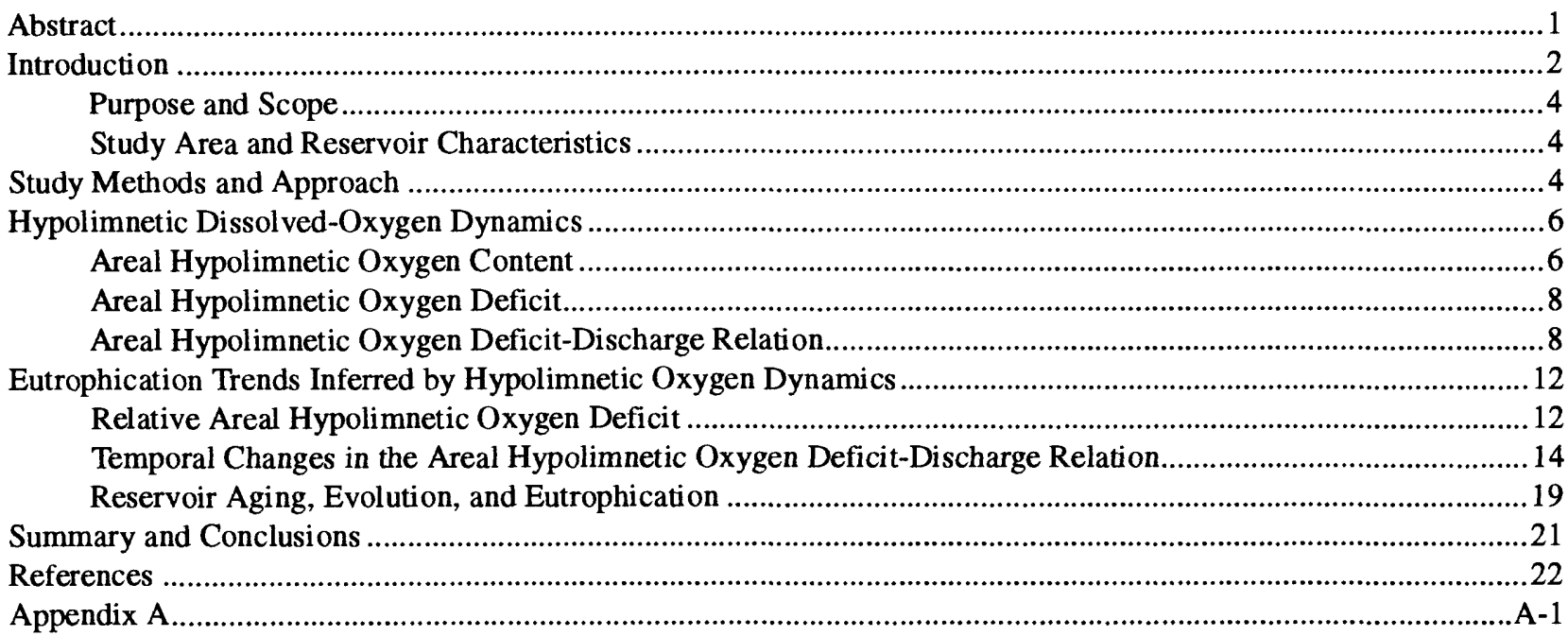

\section{ILLUSTRATIONS}

1. Diagram showing a generalized model of the initial location and extent of longitudinal development of the anoxic zone during years of high, average, and low flow in a deep-storage reservoir................................... 3

2. Map showing location of Beaver, Table Rock, Bull Shoals, and Norfork Lakes ..........................................5

3-13. Graphs showing:

3. Rate of change in areal hypolimnetic oxygen content for Bull Shoals Lake during the 1994 season.................6

4. Annual cycle of areal hypolimnetic content in Beaver, Table Rock, Bull Shoals, and Norfork Lakes from

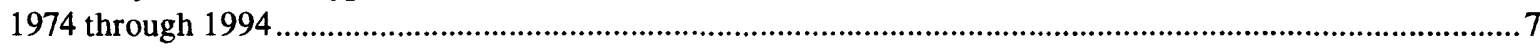

5. Measured areal hypolimnetic oxygen deficit in Beaver, Table Rock, Bull Shoals, and Norfork Lakes from 1974 through 1994 7

6. Seasonal reciprocal hydraulic residence time in Beaver, Table Rock, Bull Shoals, and Norfork Lakes from 1974 through 1994.

. Relation between reciprocal hydraulic residence time and areal hypolimnetic oxygen deficit in Beaver, Table Rock, Bull Shoals, and Norfork Lakes from 1974 through 1994

8. Relative areal hypolimnetic oxygen deficit for Beaver, Table Rock, Bull Shoals, and Norfork Lakes from 1974 through $1994 .$.

. Secchi disk transparency at sites near the dam in Beaver, Table Rock, Bull Shoals, and Norfork Lakes

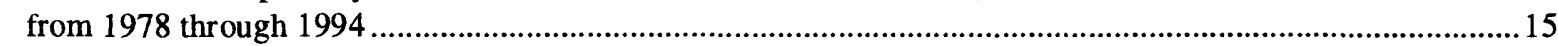

10. Chlorophyll $a$ concentrations at sites near the dam in Beaver, Table Rock, Bull Shoals, and Norfork Lakes

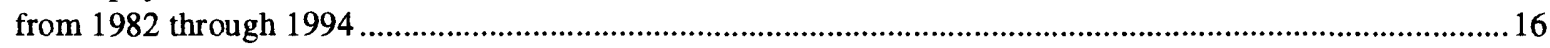

11. Total phosphorus concentrations at sites near the dam in Beaver, Table Rock, Bull Shoals, and Norfork Lakes from 1975 through 1994.

12. Time series of residuals from the oxygen deficit-discharge relations from Beaver, Table Rock, Bull Shoals, and Norfork Lakes from 1974 through 1994.

13. Conceptual model of the relation between relative reservoir age, relative level of eutrophication within each reservoir, and the 1974 through 1994 period of record 


\begin{tabular}{rll} 
Multiply & By & To obtain \\
\hline meter $(\mathrm{m})$ & 3.281 & foot \\
kilometer $(\mathrm{km})$ & 0.6214 & mile \\
square centimer $\left(\mathrm{cm}^{2}\right)$ & 0.155 & square inch \\
cubic meter $\left(\mathrm{m}^{3}\right)$ & $8.106 \times 10^{-4}$ & acre-foot \\
hectare & 2.471 & acre \\
square kilometer $\left(\mathrm{km}^{2}\right)$ & 0.3861 & square mile
\end{tabular}

Temperature in degrees Celsius $\left({ }^{\circ} \mathrm{C}\right)$ can be converted to degrees Fahrenheit $\left({ }^{\circ} \mathrm{F}\right)$ as follows:

$$
{ }^{\circ} \mathrm{F}=\left(1.8 \mathrm{x}^{\circ} \mathrm{C}\right)+32
$$




\title{
EUTROPHICATION TRENDS INFERRED FROM HYPOLIMNETIC DISSOLVED-OXYGEN DYNAMICS WITHIN SELECTED WHITE RIVER RESERVOIRS, NORTHERN ARKANSAS-SOUTHERN MISSOURI, 1974-94
}

\author{
by W. Reed Green
}

\section{ABSTRACT}

The White River Basin in northern Arkansas and southern Missouri contains four major reservoirs. Beaver, Table Rock, and Bull Shoals Lakes form a chain of reservoirs on the main stem of the White River. Norfork Lake is on the North Fork River, a tributary of the White River. Vertical water-column profiles of temperature and dissolved-oxygen concentrations have been collected monthly, in general, at sites near the dam of each reservoir since 1974. Hypolimnetic dissolved-oxygen dynamics of these reservoirs from 1974 through 1994 were examined based on the near-dam data and used to infer temporal changes in eutrophication. Regression models indicated that a positive relation existed between discharge through the dam during the stratification season and the areal hypolimnetic deficit.

Temporal changes in the relative areal hypolimnetic oxygen deficit, a model that adjusts the areal hypolimnetic oxygen deficit to standard temperature and depth, showed a decreasing trend in Beaver Lake from 1974 through 1994, indicating that the level of eutrophication decreased. Little or no change in the relative areal hypolimnetic oxygen deficit occurred in Table Rock, Bull Shoals, or Norfork Lakes over the period of record.

Temporal analysis of the residuals from the oxygen deficit-discharge model indicated that the oxygen deficit-discharge function changed over time in Beaver and Table Rock Lakes. There was little or no temporal trend in residuals of areal hypolimnetic oxygen deficit over the period of record for Bull Shoals and Norfork Lakes. Multiple regression using a time variable and discharge through the dam during the stratification season was examined for the four reservoirs. The slope coefficient of the time variable for both Beaver and Table Rock Lakes was negative, indicating that the temporal function driving the discharge related areal hypolimnetic oxygen deficit decreased over the period of record. This temporal function may be an expression of biological productivity or eutrophication. Based on these results, the level of eutrophication may have decreased in Beaver and Table Rock Lakes and remained stable in Bull Shoals and Norfork Lakes from 1974 through 1994.

It is possible that the aging and evolutionary processes in Beaver, Table Rock, Bull Shoals, and Norfork Lakes are dominant in controlling biological productivity and eutrophication in each reservoir immediately above the dam. Beaver Lake is the youngest of the four reservoirs, constructed in 1963, and for the period of record, may have been in the initial stage of high productivity followed by a declining stage of productivity that generally occurs within a reservoir soon after impoundment. Table Rock Lake was constructed in 1959 and, for the period of record, may have been in the stage of declining productivity following the peak of productivity resulting from impoundment. The impoundment of Beaver Lake upstream also may have influenced the inferred decline of productivity within Table Rock Lake. Bull Shoals and Norfork Lakes are older than Beaver and Table Rock Lakes, constructed in 1951 and 1944, respectively. The reason that 
changes in eutrophication were not detected in Bull Shoals and Norfork Lakes could be that these reservoirs, for the period of record, were characterized by the stage of low and stable productivity that generally occurs within a reservoir many years after impoundment.

\section{INTRODUCTION}

Dissolved oxygen (DO) is a critical constituent in lakes and reservoirs because it is essential to the metabolism of all aerobic aquatic organisms (Wetzel, 1983). Understanding the dynamics of oxygen distribution is fundamental to assessing the water-quality condition and metabolic characteristics of lakes and reservoirs.

In lakes and reservoirs, oxygen production occurs in the trophogenic zone (euphotic zone), the upper stratum where photosynthetic production predominates. Oxygen consumption occurs throughout the water column, but in the tropholytic zone, the aphotic deep stratum, metabolic decomposition of organic matter predominates. The rate of oxygen loss from this tropholytic zone (hypolimnion) from the beginning to end of the summer thermal stratified period is termed the oxygen deficit (Wetzel, 1983). The oxygen deficit is simply a quantified measure reflective of the decomposition of organic matter pre-existent in the hypolimnion, delivered to the hypolimnion from inflow, or that settled down into the hypolimnion from above.

Ecosystem characteristics and properties differ between reservoirs and natural lakes (Wetzel, 1990). Reservoirs are generally narrow and elongated and natural lakes are more circular. The deepest reach of a reservoir is at the dam, the downstream end. The deepest reach of a natural lake is most often near the center. Inflow into a reservoir generally results from higher order tributaries penetrating the water body as density dependent over-, inter-, or underflows. Inflow into a natural lake generally results from lower order streams and the penetration of the inflow into the water body is more dispersive. Outflow from a reservoir is highly irregular, from the surface layers or from the bottom. Outflow from a natural lake is more stable, from the surface. External constituent loading is greater in reservoirs than in natural lakes because the drainage basins of reservoirs are larger. Loading dynamics of reservoirs are also more variable and often unpredictable because of greater levels of human activity.
Horizontal variability in dissolved oxygen is greater in reservoirs than in natural lakes, because of greater variability in inflow, constituent loading patterns, and the longitudinal zonation of the reservoir (riverine, transitional, and lacustrine). Primary production in reservoirs is more variable than in natural lakes, with maximum volumetric productivity decreasing from the headwaters to the dam. Net production from the fish and other biotic communities is initially high, after stream impoundment, because of the inundation of the terrestrial soils and vegetation (5 - 20 years), and then decreases to a point where some form of equilibrium is reached (Straskrba and others, 1993). Ecosystem succession rates (aging and evolution) in reservoirs are similar to natural lakes, but greatly accelerated because of stresses created by human activities within the drainage basin (Straskrba and others, 1993).

Hypolimnetic temperature and dissolved-oxygen concentration vary from summer to summer in reservoirs, more so than in natural lakes, largely in relation to the magnitude of flow into and release out of the water body. In a bottom-release reservoir, during periods of high outflow, the coldest hypolimnetic waters are often released and replaced by the warmer waters above (Cole and Hannan, 1990). The temperature of hypolimnetic waters during years of high inflow/outflow will be greater than during years of low inflow/outflow. Warmer waters contain less oxygen than cooler waters and allow for greater oxygen consumption because of increased metabolic rates.

A general pattern of hypolimnetic oxygen dynamics has been described in deep-storage reservoirs following the onset of thermal stratification (Cole and Hannan, 1990) (fig. 1). In general, the hypolimnetic anoxic zone initially develops in the thalweg towards the upper end of the reservoir following the setup of thermal stratification in early spring. Hypolimnetic anoxia then develops both upstream and downstream as the summer stratified season proceeds. At the same time, the anoxic zone develops upward and laterally out of the thalweg. In many cases, the hypolimnetic anoxic zone intergrades with a deepening metalimnion (the stratum between the epilimnion and hypolimnion exhibiting marked thermal discontinuity), which is often low in dissolved oxygen. This generalized pattern of hypolimnetic dissolved-oxygen depletion results from an interaction of flow and morphology, which in turn affects sedimentation, primary production, the hypolimnetic temperature regime, and 

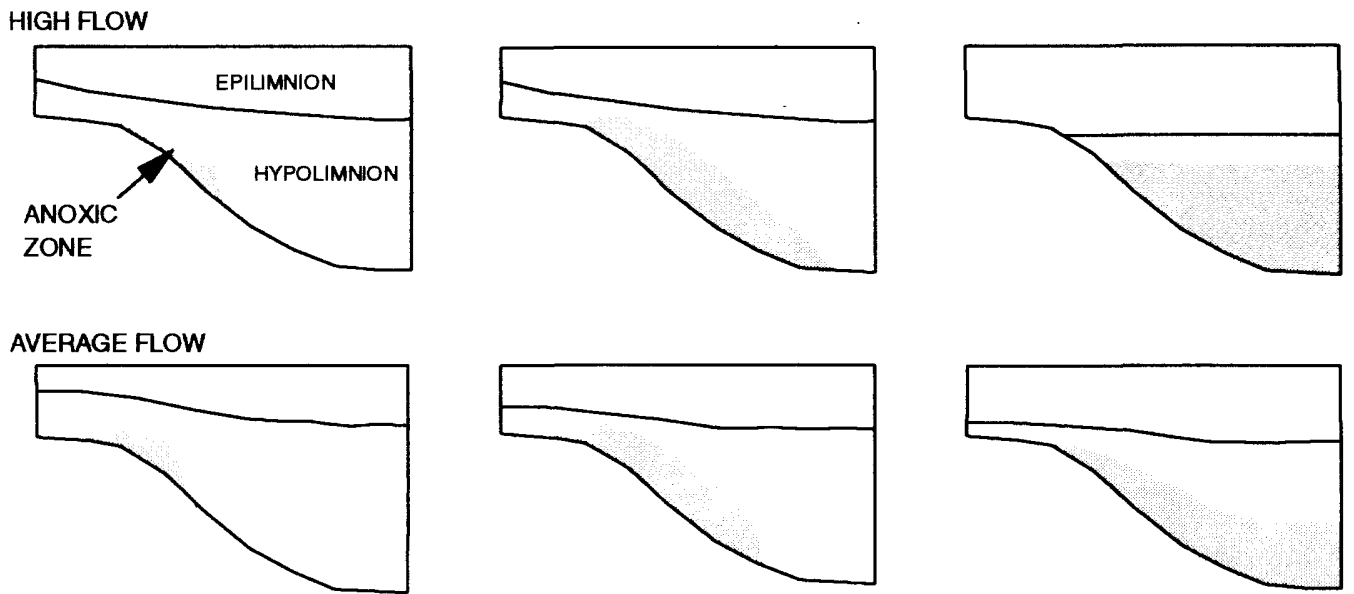

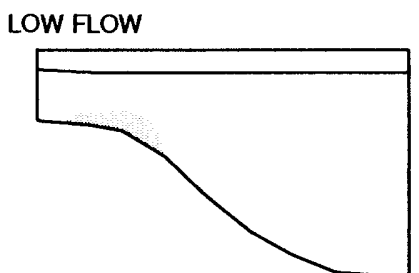

EARLY SUMMER

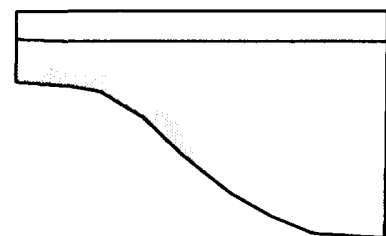

MIDDLE SUMMER

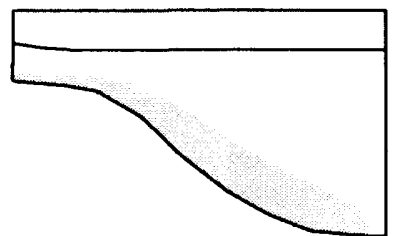

LATE SUMMER

Figure 1. Generalized model of the initial location and extent of longitudinal development of the anoxic zone during years of high, average, and low flow in a deep-storage reservoir (from Cole and Hannan, 1990).

ultimately, the amount of dissolved oxygen available to meet hypolimnetic oxygen demands.

Because eutrophication can be defined as the acceleration of biological productivity resulting from increased nutrient and organic loading, hypolimnetic oxygen consumption rates or deficits could provide a useful tool in analyzing temporal changes in water quality. When long-term records of dissolved oxygen are available, especially when detailed data on water quality and biological production are lacking, the oxygen deficit can be indicative of the general trophic status and overall changes in water quality of a lake or reservoir.

The theory and use of oxygen deficits as an approximation of lake productivity has a long history dating back to the works of Birge and Juday (1911) and Thienemann (1928), as discussed by Wetzel (1983). The techniques of estimating oxygen deficit are still in use today. Hutchinson $(1938,1957)$ set ranges of oxygen deficit along categories of unproductive to productive lakes as: oligotrophic, less than 0.017 milligrams dissolved oxygen per square centimeter per day $\left(\mathrm{mgDO} \cdot \mathrm{cm}^{-2} \cdot\right.$ day $\left.^{-1}\right)$ and eutrophic, greater than $0.033 \mathrm{mgDO} \cdot \mathrm{cm}^{-2} \cdot$ day $^{-1}$. Walker (1979) demonstrated the feasibility of relating measures of epilimnetic algal standing crop to hypolimnetic oxygen depletion. Charlton (1980) demonstrated that hypolimnetic oxygen consumption is related to hypolimnetic thickness (volume) and temperature, as well as to productivity, and determined that the use of oxygen depletion rates to compare the productivity of lakes is not justified without reference to hypolimnetic thickness and temperature. Lind and Dávalos-Lind (1993) expanded on Charlton's work, using the relative areal hypolimnetic oxygen deficit method to detect increasing eutrophication rates in Douglas Lake, Michigan. Lind and Dávalos-Lind (1993) illustrated the use of oxygen deficit adjusted to standard temperature and depth to assess changes in the rate of eutrophication.

Beaver, Table Rock, Bull Shoals, and Norfork Lakes are large, deep-storage reservoirs located in northern Arkansas and southern Missouri. These reservoirs and their tailwaters are used by the public for a number of recreational activities and are important to local and State economies. Public concern over the water quality of Beaver and Table Rock Lakes and the upper reaches of Bull Shoals Lake has increased over 
recent years because of increased population growth in northwestern Arkansas and the Branson-Springfield, Missouri areas, and the growth of the poultry industry within the White River Basin. The tailwaters of Beaver, Bull Shoals, and Norfork Lakes support a cold water trout fishery of major economic proportion. Concern has developed about the sustainability of these fisheries because of the concern over the water quality of these systems. Comprehensive information is needed to address the water quality and eutrophication status of these reservoirs.

This study was done in cooperation with the Arkansas Game and Fish Commission. Contributors to the study also include the Arkansas Game and Fish Foundation; Arkansas Department of Pollution Control and Ecology; Missouri Department of Conservation; the Arkansas Chapter of Trout Unlimited; and the Northeast Arkansas, Mid-South, and Dallas Flyfishers of the Federation of Flyfishers. This study was requested by the White River Low Dissolved Oxygen Committee which consists of representatives from the U.S. Army Corps of Engineers - Little Rock District, U.S. Department of Energy - Southwest Power Administration, Arkansas Game and Fish Commission, Arkansas Department of Pollution Control and Ecology, Arkansas Soil and Water Conservation Commission, Arkansas Department of Parks and Tourism, Missouri Department of Conservation, and Missouri Department of Natural Resources. The U.S. Geological Survey (USGS) was responsible for the collection, processing, and storage of the temperature and dissolved-oxygen data used in this report, under agreement with the U.S. Army Corps of Engineers (USCE).

\section{Purpose and Scope}

The purpose of this report is to examine trends in eutrophication based on near-dam hypolimnetic dissolved-oxygen dynamics from 1974 through 1994 in Beaver, Table Rock, Bull Shoals, and Norfork Lakes, four major reservoirs in the White River Basin in northern Arkansas and southern Missouri.

The results of this study are based on data collected at sites near the dam of each reservoir and thus reflect the water-quality condition of the lacustrine (lake-like) region within each reservoir. The magnitude and variability in water-quality characteristics of the upper regions of the reservoir or within lateral tributary embayments may not be reflected in as much detail in the near- dam data. Near-dam data represent the least variable and most conservative water-quality condition of the reservoir, and is the result of the integration of all water-quality processes within the entire drainage basin (ecosystem). The near-dam data also describe the condition of the water that is discharged downstream.

\section{Study Area and Reservoir Characteristics}

Beaver, Table Rock, and Bull Shoals Lakes form a chain of reservoirs along the main stem of the White River (fig. 2). Norfork Lake is a solitary reservoir on the North Fork River, a tributary to the White River. All four reservoirs were built for flood control and hydroelectric power generation. Beaver Lake covers 11,420 hectares $(28,220$ acres) and has a capacity of $2.04 \times 10^{9} \mathrm{~m}^{3}(1,652,000$ acre-feet $)$ at normal pool elevation. Table Rock Lake covers 21,650 hectares $\left(53,500\right.$ acres) and has a capacity of $3.33 \times 10^{9} \mathrm{~m}^{3}$ $(2,702,000$ acre-feet) at normal pool elevation. Bull Shoals Lake, the largest of the four reservoirs, covers 28,830 hectares $(71,240$ acres) and has a capacity of $3.76 \times 10^{9} \mathrm{~m}^{3}(3,048,000$ acre-feet) at normal pool elevation. Norfork Lake covers 12,420 hectares $\left(30,700\right.$ acres) and has a capacity of $1.54 \times 10^{9} \mathrm{~m}^{3}$ (1,251,000 acre-feet). The drainage areas of Beaver, Table Rock, and Bull Shoals Lakes are 3,087, 10,412, and $15,633 \mathrm{~km}^{2}\left(1,192,4,020\right.$, and $\left.6,036 \mathrm{mi}^{2}\right)$, respectively. The drainage area of Norfork Lake is $4,678 \mathrm{~km}^{2}$ $\left(1,806 \mathrm{mi}^{2}\right)$. Construction of these reservoirs was completed in 1963, 1959, 1951, and 1944, respectively.

\section{STUDY METHODS AND APPROACH}

Vertical profiles of temperature and dissolvedoxygen concentrations were collected monthly, in general, at sites near the dam of each reservoir. All data were collected using multiparameter water-quality data sonde units, calibrated prior to each day's deployment. Under conditions of thermal stratification, temperature and dissolved-oxygen concentrations were measured at varying depth increments chosen so that temperature did not change more than $1{ }^{\circ} \mathrm{C}$ between measuring points. Data were collected at $0.3-\mathrm{m}$ increments within the metalimnion where changes in temperature and dissolved-oxygen concentrations were the greatest. Sufficient data were not collected during water year 1990 in any of the reservoirs. Also, sufficient data were not collected during 1974 in Table 


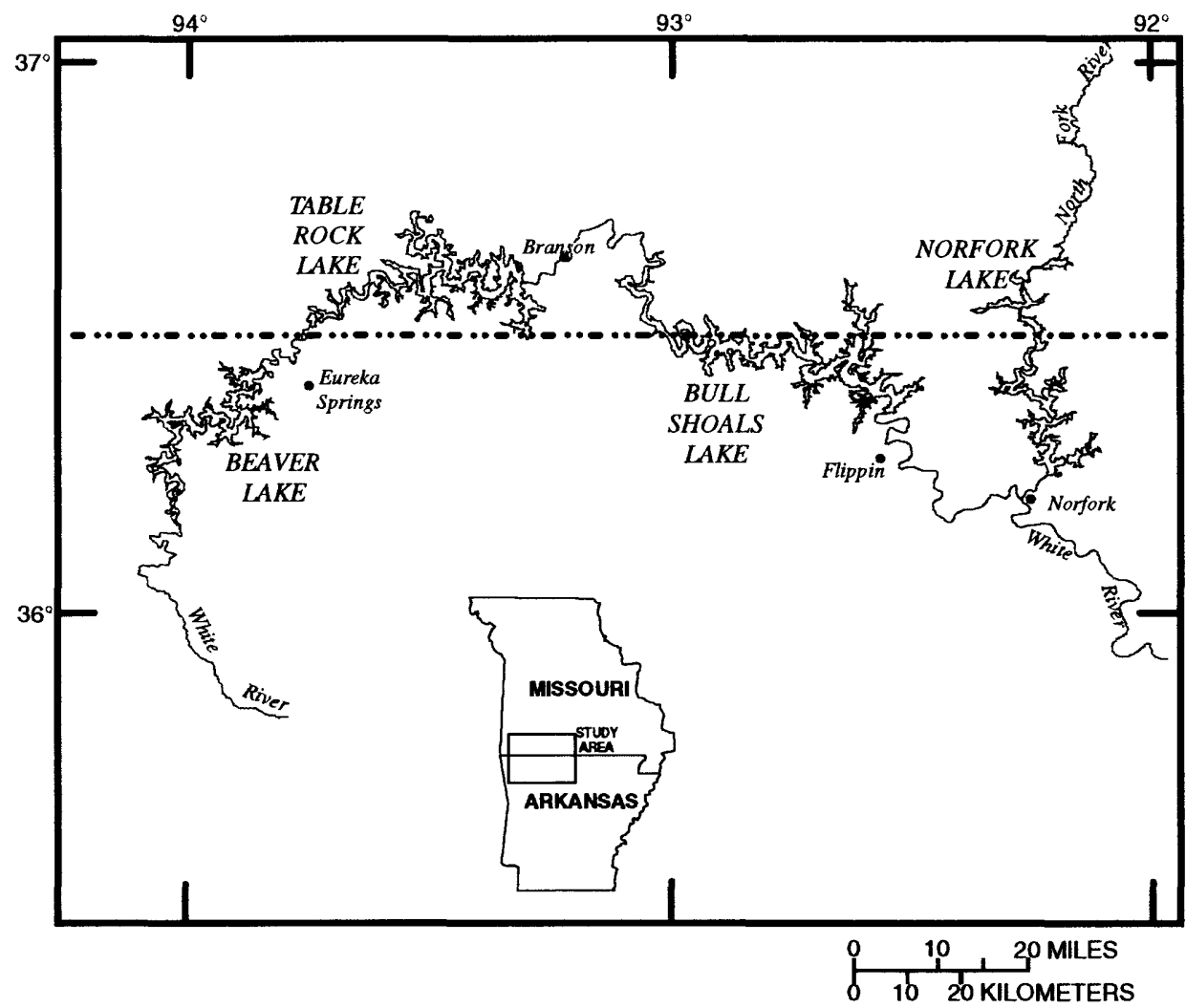

Figure 2. Location of Beaver, Table Rock, Bull Shoals, and Norfork Lakes.

Rock Lake or during 1988 in Bull Shoals Lake. The USGS station number and site names for each reservoir site location are as follows:

Beaver Lake - 07049690 Beaver Lake near Eureka Springs, Arkansas

Table Rock Lake - 07053400 Table Rock Lake near Branson, Missouri

Bull Shoals Lake - 07054500 Bull Shoals Lake near Flippin, Arkansas

Norfork Lake - 07059500 Norfork Lake near Norfork, Arkansas

Dissolved-oxygen concentration, temperature, and volume of each hypolimnetic stratum (between measured points in the water column) were used to calculate areal hypolimnetic oxygen content, mean hypolimnetic thickness, and volume weighted hypolimnetic temperature for each profile date. Dissolved-oxygen concentrations and temperature were assumed to be horizontally constant with depth, using the value of the data collected at the near-dam locations. Reservoir elevation-surface area-capacity tables provided by the USCE were used to determine volumes of hypolimnetic strata. Hypolimnetic volume and hypolimnetic surface area values for each vertical profile sampling depth were determined at the profile data depth or at the nearest $0.3-\mathrm{m}$ increment below the profile data depth.

Records of discharge into and through the dam of each reservoir were provided by the USCE. Normal reservoir pool volume determined by the USCE was then divided by the sum of seasonal discharge through the dam to determine seasonal hydraulic residence time $(R)$. The reciprocal of seasonal hydraulic residence time $\left(R^{-1}\right)$ was used as an explanatory variable in regression analysis of the areal hypolimnetic oxygen deficit. The reciprocal of hydraulic residence time equals the proportion of normal reservoir volume that was discharged through the dam daily over the specified season. For example, a reciprocal hydraulic residence time of 0.001 would be equivalent to one tenth of one percent of the total reservoir volume discharged through the dam per day.

The rate of change in the amount of oxygen present below a given depth at the beginning and end of the thermal stratification period is referred to as the hypolimnetic oxygen deficit. Areal hypolimnetic oxygen deficit (AHOD) is defined as the change in oxygen per square centimeter of hypolimnetic surface per day 
$\left(\mathrm{mgDO} \cdot \mathrm{cm}^{-2} \cdot \mathrm{day}^{-1}\right)$ over the stratification season. Areal hypolimnetic oxygen deficit was determined for each reservoir during each stratification season by calculating the coefficient or slope of the temporal change in areal hypolimnetic oxygen content (AHOC) between the spring maximum and fall minimum (fig. 3 ). The change in AHOC over the stratification season results in a negative slope. The absolute value of the slope represents the rate of dissolved-oxygen consumption or AHOD. The AHOD value for each stratification season from each reservoir was used as the oxygen dynamic variable to assess annual changes in hypolimnetic oxygen deficit. Inferences into temporal changes in the rate of eutrophication and water quality in each reservoir were developed based on annual changes in the AHOD of each reservoir.

\section{HYPOLIMNETIC DISSOLVED-OXYGEN DYNAMICS}

Annual thermal stratification cycles within Beaver, Table Rock, Bull Shoals, and Norfork Lakes exhibited typical monomictic (one turnover per year) characteristics. Towards the end of the stratification period, these reservoirs developed typical clinograde (oxic in the epilimnion, anoxic in the hypolimnion) oxygen profiles. Metalimnetic oxygen depletion often developed early and eventually integrated with the oxygen depletion in the hypolimnion to appear as if oxygen consumption was entirely hypolimnetic. Timedepth distributions of temperature and dissolved-oxygen concentration for each reservoir over the period of record (1974 through 1994) are shown in the Appendix.

\section{Areal Hypolimnetic Oxygen Content}

Areal hypolimnetic oxygen content (AHOC) for each reservoir exhibited typical annual cycles where oxygen content was the greatest during the winter months and declined at a steady rate from April through September within Table Rock and Norfork Lakes and through October within Beaver and Bull Shoals Lakes (fig. 4). Table Rock and Norfork Lakes exhibited generally lower minimum AHOC over the period of record than did Beaver or Bull Shoals Lakes. The season-ending minimum AHOC of Beaver Lake was generally greater than the other reservoirs.
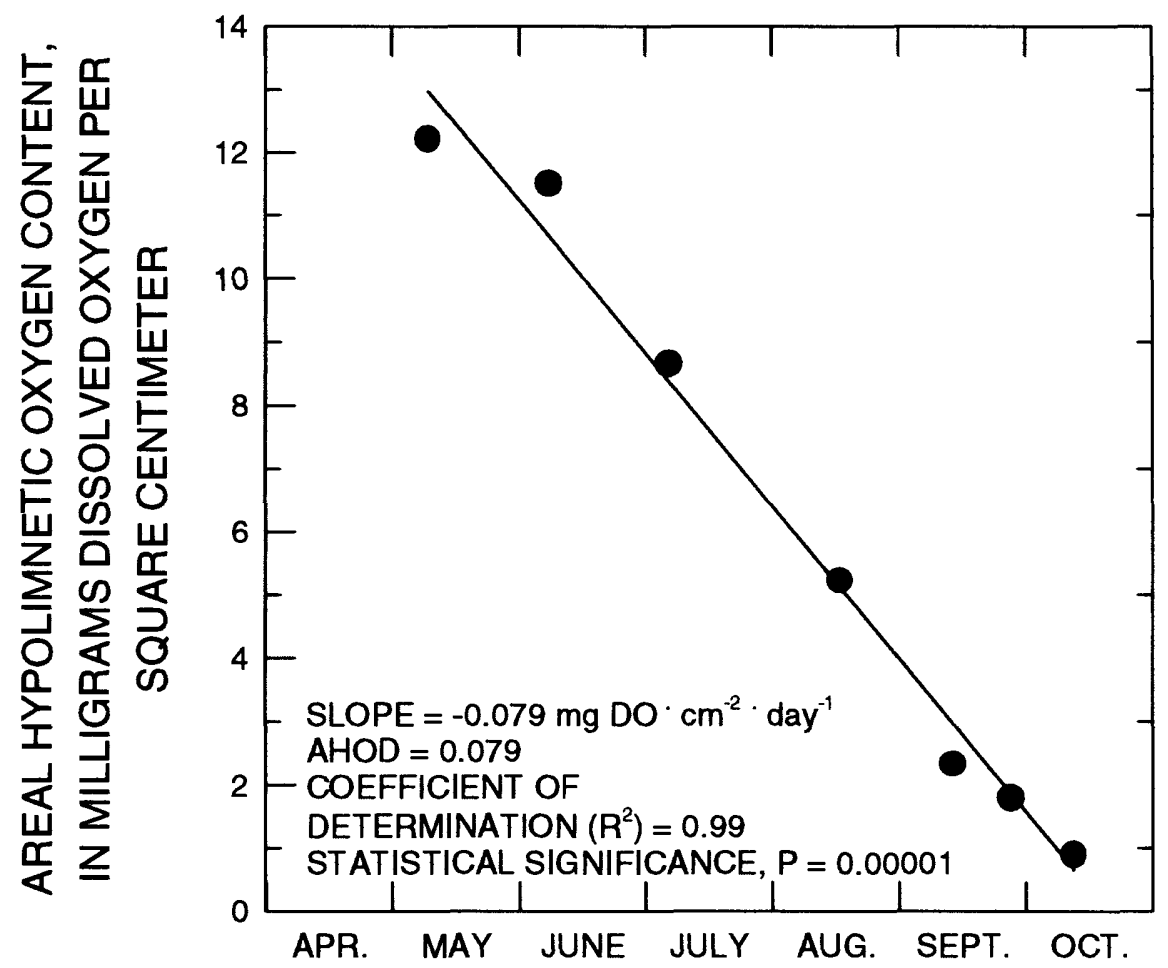

1994

Figure 3. Rate of change in areal hypolimnetic oxygen content for Bull Shoals Lake during the 1994 season. 


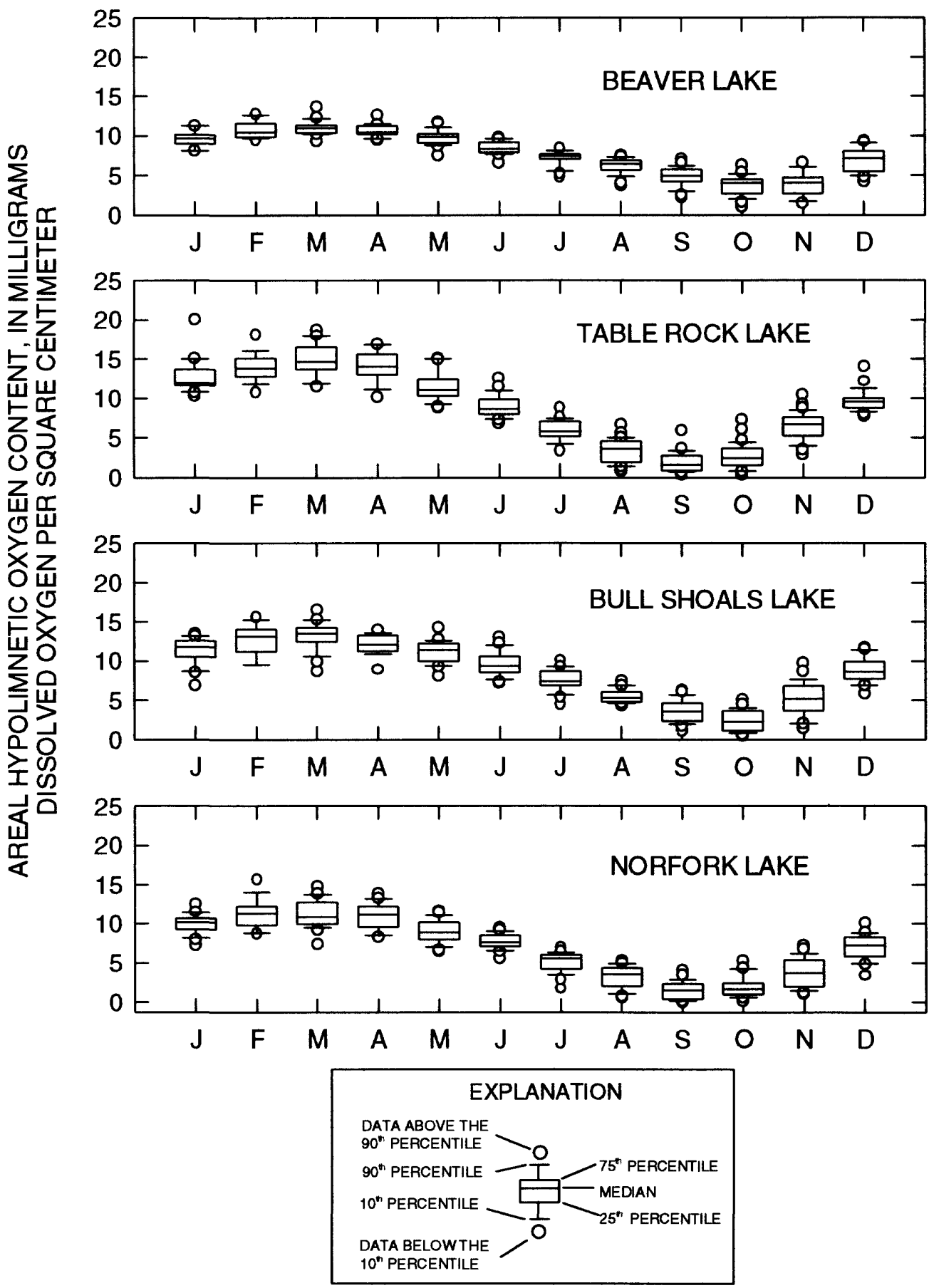

Flgure 4. Annual cycle of areal hypolimnetic oxygen content in Beaver, Table Rock, Bull Shoals, and Norfork Lakes from 1974 through 1994. 


\section{Areal Hypolimnetic Oxygen Deficit}

The seasonal areal hypolimnetic oxygen deficit (AHOD) of each reservoir system varied over the period of record (1974-94) within each reservoir and among reservoirs (fig. 5). Annual values of AHOD within each reservoir showed cyclical distributions presumably because of changes in climatic conditions and the resulting flow dynamics. The AHOD values from Beaver Lake were consistently lower than the other reservoirs, while the AHOD values from Table Rock Lake were consistently higher.

Simple linear regression and nonparametric correlation analysis (Kendall's Tau test) were used to evaluate temporal changes in areal hypolimnetic oxygen deficits from 1974 through 1994. Although the AHOD in Beaver and Table Rock Lakes appears to decrease from 1974 through 1994, these changes were not statistically significant. Likewise, the changes in AHOD over the period of record in Bull Shoals and Norfork Lakes were not statistically significant.

\section{Areal Hypolimnetic Oxygen Deficit- Discharge Relation}

Flow dynamics drive reservoir processes and should be considered when analyzing hypolimnetic oxygen deficit rates. Hydraulic residence time $(R)$ is a variable used in describing reservoir hydrodynamics; however, it is a theoretical value and does not consider the internal density dependent flow regimes within the system, such as interflow or underflow, or water that enters from a lateral tributary. In this report, seasonal hydraulic residence time was used and is defined as reservoir volume at normal pool elevation divided by discharge out of the reservoir that occurred over a defined period of time during the stratification season. Seasonal hydraulic residence time was determined from April 1 through October 31 for Beaver and Bull Shoals Lakes and from April 1 through September 30 in Table Rock and Norfork Lakes. Based on the seasonal distribution of areal hypolimnetic oxygen content within these reservoirs presented earlier (fig. 4), initial hypolimnetic oxygen depletion occurred after March and turnover occurred after October in Beaver and Bull Shoals Lakes, and after September in Table Rock and Norfork Lakes.

The reciprocal of hydraulic residence time $\left(R^{-1}\right)$ was used in this report as the explanatory discharge variable because it represents the proportion of total reservoir volume that passes through the dam, on average, per day and normalizes the discharge data among the reservoirs. Seasonal reciprocal hydraulic residence time values for each year within each reservoir are presented in figure 6 . The seasonal reciprocal hydraulic residence time for Beaver Lake, over the period of record, was generally lower than the other reservoirs, ranging from 0.0001 to 0.0024 reservoir volumes per day, and was less variable. The seasonal reciprocal hydraulic residence time was generally greater in Bull Shoals Lake than the other reservoirs, and was also the most variable, ranging from 0.0006 to 0.0060 reservoir volumes per day, over the period of record. The seasonal reciprocal hydraulic residence time in Table Rock and Norfork Lakes ranged from 0.0005 to 0.0050 and 0.0011 to 0.0055 reservoir volumes per day, respectively.

The relation between AHOD and seasonal hydraulic residence time $\left(R^{-1}\right)$ in Beaver, Table Rock, Bull Shoals and Norfork Lakes was examined through linear regression (fig. 7). The probability of the slope being zero was less than 0.003 in all four relations. Results show that between 41 and 68 percent of the variability in AHOD is explained by $R^{-1}$. The empirical relations between AHOD and $R^{-1}$ were determined as:

Beaver Lake -

$$
A H O D=0.0246+12.37\left(R^{-1}\right) ; R^{2}=0.41, P=0.0024
$$

Table Rock Lake -

$$
A H O D=0.0451+11.16\left(R^{-1}\right) ; R^{2}=0.58, P=0.00017
$$

Bull Shoals Lake -

$$
A H O D=0.0323+6.267\left(R^{-1}\right) ; R^{2}=0.57, P=0.00019
$$

Norfork Lake -

$$
A H O D=0.0297+10.38\left(R^{-1}\right) ; R^{2}=0.68, P=0.00001
$$

where,

$$
\begin{aligned}
& \mathrm{R}^{2} \text { is the coefficient of determination, and } \\
& \mathrm{P} \text { is the probability that the slope coefficient is } \\
& \text { zero. }
\end{aligned}
$$



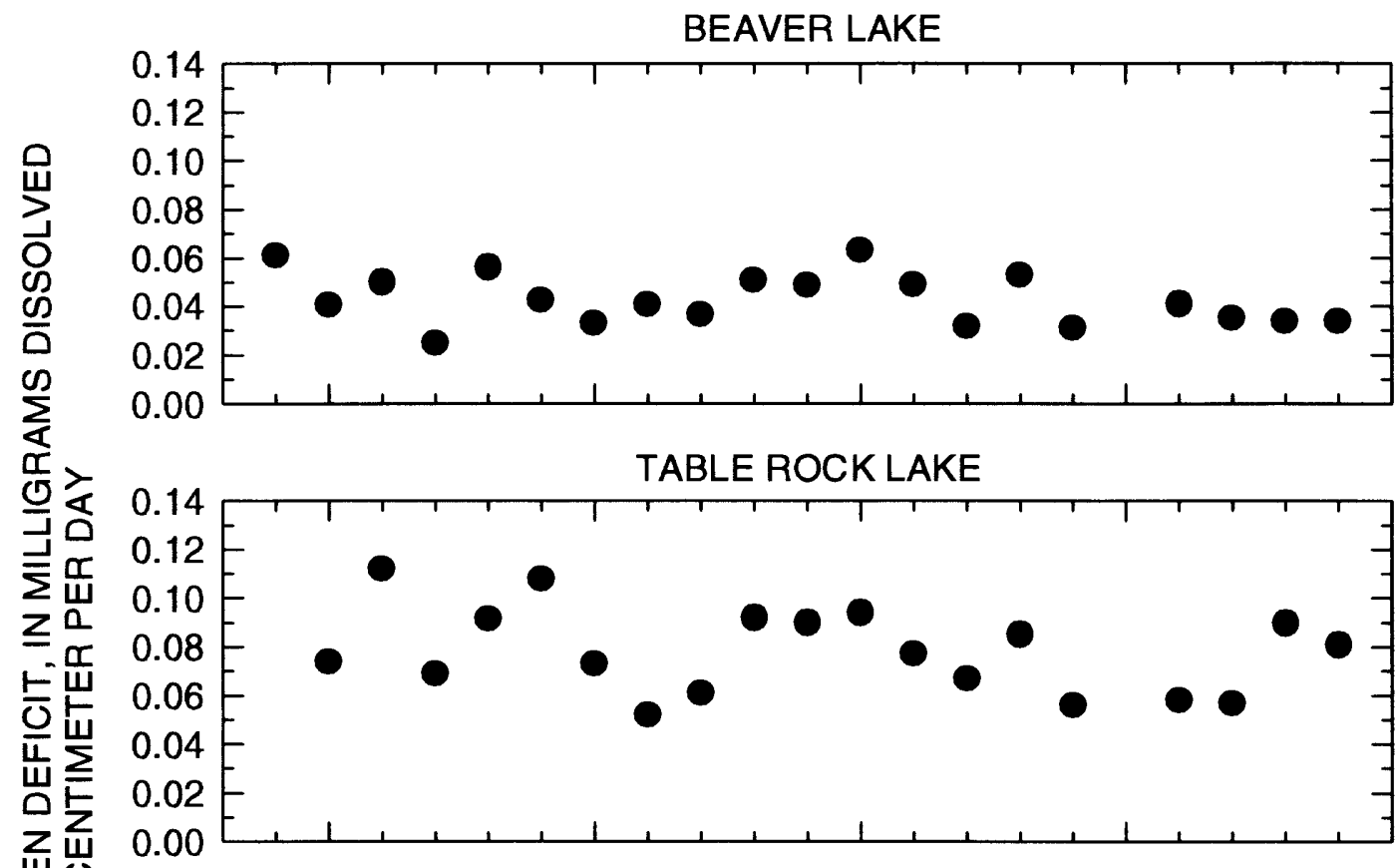

崩

心

文嵅

은

岩和

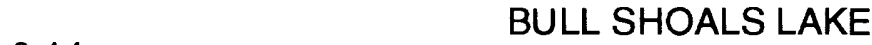

0.12

0.10

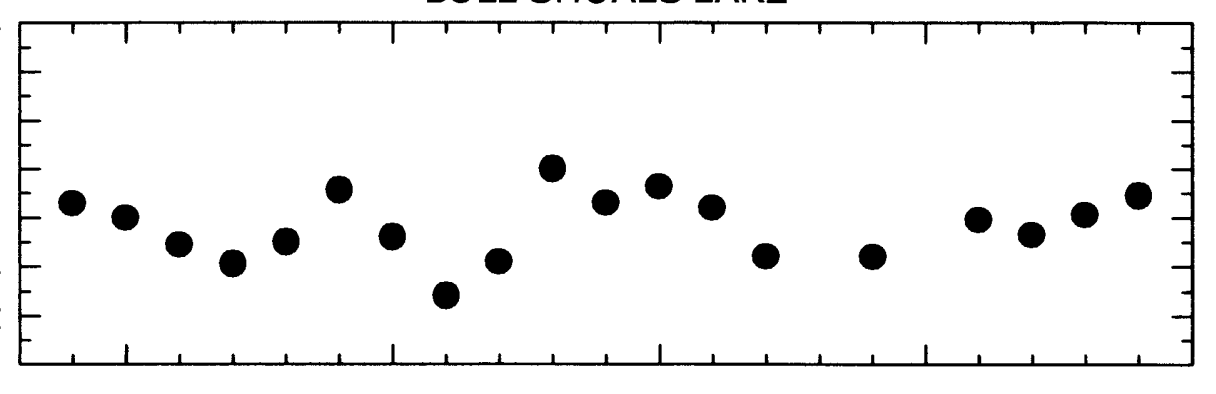

0.08

0.06

0.04

文文

0.02

0.00

$\varangle$

NORFORK LAKE

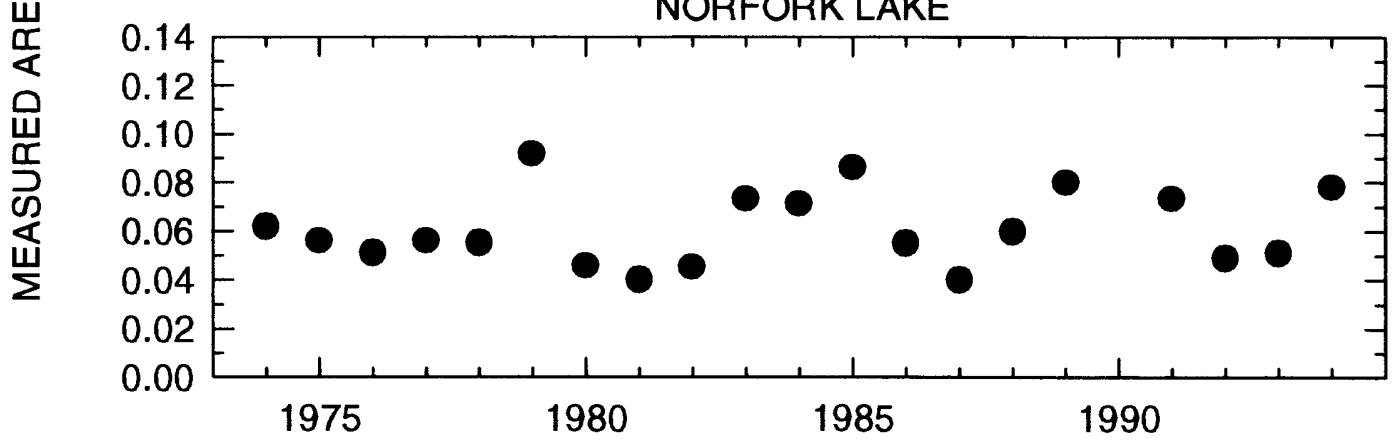

Figure 5. Measured areal hypolimnetic oxygen deficit in Beaver, Table Rock, Bull Shoals, and Norfork Lakes from 1974 through 1994. 


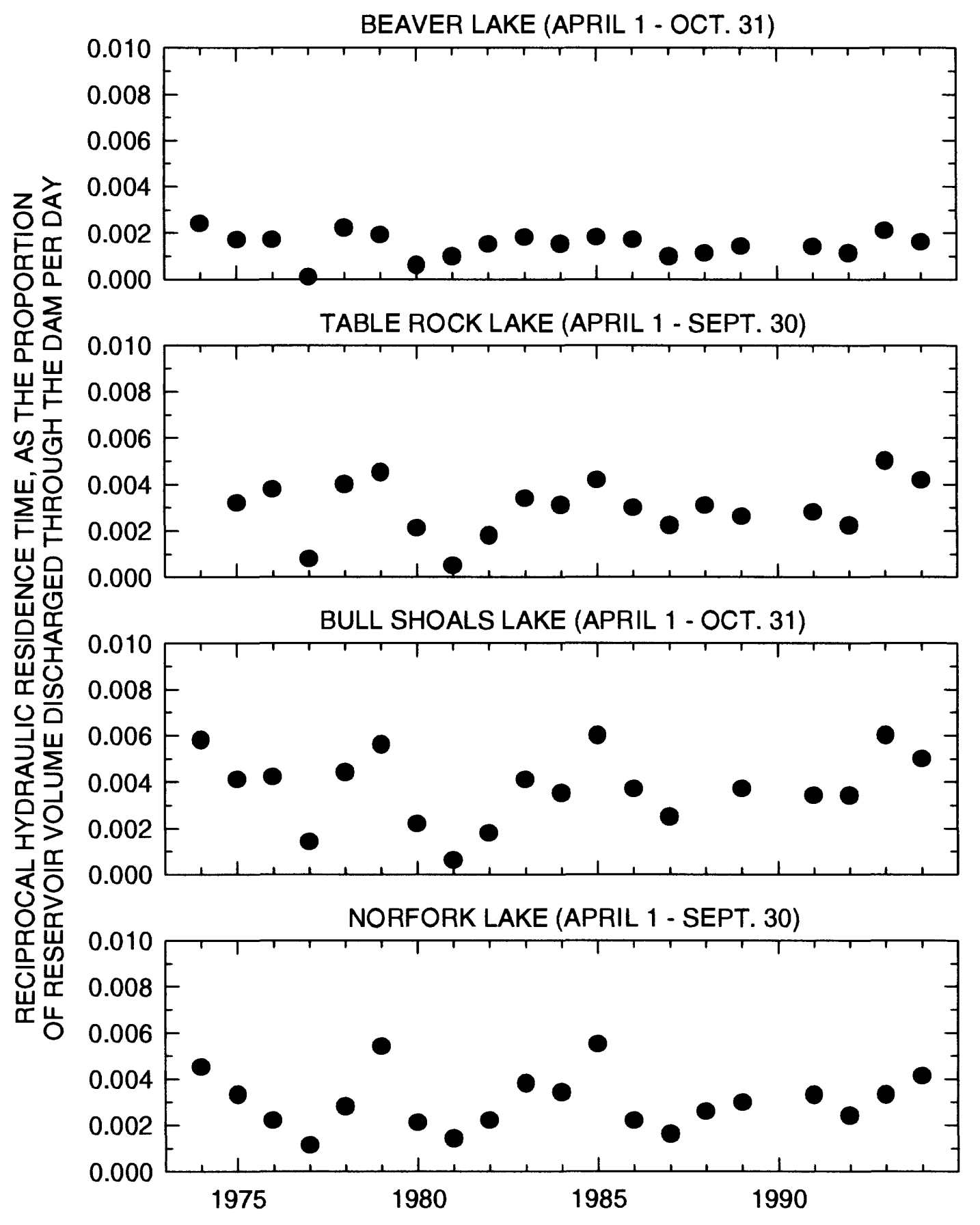

Figure 6. Seasonal reciprocal hydraulic residence time in Beaver, Table Rock, Bull Shoals, and Norfork Lakes from 1974 through 1994. 

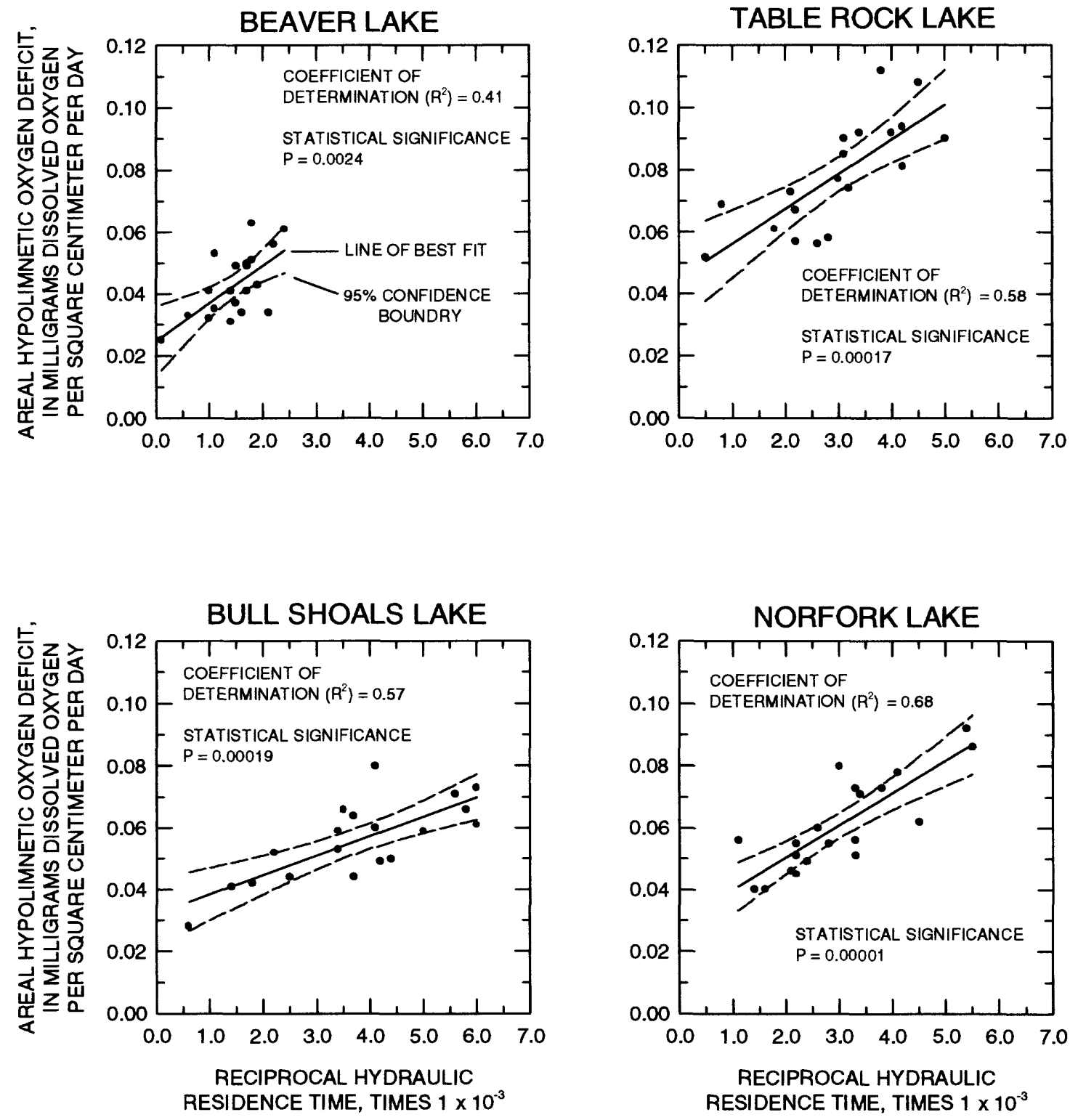

Figure 7. Relation between reciprocal hydraulic residence time and areal hypolimnetic oxygen deficit in Beaver, Table Rock, Bull Shoals, and Norfork Lakes from 1974 through 1994. 


\section{EUTROPHICATION TRENDS INFERRED FROM HYPOLIMNETIC OXYGEN DYNAMICS}

In general, as the level of eutrophication increases within a water body, so does the hypolimnetic oxygen deficit. However, other factors are involved in the oxygen depletion process besides those related to eutrophication. Traditionally, oxygen dynamics have been examined in natural lake systems rather than in reservoirs and most often are related to lake morphometry, hypolimnetic temperature and volume, and primary productivity (Wetzel, 1983; Charlton, 1980). Flow dynamics have been overlooked or assumed as insignificant when describing general oxygen dynamics patterns in natural lake systems. In reservoirs, flow dynamics drive patterns of oxygen concentration, especially in deep-storage reservoirs (Cole and Hannan, 1990). Therefore, discharge into and out of a deep-storage reservoir needs consideration when analyzing oxygen dynamics in these types of systems.

In reservoirs, the hypolimnetic oxygen deficit can be described as a function of physical variables such as hypolimnetic volume, residence time, and temperature, as well as a function of biotic productivity and metabolism. Hypolimnetic volume and temperature are affected by reservoir morphometry and hydrodynamics, and biotic productivity and metabolism are related, in part, to nutrient and organic loading. Nutrient and organic loading can be thought of as eutrophication variables and are also dependent, in part, upon flow or runoff into the system. The mass flux of nutrients and organic matter increases with increased flow into the system because greater quantities of constituents generally are delivered with greater streamflow. The nutrient and organic mass contained within the inflow water is dependent upon the quantity of constituents available for transport. Human stresses on the landscape within the drainage area upstream of a reservoir can increase the amount of nutrients and organic compounds available for transport, and, therefore, can accelerate eutrophication processes within the reservoir. If the oxygen deficit within a given system can be explained reasonably by the physical variables, such as volume, residence time, temperature, and water inflow and outflow, then the influence that eutrophication has upon the oxygen deficit can be estimated by factoring out the variability explained by one or more of those variables.

\section{Relative Areal Hypolimnetic Oxygen Deficit}

Charlton (1980) determined that the areal hypolimnetic oxygen deficit within the Laurentian Great Lakes was a function of chlorophyll content, hypolimnetic thickness (volume), and temperature:

$$
A H O D=4.09 \cdot\left[\text { fChla } \cdot Z 50+Z^{-1} \cdot 2^{(T-4) / 10}\right]+0.07
$$

where,

$f \mathrm{Chl} a$ is the chlorophyll function,

$\bar{Z}$ is mean seasonal hypolimnetic thickness, in meters, and

$\bar{T}$ is mean seasonal volume weighted hypolimnetic temperature, in degrees Celsius.

The chlorophyll function in Charlton's (1980) AHOD model (equation 5) can be estimated relative to the areal hypolimnetic oxygen deficit by standardizing AHOD under conditions of constant temperature $\left(4^{\circ} \mathrm{C}\right)$ and depth $(50 \mathrm{~m})$ and is represented as the relative areal hypolimnetic oxygen deficit (RAHOD):

$$
R A H O D=A H O D \cdot\left[\bar{Z}(50+\bar{Z})^{-1} \cdot 2^{(\bar{T}-4) / 10}\right]^{-1}
$$

The relative areal hypolimnetic deficit represents the eutrophication function expressed in the areal hypolimnetic deficit. By examining RAHOD over time, inferences can be made concerning differences in the level of eutrophication within a given system or among systems.

Equation 6 was used by Lind and Dávalos-Lind (1993) to examine temporal changes in the level of eutrophication within Douglas Lake, Michigan, from 1971 through 1991. Changes in the level of eutrophication in Douglas Lake were expressed by changes in RAHOD over the period of record. This technique was applied to AHOD values determined for Beaver, Table Rock, Bull Shoals, and Norfork Lakes to examine changes in the levels of eutrophication.

Based on the range and magnitude of the RAHOD values for each reservoir, Table Rock Lake appears to be the most eutrophic, followed by Norfork, Beaver, and Bull Shoals Lakes (fig. 8). Linear regression and nonparametric correlation analysis (Kendall's Tau test) suggest that RAHOD decreased significantly in Beaver Lake from 1974 through 1994. Probability of the slope being zero in either the linear regression or Kendall's Tau test were 0.009 and 0.021 , respec- 


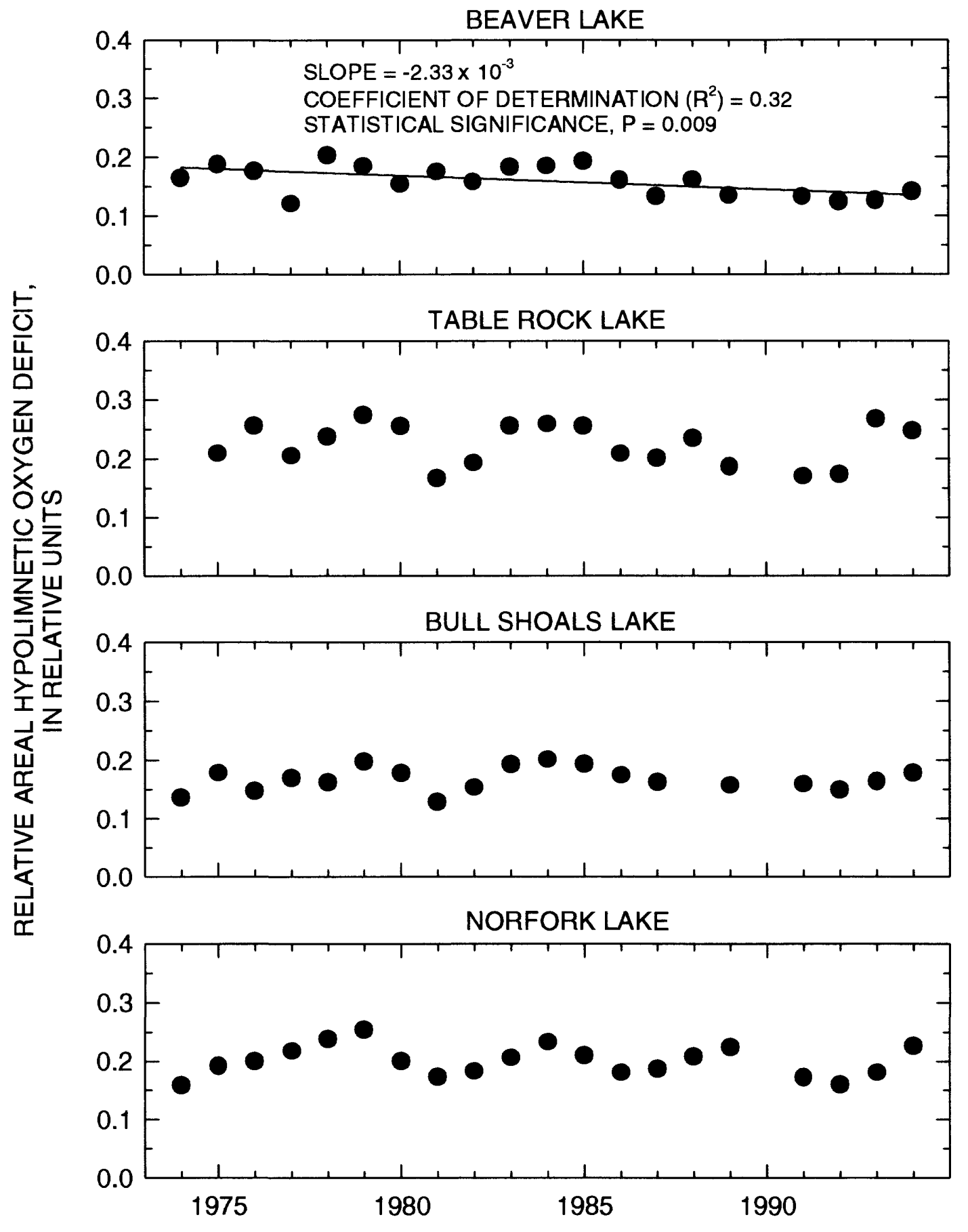

Figure 8. Relative areal hypolimnetic oxygen deficit for Beaver, Table Rock, Bull Shoals, and Norfork Lakes from 1974 through 1994; calculated by using equation 6 (Charton, 1980). 
tively. Linear regression results suggest that RAHOD decreased in Beaver Lake from 1974 through 1994 by 22 percent. Changes in RAHOD in Table Rock, Bull Shoals, and Norfork Lakes over that period of record were not statistically significant. These results indicate that the level of eutrophication or biological productivity decreased in Beaver Lake over the period of record. The level of eutrophication in Table Rock, Bull Shoals, and Norfork Lakes remained stable over the same period of time.

Examination of the temporal variations of selected trophic state variables (Secchi disk transparency, chlorophyll $a$ concentration, and total phosphorus concentration) from sampling locations near each dam, yielded mixed results when compared with the RAHOD results. Based on linear regression and nonparametric correlation (Kendall's Tau test), Secchi disk transparency changed (decreased) from 1978 through 1994 in Table Rock and Bull Shoals Lakes (fig. 9). Linear regression results suggest that Secchi disk transparency decreased by 19 percent or $0.82 \mathrm{~m}$ in Table Rock Lake and by 15 percent or $0.68 \mathrm{~m}$ in Bull Shoals Lake. The probability of the slope equaling zero in the linear regression and Kendall's Tau test were 0.007 and 0.002 , respectively, for Table Rock Lake and 0.074 and 0.009 , respectively, for Bull Shoals Lake.A decrease in Secchi disk transparency indicates that the water near the dam became more turbid over time which might indicate an increase in the level of eutrophication. However, the RAHOD results did not indicate an increase in the level of eutrophication in either Table Rock or Bull Shoals Lakes.

Changes in chlorophyll $a$ concentrations from 1982 through 1994 in Beaver, Table Rock, Bull Shoals, and Norfork Lakes were not statistically significant (fig. 10). Most of the total phosphorus concentrations in Beaver, Table Rock, Bull Shoals, and Norfork Lakes were at or below analytical detection limits $(0.01$ or $0.02 \mathrm{mg} / \mathrm{L}$ ) (fig. 11).

\section{Temporal Changes in the Areal Hypolimnetic Oxygen Deficit-Discharge Relation}

Temporal analysis of the residuals (measured estimated value) from the areal hypolimnetic oxygen deficit-discharge relations discussed earlier (equations 1 - 4) indicate that the influence of discharge through the dam during the stratification season $\left(R^{-I}\right)$ changed over time in Beaver and Table Rock Lakes (fig. 12).
There was little or no temporal trend in residuals of AHOD in Beaver Lake from 1974 through 1988. However, from 1989 through 1994 the discharge relation overpredicted AHOD. The discharge relation underpredicted AHOD in Table Rock Lake from 1976 to 1981 and overpredicted AHOD from 1989 through 1994. There was little or no temporal trend in residuals of AHOD over the period of record for Bull Shoals and Norfork Lakes. The results for Beaver and Table Rock Lakes indicate that an additional variable, one that is changing over time would aid in the explanation of the variability in AHOD within these systems.

Multiple regression using a time variable (arbitrarily assigned as 74 through 94 to represent the years 1974 through 1994) and discharge through the dam during the stratification season $\left(R^{-1}\right)$ was examined for the four reservoirs:

Beaver Lake -

$$
\begin{aligned}
& A H O D=0.0636-0.000459(\text { year })+ \\
& 12.004\left(R^{-1}\right) ; R^{2}=0.48
\end{aligned}
$$

Table Rock Lake -

$$
\begin{aligned}
& A H O D=0.1596-0.00141(\text { year })+ \\
& 12.600\left(R^{-1}\right) ; R^{2}=0.79
\end{aligned}
$$

Bull Shoals Lake -

$$
\begin{aligned}
& A H O D=0.3624-4.77 \times 10^{-5}(\text { year })+ \\
& 6.290\left(R^{-1}\right) ; R^{2}=0.57
\end{aligned}
$$

Norfork Lake -

$$
\begin{aligned}
& A H O D=0.0047+0.0003(\text { year })+ \\
& 10.301\left(R^{-1}\right) ; R^{2}=0.69
\end{aligned}
$$

where,

$$
R^{2} \text { is the coefficient of determination. }
$$

Including time as an explanatory variable increased the percent of variance explained in Beaver Lake from 41 percent (equation 1), when only $R^{-1}$ was used as an explanatory variable, to 48 percent (equation 7). The percent variance explained increased from 58 to 79 percent for Table Rock Lake (equation 2 and 8 , respectively). The addition of time to the dischargeAHOD relation did not change the explained variance in Bull Shoals Lake and only increased the explained variance by 1 percent in Norfork Lake. The slope coefficient of the time variable for both Beaver and 


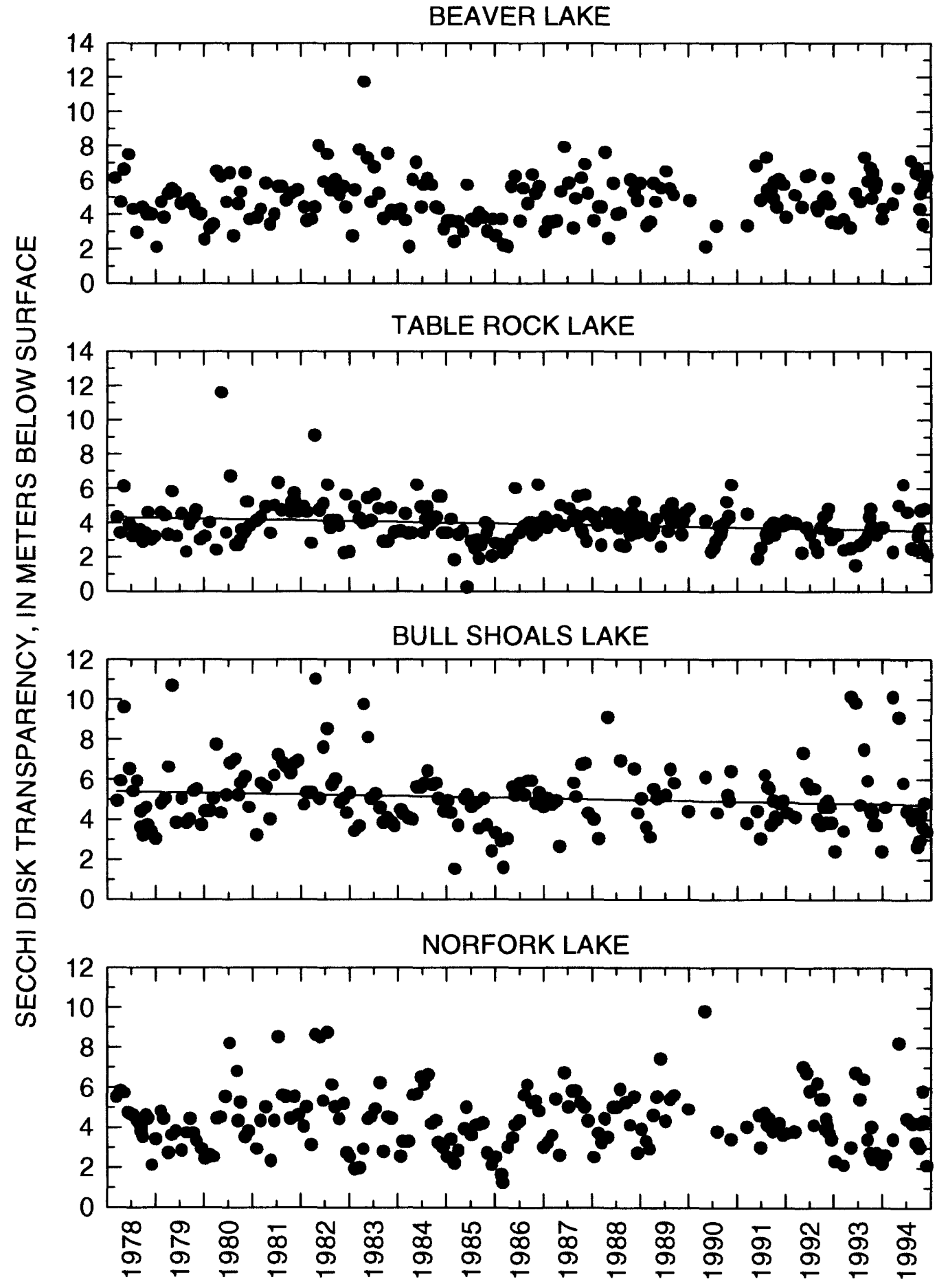

Figure 9. Secchi disk transparency at sites near the dam in Beaver, Table Rock, Bull Shoals, and Norfork Lakes from 1978 through 1994. 


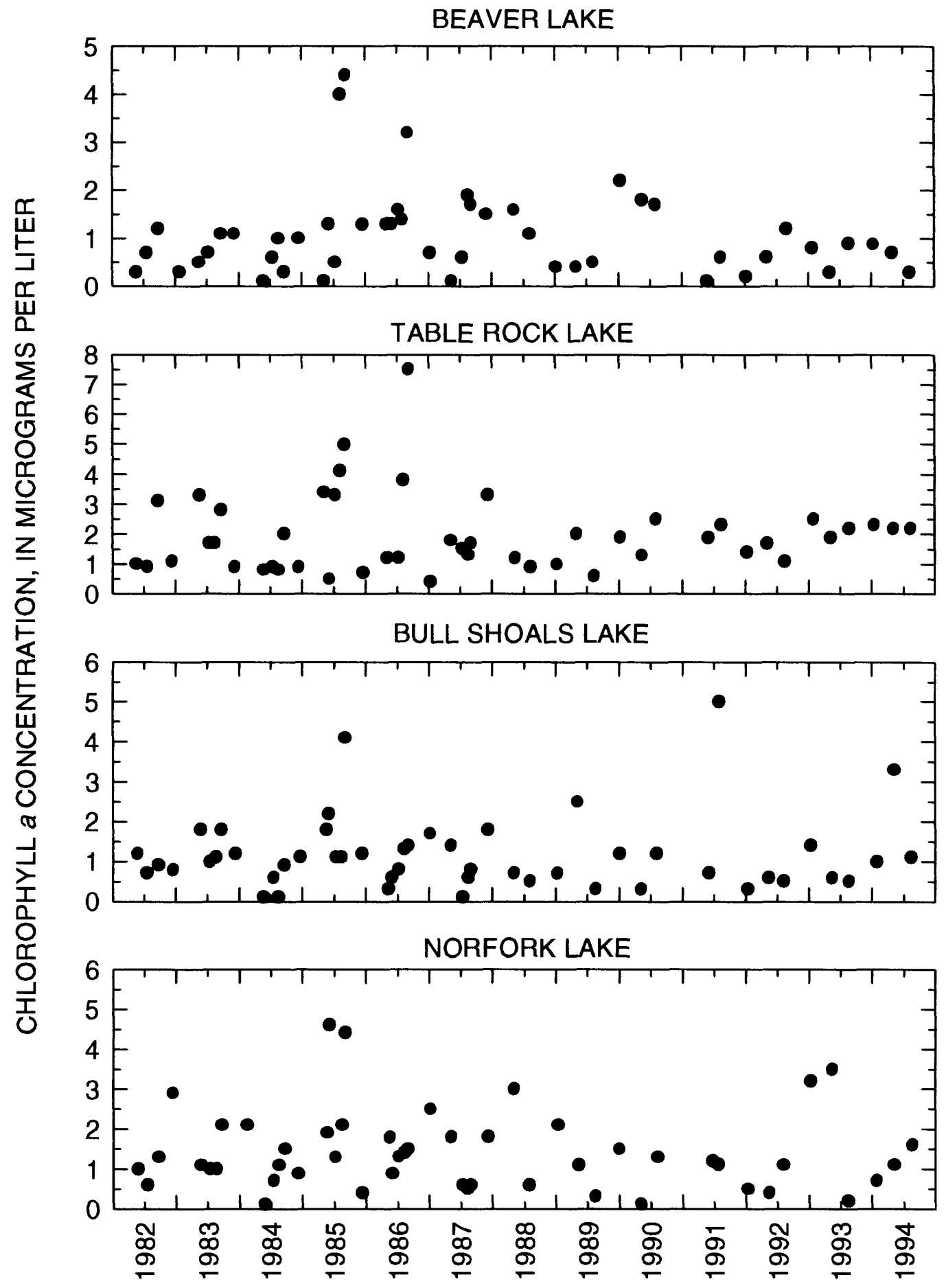

Figure 10. Chlorophyll a concentrations at sites near the dam in Beaver, Table Rock, Bull Shoals, and Norfork Lakes from 1982 through 1994. 
BEAVER LAKE

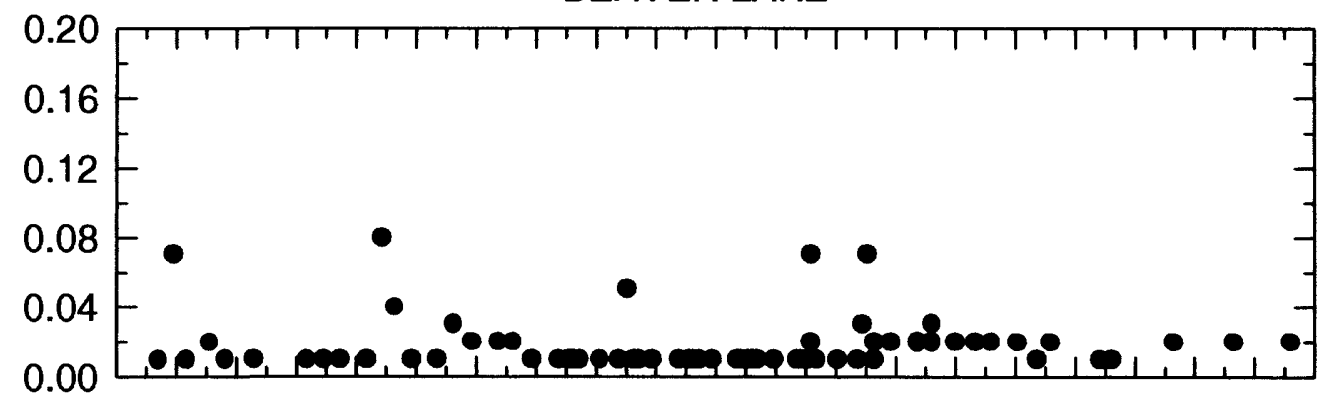

TABLE ROCK LAKE

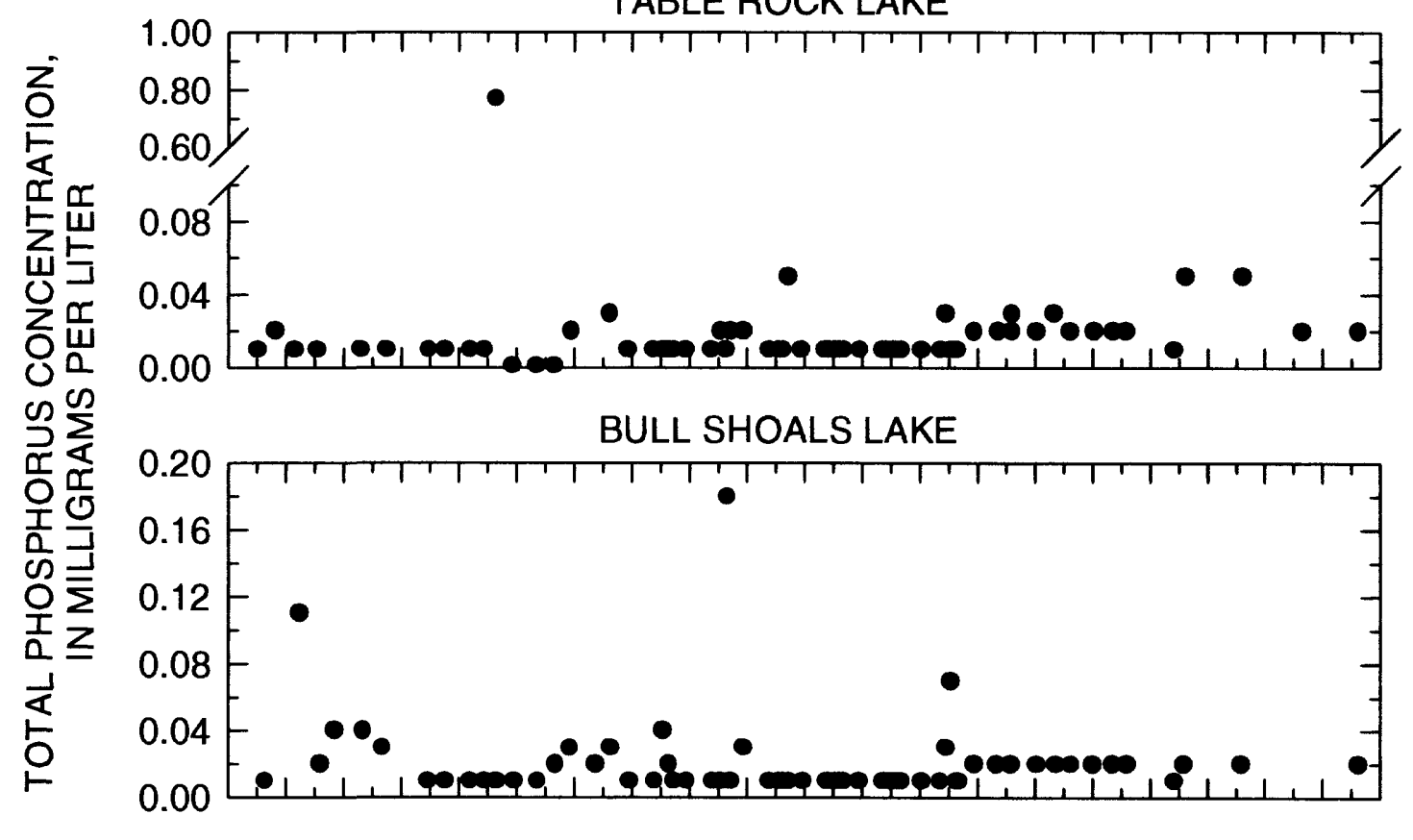

NORFORK LAKE

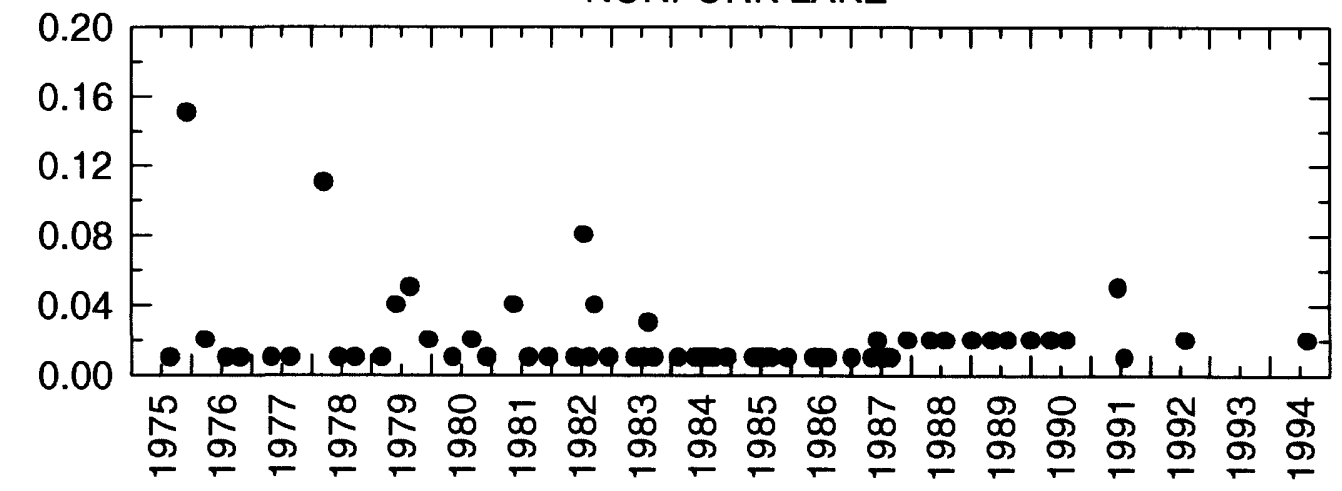

Figure 11. Total phosphorus concentrations at sites near the dam in Beaver, Table Rock, Bull Shoals, and Norfork Lakes from 1975 through 1994. 


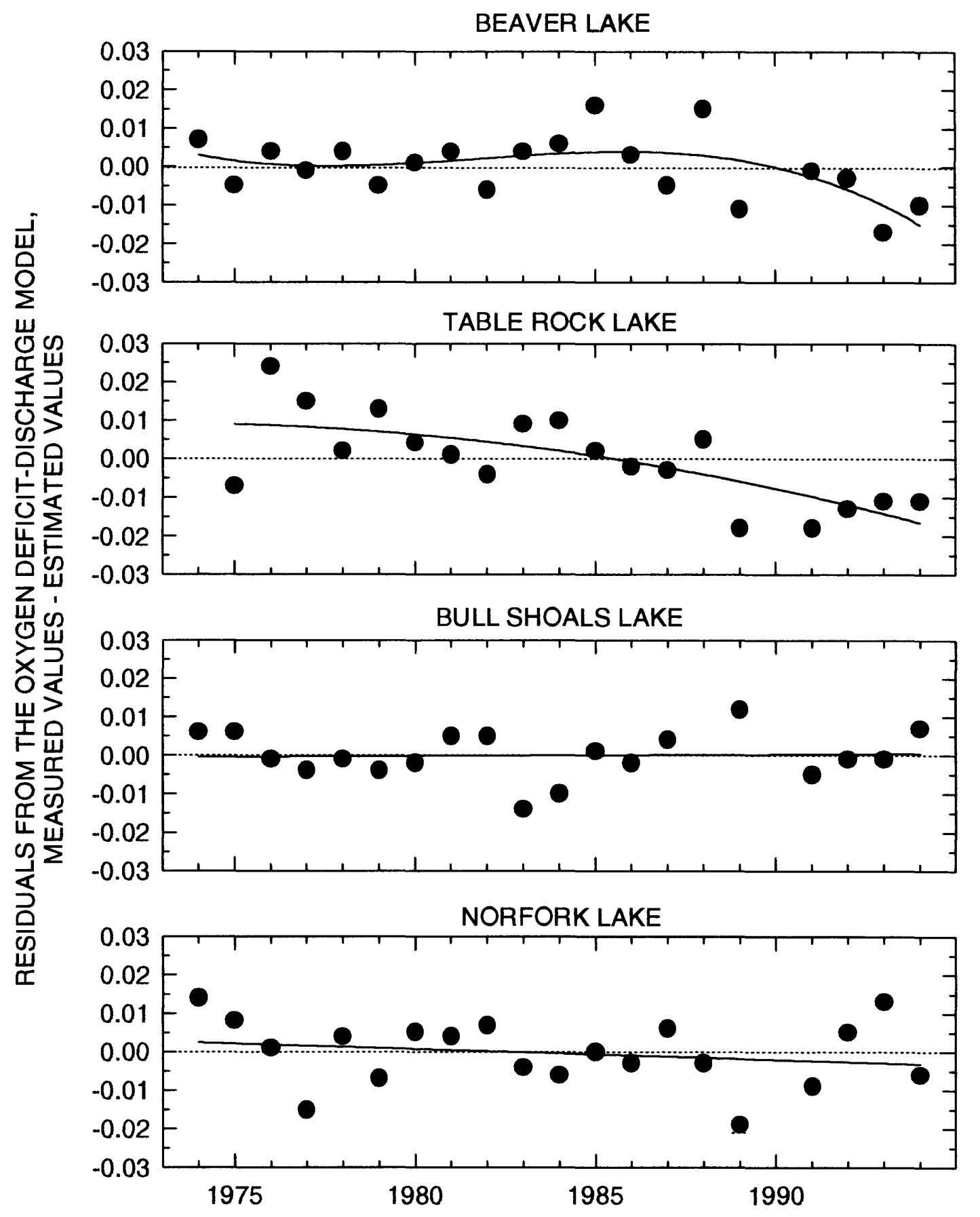

Figure 12. Time series of residuals from the oxygen deficit-discharge relations from Beaver, Table Rock, Bull Shoals, and Norfork Lakes from 1974 through 1994. 
Table Rock Lakes was negative, indicating that the temporal function driving AHOD, relative to $R^{-1}$, decreased over the period of record. The probability that the temporal variable slope coefficients were zero in the Beaver and Table Rock Lake equations were 0.092 and 0.019 , respectively. It is not known what the temporal variable in these models represents, but the negative slope of the temporal function in Beaver and Table Rock Lakes may be an expression of temporal changes in water quality, biological productivity, and the level of eutrophication affecting the areal hypolimnetic oxygen deficit within these reservoirs.

\section{Reservoir Aging, Evolution, and Eutrophication}

Reservoir aging and evolution (Straskraba and others, 1993) refers to large-scale temporal limnological changes that take place in a reservoir after impoundment. Reservoir aging refers to the changes that take place during years after first filling. Reservoir evolution refers to a much longer term limnological phenomenon that lasts for decades or centuries. The time frame of reservoir aging and evolution will differ among reservoirs because of the size of the reservoir and its watershed, reservoir morphometry, hydraulic residence time, and hydrodynamics.

In general, the aging process (Straskraba and others, 1993) starts upon impoundment of the river or stream. Inundation of terrestrial soils and vegetation allows for nutrient release through leaching of soils and increased carbon supply through decomposition of vegetation. The intensity of nutrient leaching from the soils and decomposition of vegetation decreases with time. During the initial years following impoundment, biological productivity in the reservoir is high. This stage is marked by high phytoplankton and zooplankton production followed by increased fish production. Phytoplankton, zooplankton, and fish production eventually reaches a point of maximal density soon after impoundment. After maximal production is reached, the internal sources of nutrient mobilization and carbon assimilation are diminished and biological production in the reservoir declines and eventually stabilizes. The subsequent evolution of the reservoir will follow a natural sequence of developmental or successional phases, which will lead to the accumulation of bottom sediments, decreasing the depth and volume of water. Changes in the developmental or successional phases of the reservoir and the reservoir environment will be affected by man's activities within the basin. Increased nutrient and carbon loading into the reservoir will increase the rate of biological production or eutrophication and accelerate or alter the evolutionary processes that would otherwise occur naturally within the reservoir.

It is possible that the aging and evolutionary processes in Beaver, Table Rock, Bull Shoals, and Norfork Lakes are more dominant in controlling biological production and eutrophication in each reservoir immediately above the dam than loading phenomena from the respective basins. The period of record, 1974 through 1994, on which the results of this study were based, represented different age periods in Beaver, Table Rock, Bull Shoals, and Norfork Lakes. Beaver Lake, during the period of record, was 11 through 32 years old. Table Rock Lake was 15 through 36 years old. Bull Shoals Lake was 23 through 44 years old, and Norfork Lake was 30 through 51 years old. The hypolimnetic oxygen deficit results should reflect the level of biological production or eutrophication characteristic of the different aging and evolutionary stages of the reservoirs.

Based on the RAHOD results (fig. 8) and the temporal relation between discharge through the dam during the stratification season and the areal hypolimnetic oxygen deficit (fig. 12), it appears that the level of eutrophication may have decreased in Beaver and Table Rock Lakes and remained stable in Bull Shoals and Norfork Lakes from 1974 through 1994. Conceptually, these results may be characteristic of the aging and evolutionary stage or phase within each reservoir (fig. 13). Beaver Lake may have been characterized by the later period of the initial stage of high biological production (1974 - 1988), which occurs after impoundment, and continued into the earlier period of the declining stage of biological production (1989 1994), which occurs after the initial stage of peak biological production. Table Rock Lake, over the period of record, may have been characterized by the stage of declining biological productivity, which follows the initial stage of peak production. The impoundment of Beaver Lake upstream may have also influenced the inferred decline of biological production within Table Rock Lake during the period of record. The reason that no changes in the level of eutrophication could be determined in Bull Shoals and Norfork Lakes could be that these reservoirs, for the period of record, were characterized by the stage of low and stable biological 


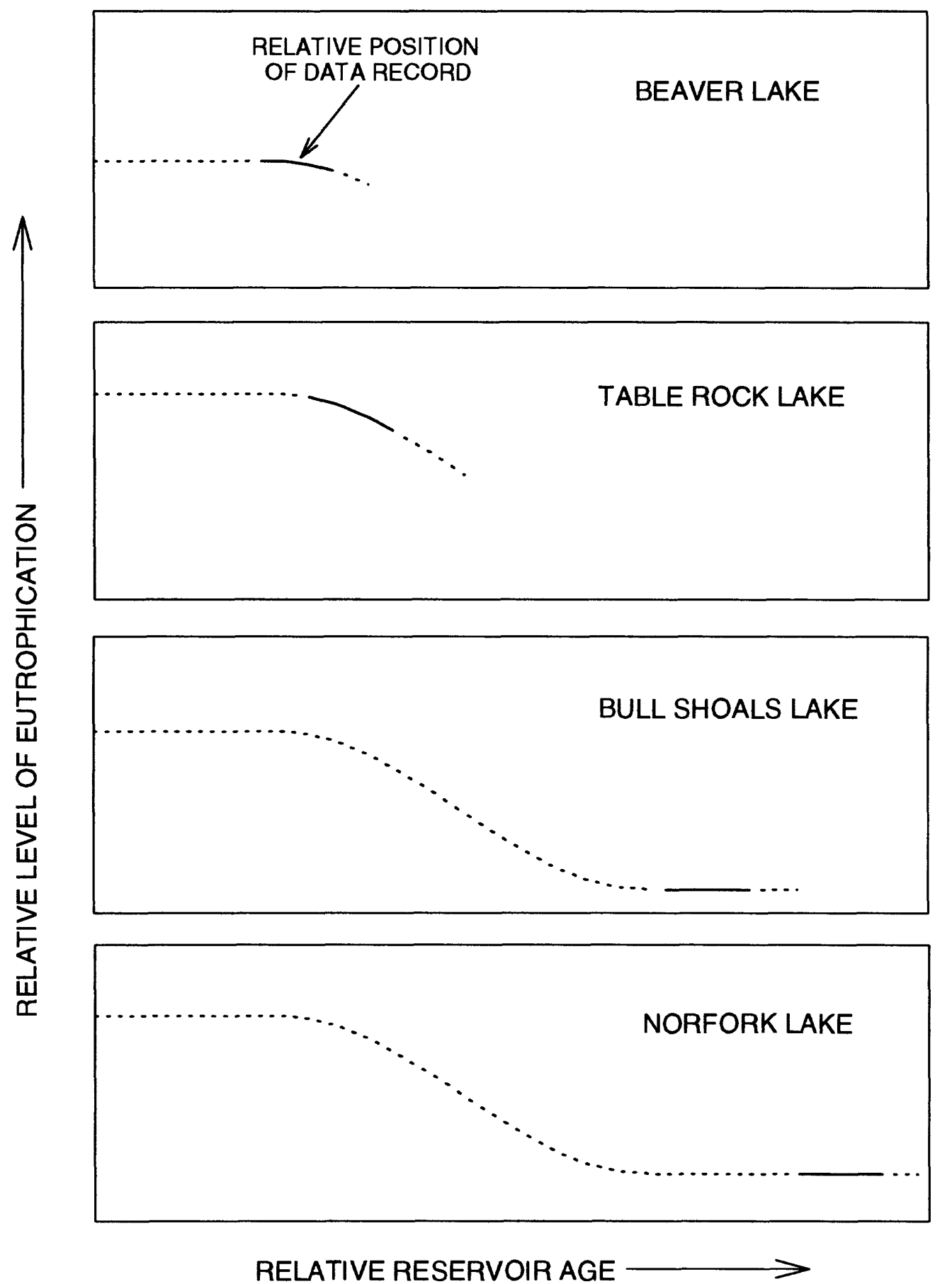

Figure 13. Conceptual model of the relation between relative reservoir age, relative level of eutrophication within each reservoir; and the 1974 through 1994 period of record. 
production, which generally occurs within a reservoir many years after impoundment.

If human stresses upon these reservoirs were minimal, the water quality in Beaver and Table Rock Lakes would probably continue to improve while the trophic state decreased until some level of equilibrium is reached. The water quality in Bull Shoals and Norfork Lakes would probably continue to remain stable. However, increased nutrient and organic loading into these reservoirs, such as from increased anthropogenic activities within the basin, would counteract these trends, accelerating the eutrophication rates.

\section{SUMMARY AND CONCLUSIONS}

The White River Basin in northern Arkansas and southern Missouri contains four major reservoirs. Beaver, Table Rock, and Bull Shoals Lakes form a chain of reservoirs on the main stem of the White River. Norfork Lake is on the North Fork River, a tributary of the White River. Vertical water-column profiles of temperature and dissolved-oxygen concentrations have been collected monthly, in general, at sites near the dam of each reservoir since 1974 . Hypolimnetic dissolved-oxygen dynamics of these reservoirs from 1974 through 1994 were examined based on the near-dam data and used to infer temporal changes in eutrophication.

The results of this study, based on data collected at sites near the dam of each reservoir, reflect the water-quality condition of the lacustrine (lake-like) region within each reservoir system, least affected by upper reservoir variability. Near-dam data represents the least variable and most conservative water-quality condition of the reservoir and is the result of the integration of all water-quality processes within the entire drainage basin. The near-dam data also describes the condition of the water that is discharged downstream.

Changes in the level of eutrophication within Beaver, Table Rock, Bull Shoals, and Norfork Lakes were evaluated following the concept that the hypolimnetic oxygen deficit changes as eutrophication changes. Areal hypolimnetic oxygen content was determined on the date of each reservoir profile over the period of record. The rate of change in areal hypolimnetic oxygen content during each stratification season, expressed as the areal hypolimnetic oxygen deficit, was then determined for each reservoir. Discharge through the dam of each reservoir was examined to determine if the quantity of water removed from the hypolimnion during the stratification season affected the areal hypolimnetic oxygen deficit.

Regression models indicated that a positive relation existed between discharge through the dam during the stratification season and the areal hypolimnetic oxygen deficit for each reservoir. From 41 to 68 percent of the variability in areal hypolimnetic oxygen deficit from 1974 through 1994 among the four reservoirs was explained by discharge through the dam during the stratification season.

Temporal changes in the level of eutrophication from 1974 through 1994 in Beaver, Table Rock, Bull Shoals, and Norfork Lakes were examined using an existing relative areal hypolimnetic oxygen deficit model, which adjusts the areal hypolimnetic oxygen deficit to standard temperature and depth. The relative areal hypolimnetic oxygen deficit model estimates the productivity or chlorophyll function that drives the oxygen deficit. The relative areal hypolimnetic oxygen deficit decreased in Beaver Lake from 1974 through 1994, indicating that the level of eutrophication decreased. Little or no change in the relative areal hypolimnetic oxygen deficit was indicated for Table Rock, Bull Shoals, or Norfork Lakes over the period of record.

Examination of the temporal variations of selected trophic state variables (Secchi disk transparency, chlorophyll $a$ concentration, and total phosphorus concentration) from the respective near-dam sites yielded mixed results when compared with the relative areal hypolimnetic deficit results. Secchi disk transparency depth decreased in Table Rock and Bull Shoals Lakes over the period of record, while chlorophyll $a$ and total phosphorus concentrations remained level. A decrease in Secchi disk transparency suggests that the water near the dam became more turbid over time which might indicate an increase in the level of eutrophication. However, the relative areal hypolimnetic oxygen deficit results did not indicate an increase in eutrophication in either Table Rock or Bull Shoals Lakes.

Temporal analysis of the residuals from the oxygen deficit-discharge model indicated that the oxygen deficit-discharge function changed over time in Beaver and Table Rock Lakes. There was little or no temporal trend in residuals of areal hypolimnetic oxygen deficit in Beaver Lake from 1974 through 1988. The discharge relation overpredicted the areal hypolimnetic oxygen deficit in Beaver Lake from 1989 through 1994. The discharge relation underpredicted 
the areal hypolimnetic oxygen deficit in Table Rock Lake from 1976 through 1981 and overpredicted the areal hypolimnetic oxygen deficit from 1989 through 1994. There was little or no temporal trend in residuals of areal hypolimnetic oxygen deficit over the period of record for Bull Shoals and Norfork Lakes.

Multiple regression using a time variable and discharge through the dam during the stratification season was examined for the four reservoirs. Including time as an explanatory variable increased the percent of explained variation of the areal hypolimnetic oxygen deficit in Beaver Lake from 41 percent, when only discharge was used as an explanatory variable, to 48 percent. The percent of explained variation increased from 58 to 79 percent for Table Rock Lake. The slope coefficient of the time variable for both Beaver and Table Rock Lakes was negative, indicating that the temporal function driving the areal hypolimnetic oxygen deficit decreased over the period of record. This temporal function may be an expression of biological productivity or eutrophication. Based on these results, the level of eutrophication may have decreased in Beaver and Table Rock Lakes and remained stable in Bull Shoals and Norfork Lakes from 1974 through 1994.

It is possible that the aging and evolutionary processes in Beaver, Table Rock, Bull Shoals, and Norfork Lakes are more dominant in controlling biological production and eutrophication in each reservoir immediately above the dam than loading phenomena from the respective basins. Beaver Lake is the youngest of the four reservoirs, constructed in 1963, and for the period of record, may have been in the initial stage of high productivity followed by a declining stage of productivity, which generally occurs within a reservoir soon after impoundment. Table Rock Lake was constructed in 1959 and, for the period of record, may have been in the stage of declining productivity following the peak of productivity resulting from impoundment. The impoundment of Beaver Lake upstream may have also influenced the decline of productivity within Table Rock Lake. Bull Shoals and Norfork Lakes are older than Beaver and Table Rock Lakes, constructed in 1951 and 1944, respectively. The reason that changes in the level of eutrophication were not detected in Bull Shoals and Norfork Lakes could be that these reservoirs, for the period of record, were characterized by the stage of low and stable production, which generally occurs within a reservoir many years after impoundment.

\section{REFERENCES}

Birge, E.A., and Juday, C., 1911, The inland lakes of Wisconsin. The dissolved gases of the water and their biological significance: Bulletin of Wisconsin Geological and Natural History Survey 22, Scientific Series 7, 259 $\mathrm{p}$.

Charlton, N.M., 1980, Hypolimnion oxygen consumption in lakes--Discussion of productivity and morphometry effects: Canadian Journal of Fisheries and Aquatic Science, v. 37, p. 1,531-1,539.

Cole, T.M., and Hannan, H.H., 1990, Dissolved oxygen dynamics, in Thornton, K.W., Kimmel, B.L., and Payne, F.E., eds., Reservoir limnology--ecological perspectives: New York, Wiley, p. 71-107.

Hutchinson, G.E., 1938, Chemical stratification and lake morphology: Proceedings of the National Academy of Science, v. 24, p. 63-69.

1957, A treatise on limnology. Geography, physics, and chemistry, v. I: New York, Wiley, 1,015 p.

Lind, O.T., and Dávalos-Lind, L., 1993, Detecting the increased eutrophication rate of Douglas Lake, Michigan: The relative areal hypolimnetic oxygen deficit method: Lake and Reservoir Management, v. 8, p. 7376.

Straskraba, M., Tundisi, J.G., and Duncan, A., 1993, Stateof -the-art of reservoir limnology and water quality management, in Straskraba, M., Tundisi, J.G., and Duncan, A., eds., Comparative reservoir limnology and water quality management: Dordrecht, the Netherlands, Kluwer Academic Publishers, p. 213-288.

Thienemann, A. 1928, Der Sauerstoff im eutrophen und oligotrophen See. Ein Beitrag zur Seetypenlehre: Die Binnengewasser, v. 4, 175 p.

Walker, W.W., Jr., 1979, Use of hypolimnetic oxygen depletion rate as a trophic state index for lakes: Water Resources Research, v. 15, p. 1,463-1,470.

Wetzel, R.G., 1983, Limnology (2d ed.): New York, Saunders College Publishing, $858 \mathrm{p}$.

- 1990, Reservoir ecosystems: Conclusions and speculations, in Thornton, K.W., Kimmel, B.L., and Payne, F.E., eds., Reservoir limnology: ecological perspectives: New York, Wiley, p. 227-238. 
APPENDIX A - TIME/DEPTH DISTRIBUTIONS OF TEMPERATURE AND DISSOLVED OXYGEN IN BEAVER, TABLE ROCK, BULL SHOALS, AND NORFORK LAKES

FROM 1974 THROUGH 1994 


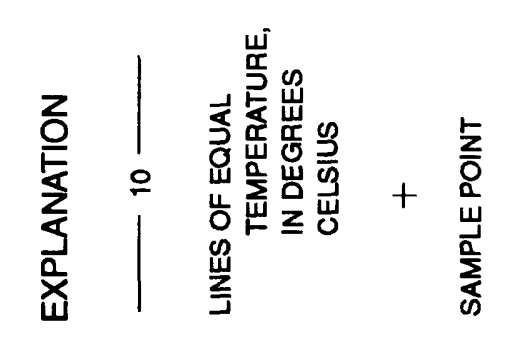
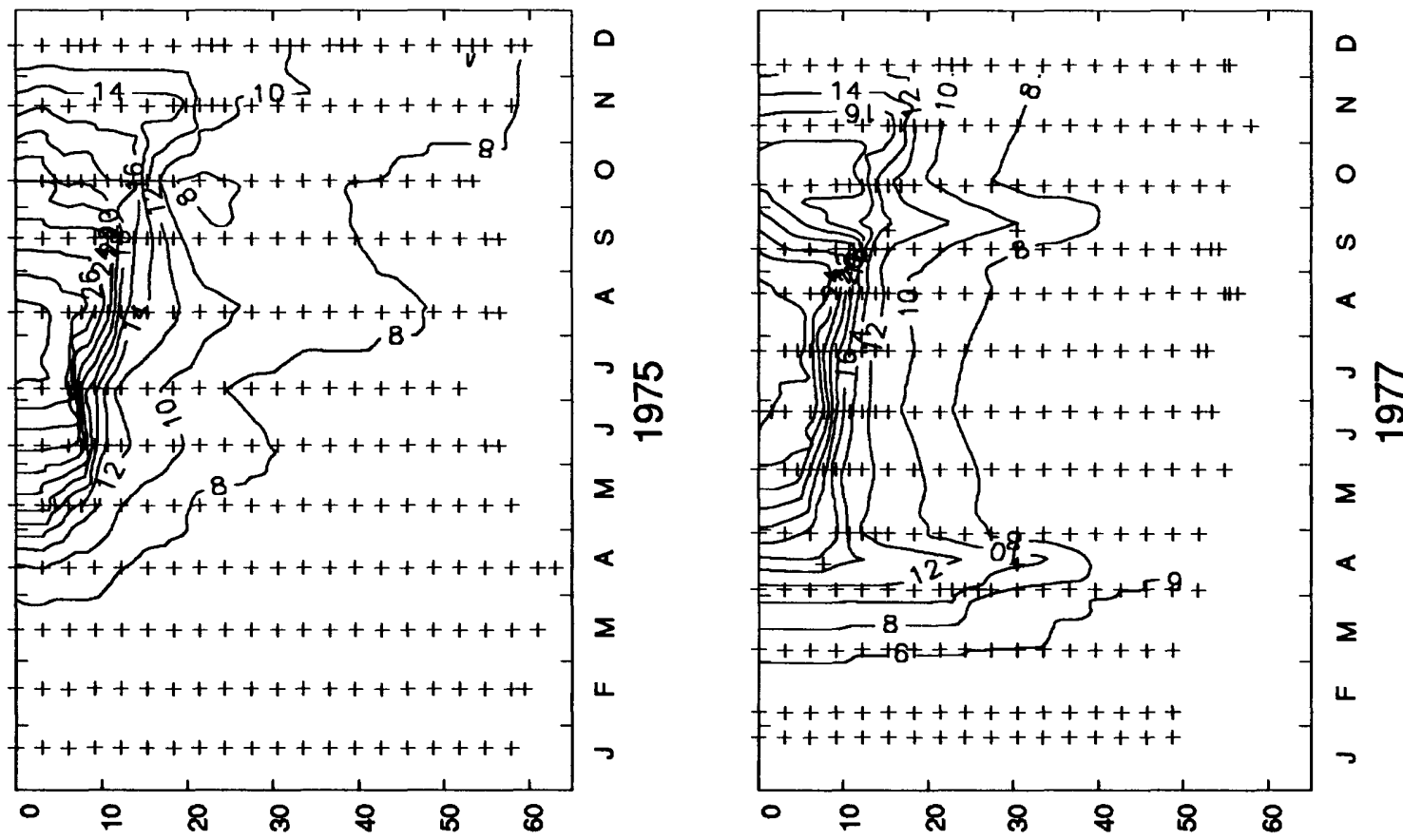

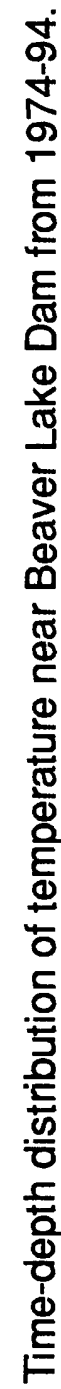

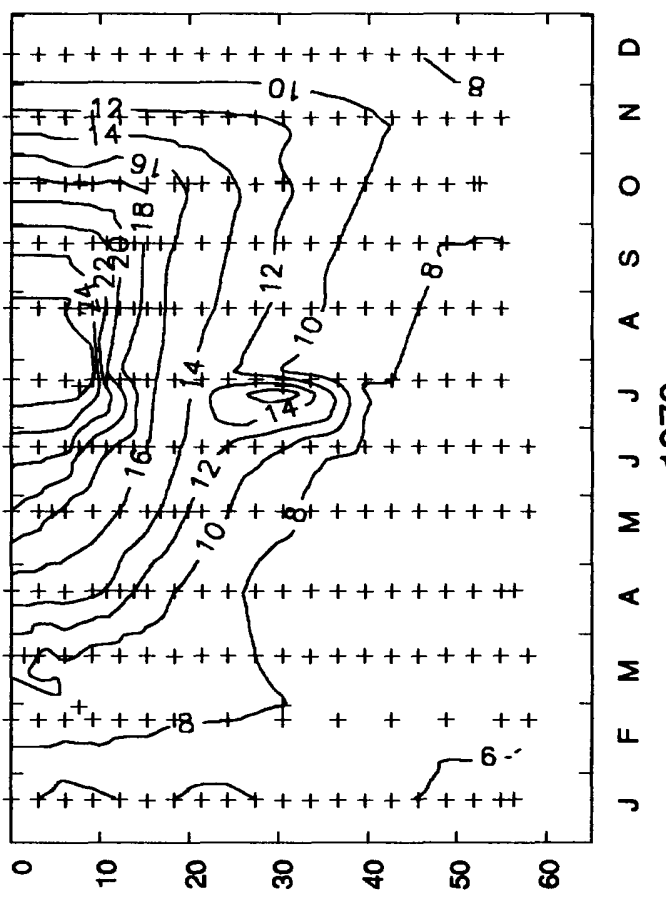

$\exists כ \forall\lrcorner y n S$ MO 


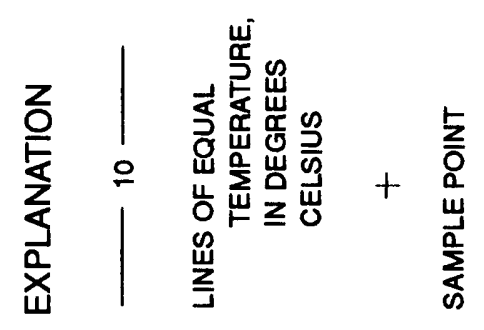
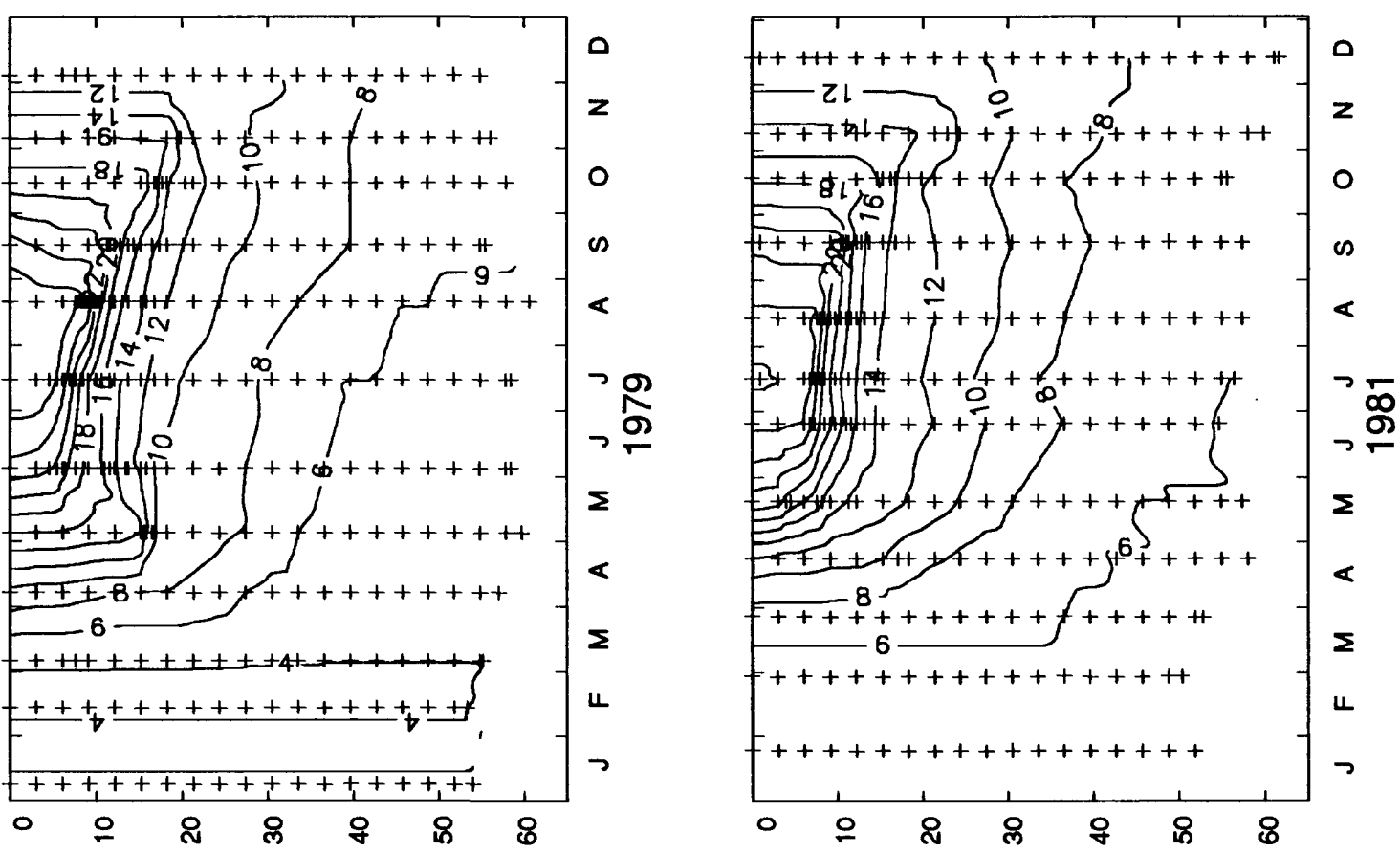

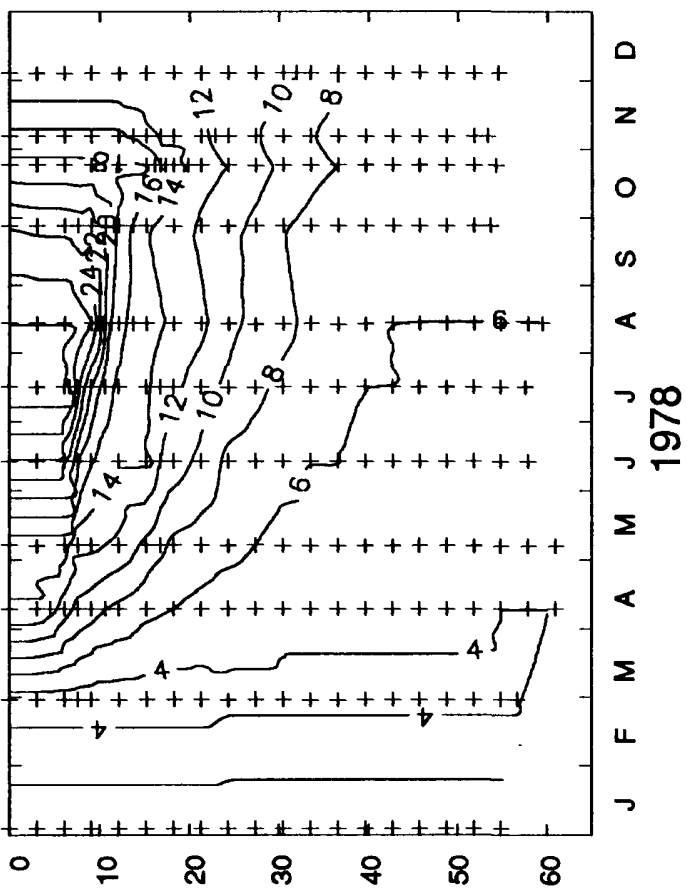

ヨอง

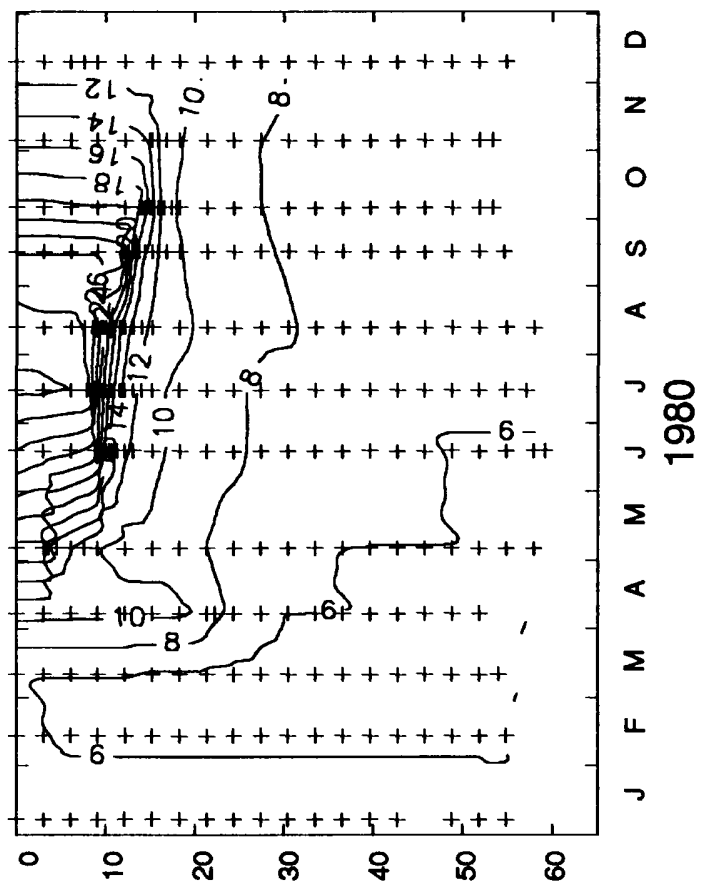

$\exists O \forall \exists \forall \cap S$ MO7ヨg S $\forall \exists \perp \exists W$ NI ‘ $H \perp d \exists O$ 

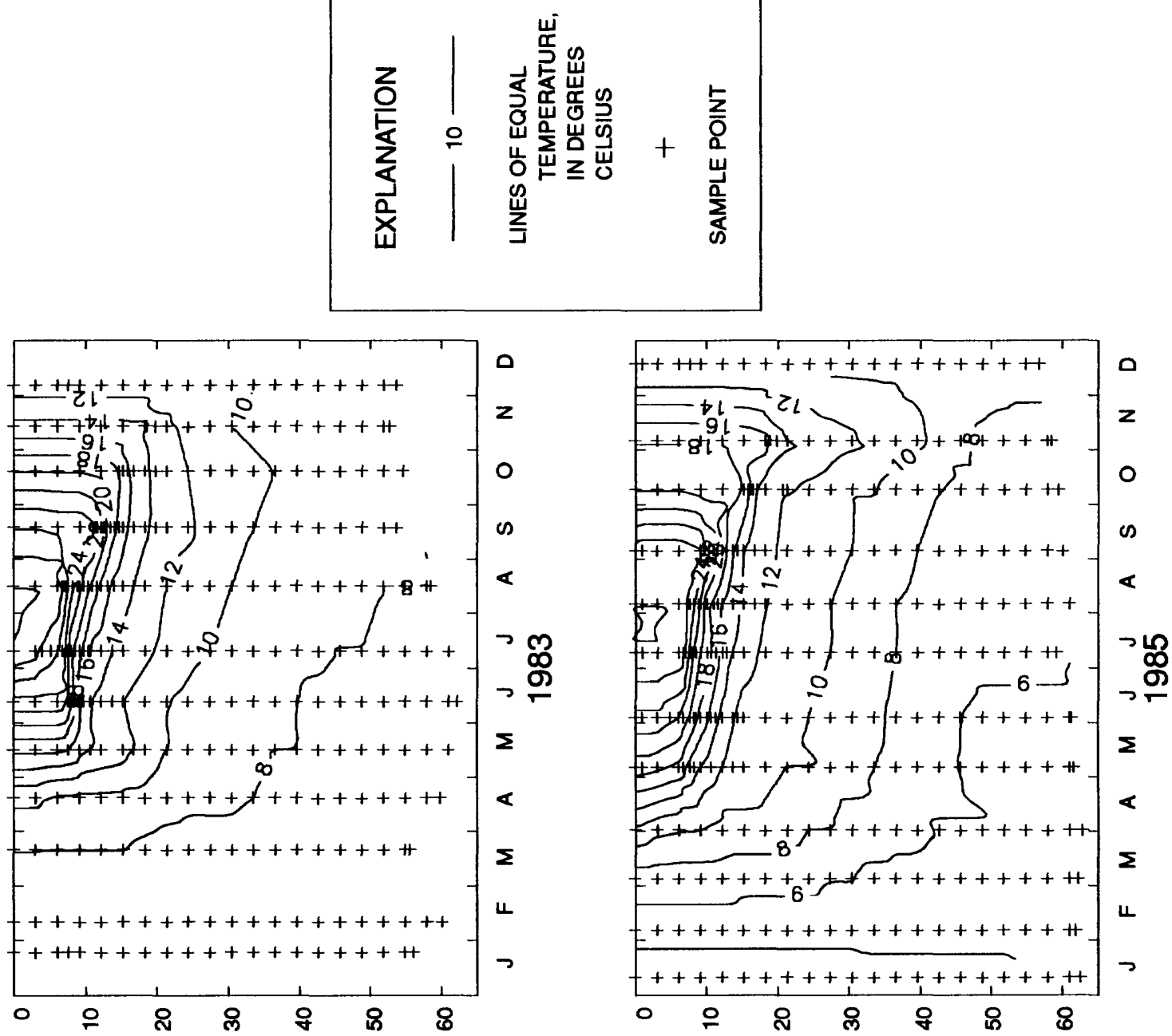

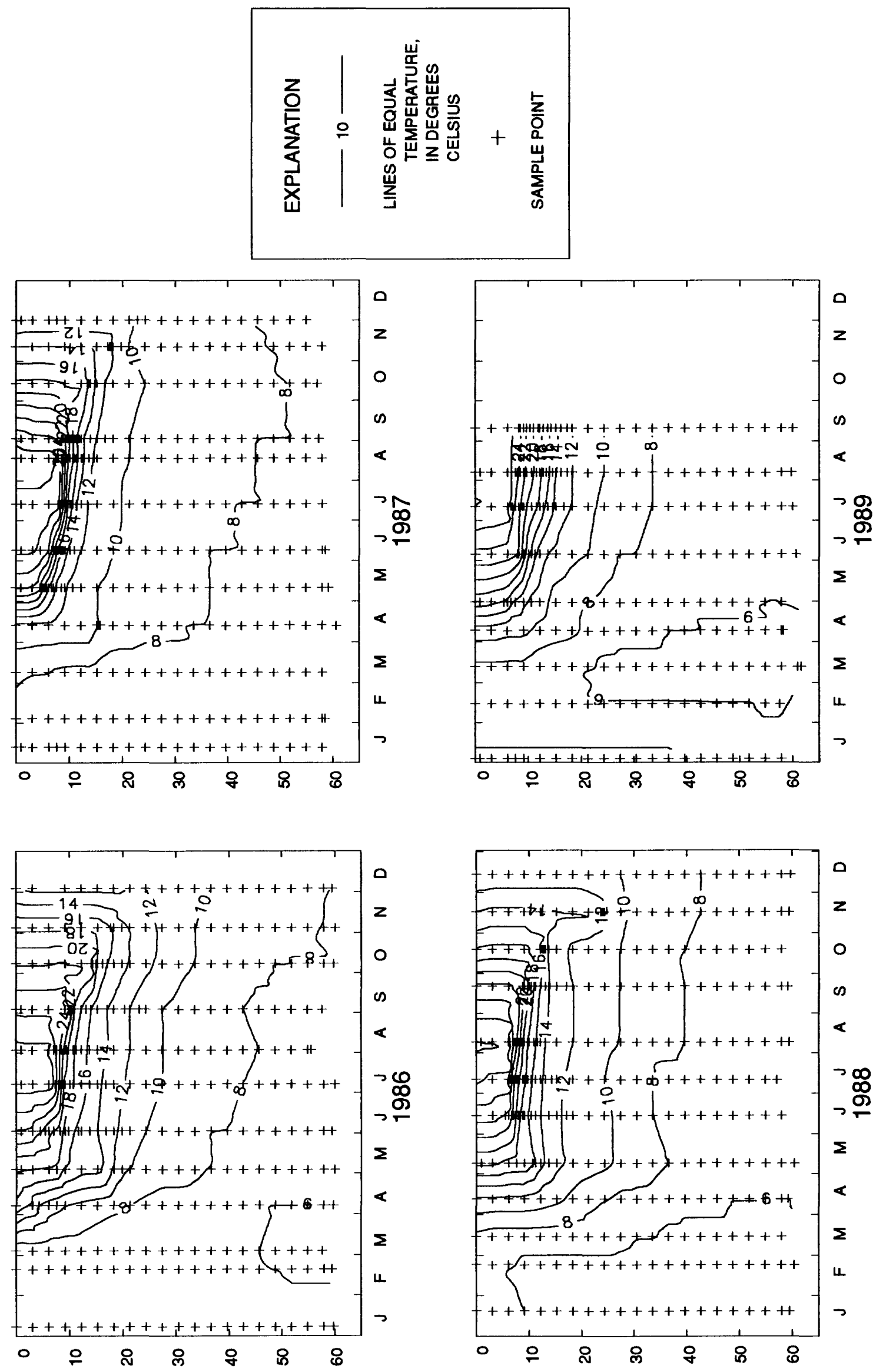

$\exists \supset \forall\lrcorner 4$ ก M MOาヨg S

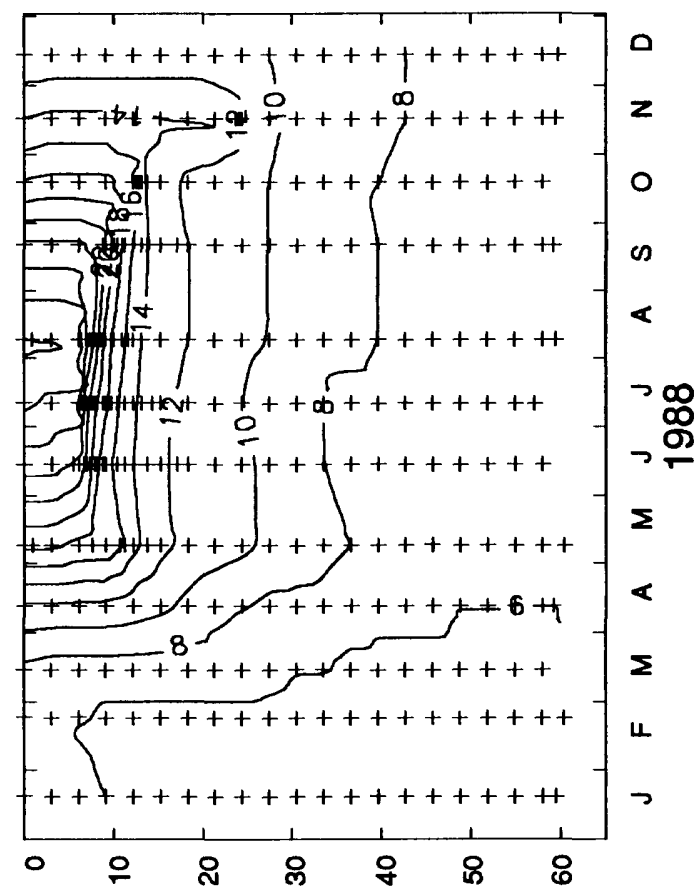

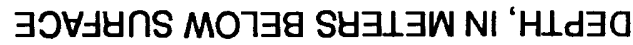




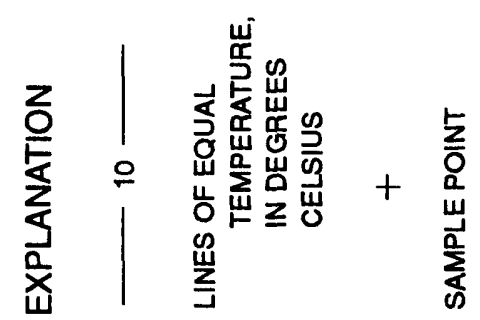
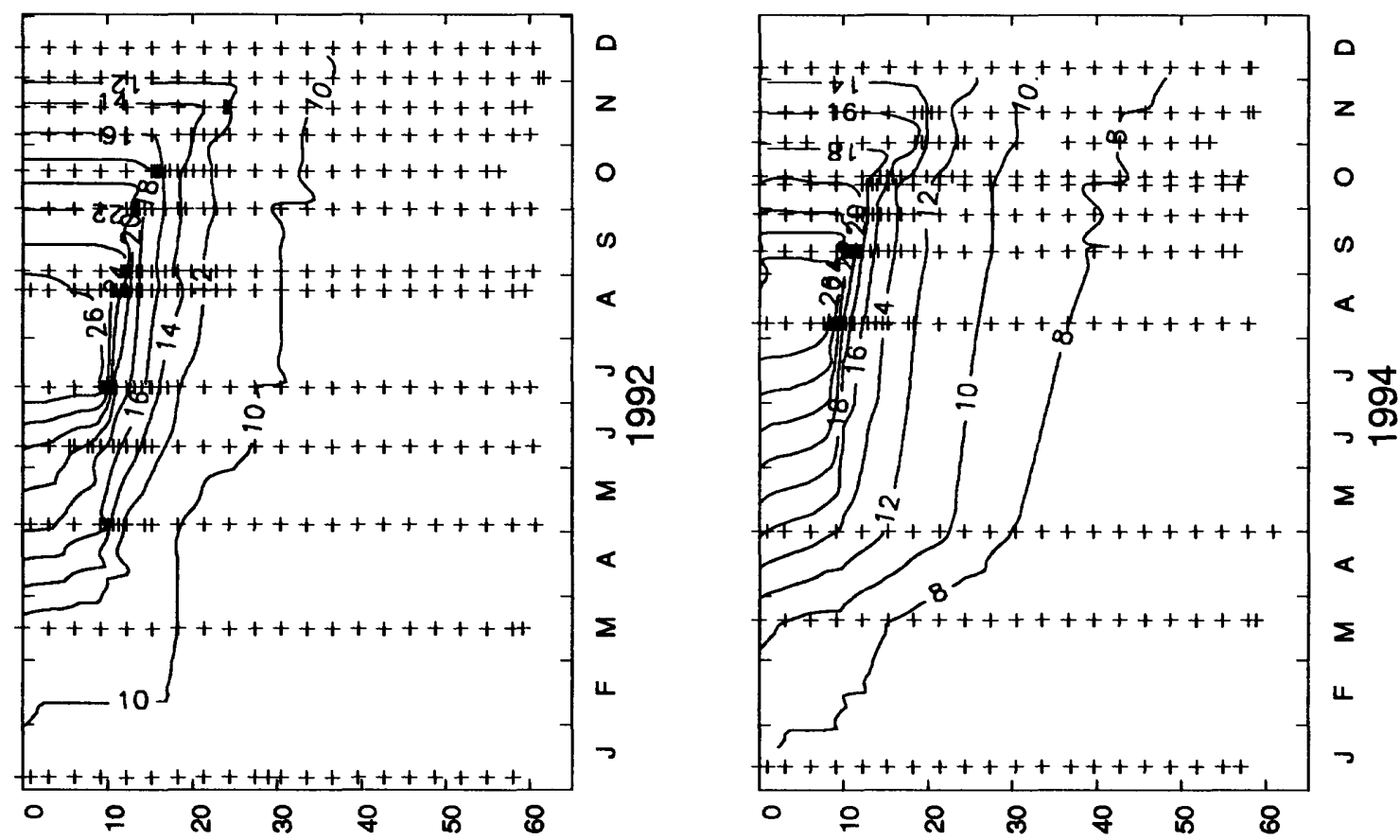

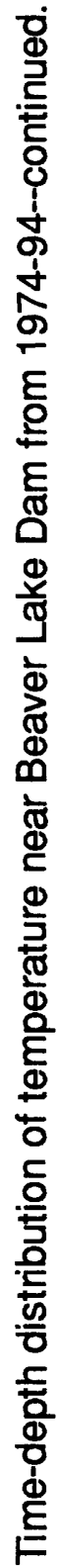

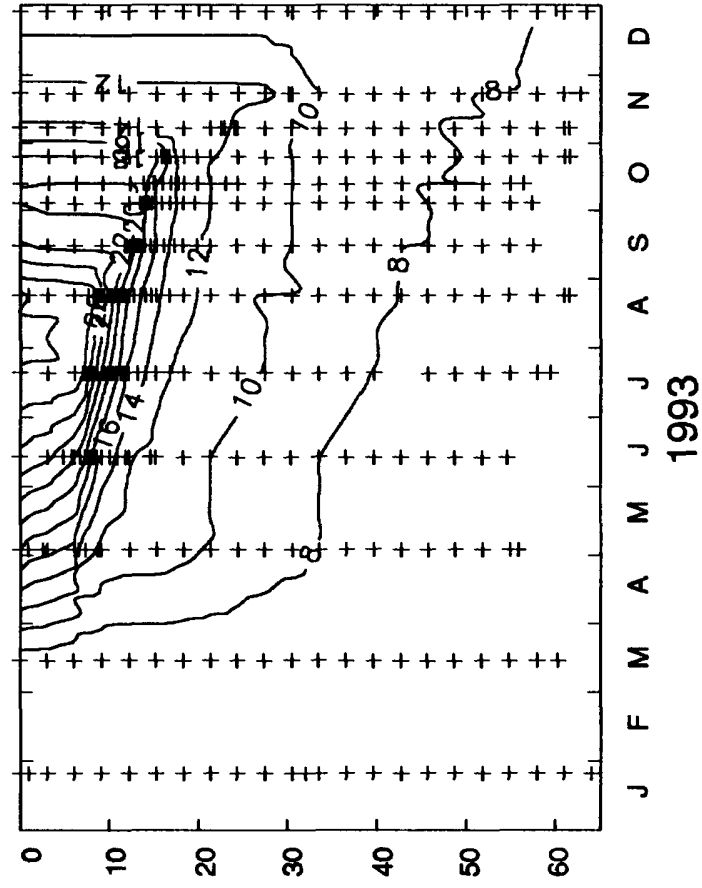

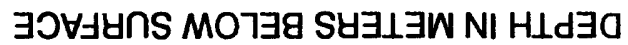



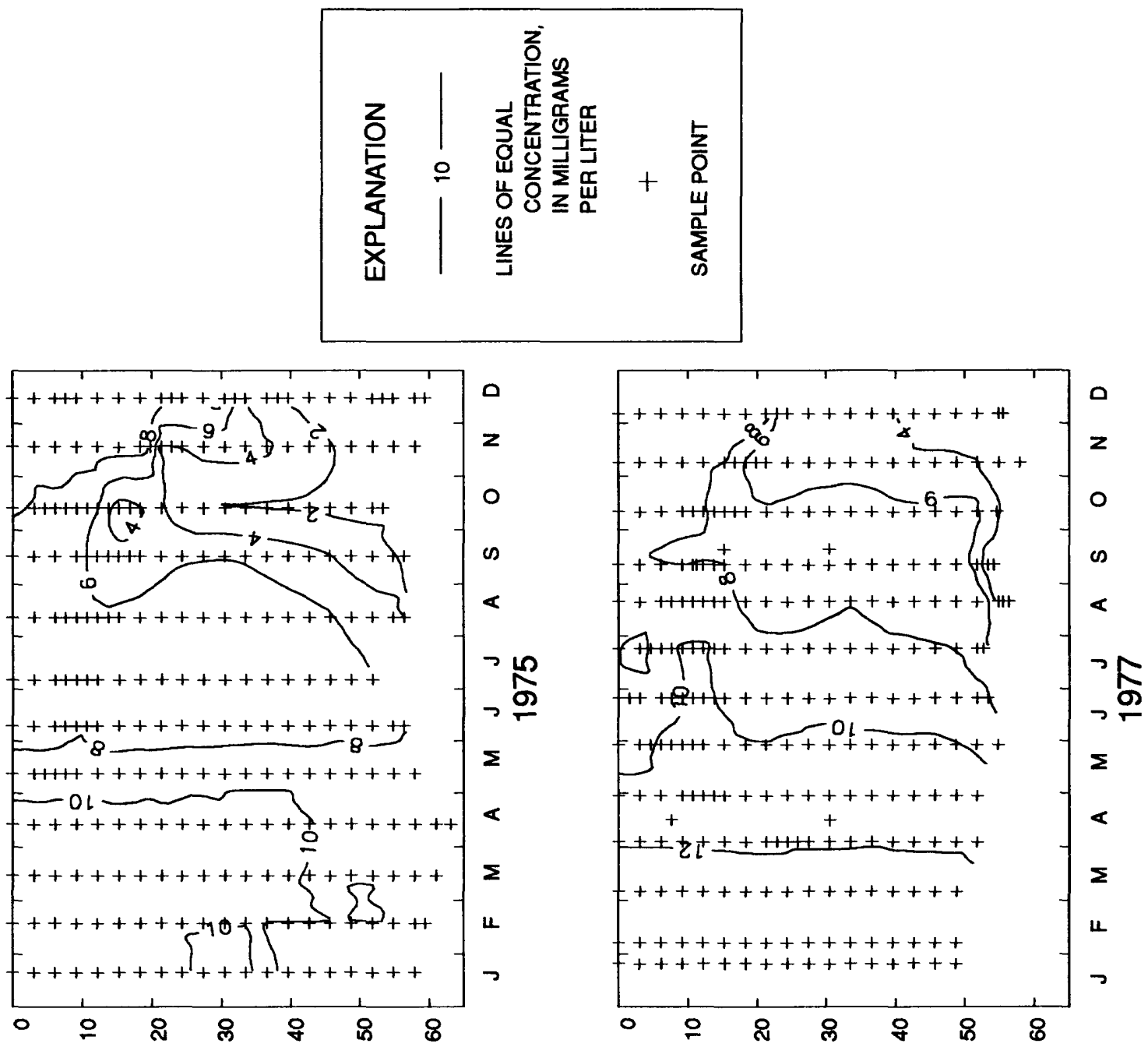

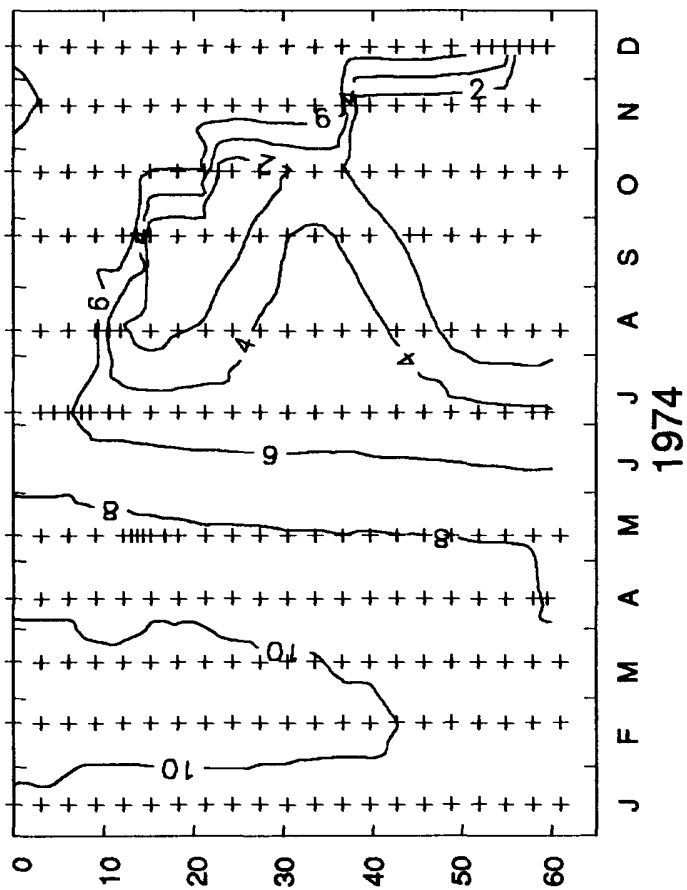

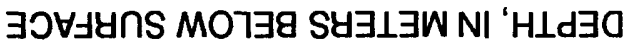

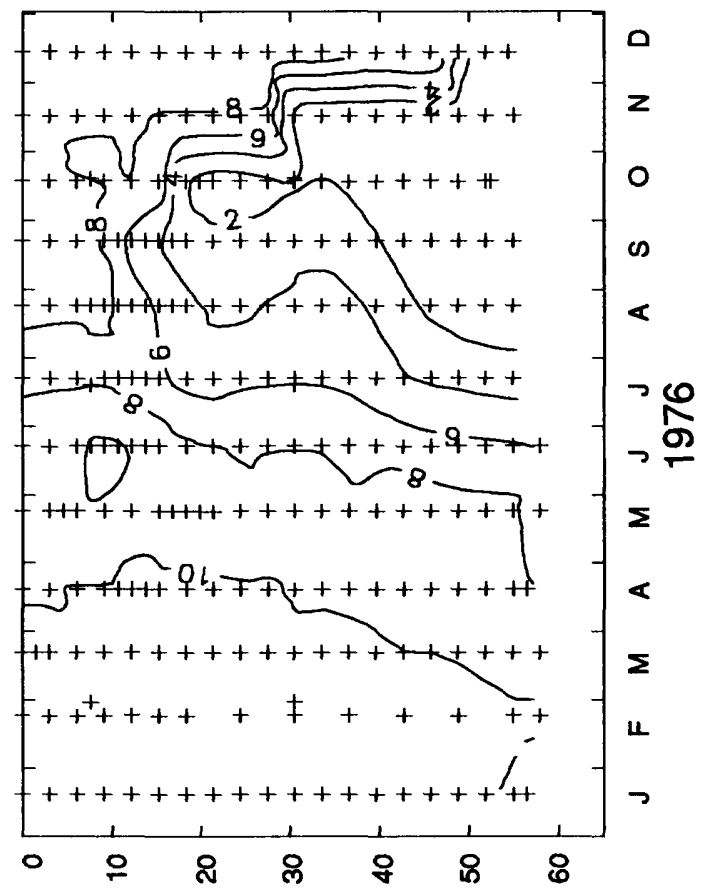

$\exists \supset \forall\lrcorner y$ ก MOフヨg S 


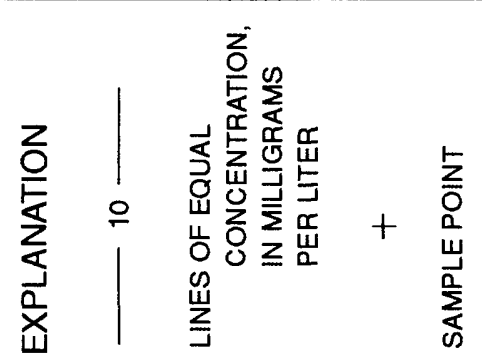
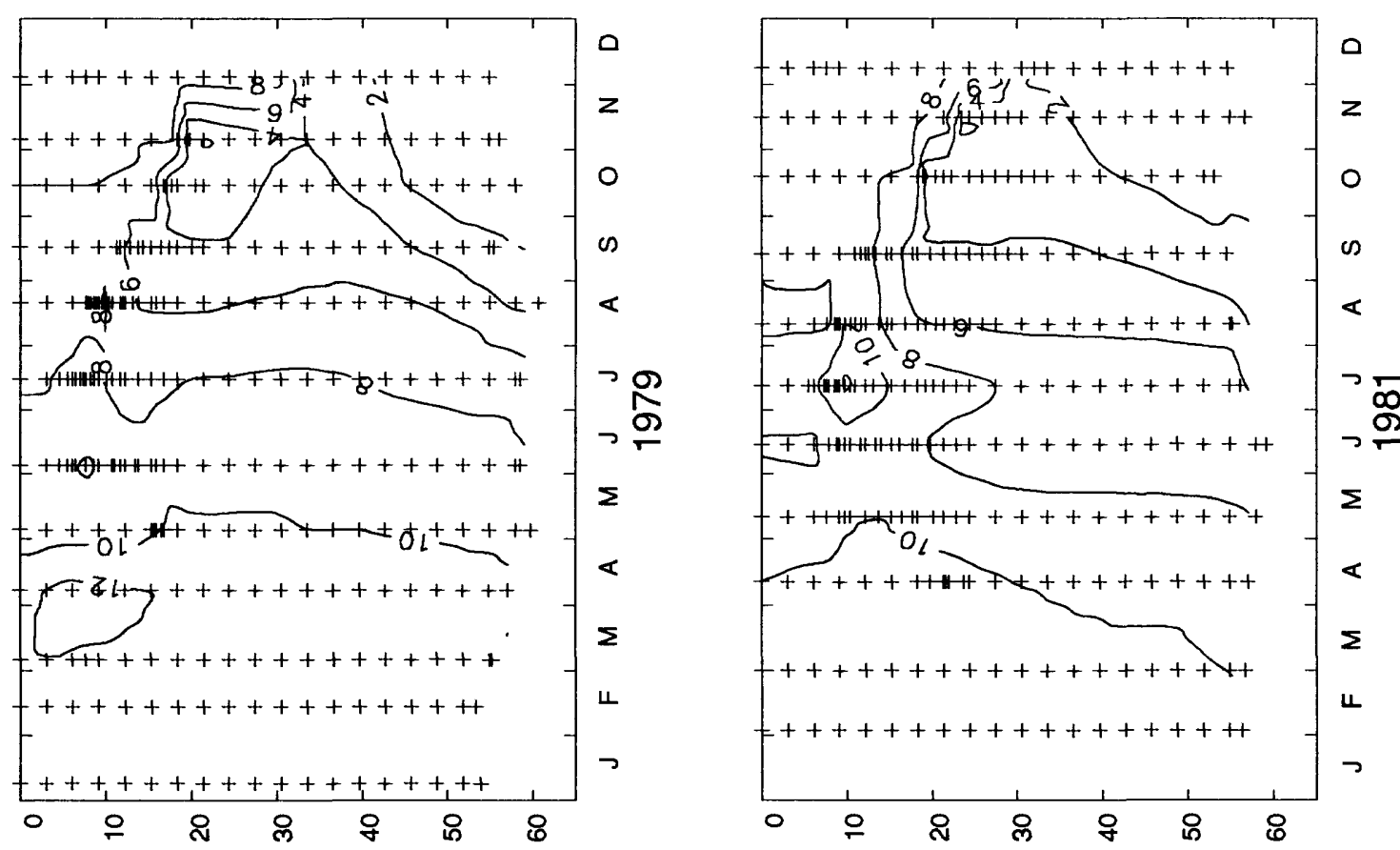

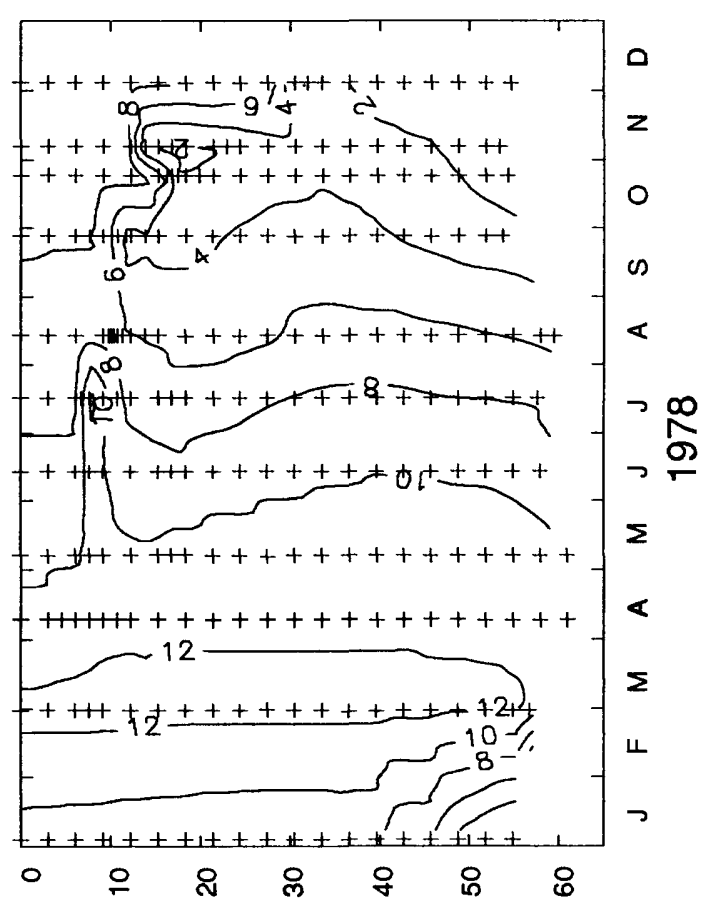

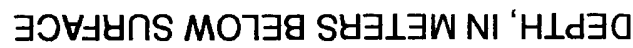

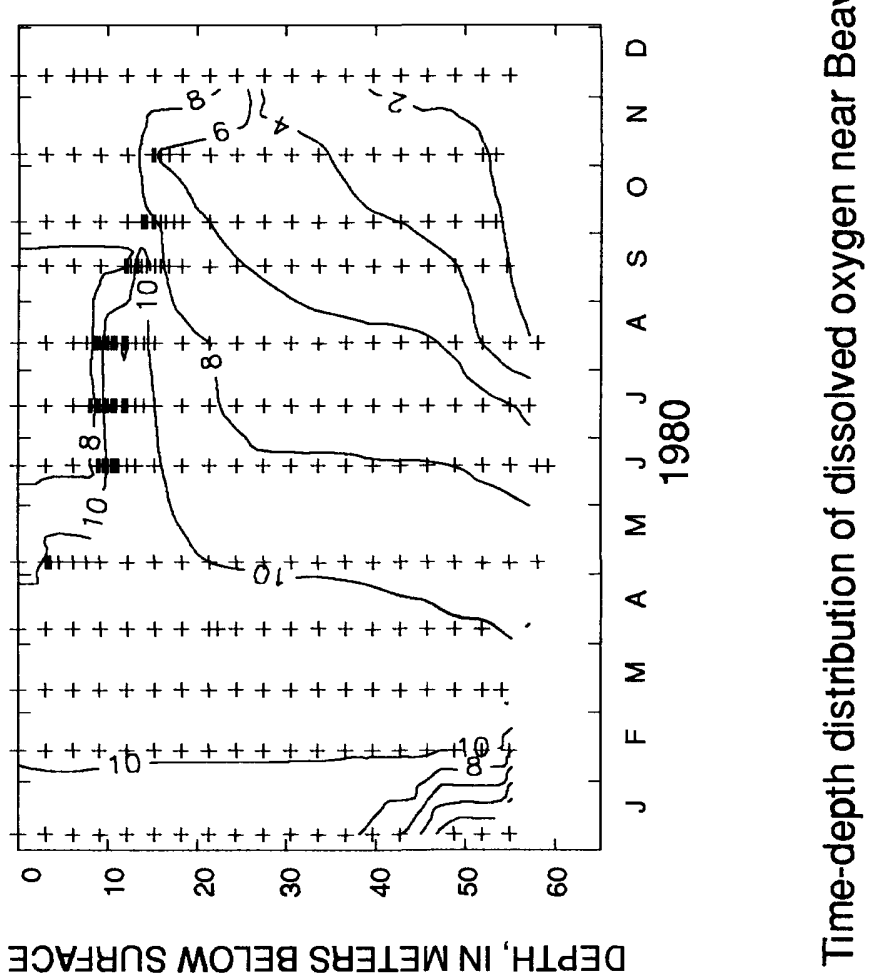



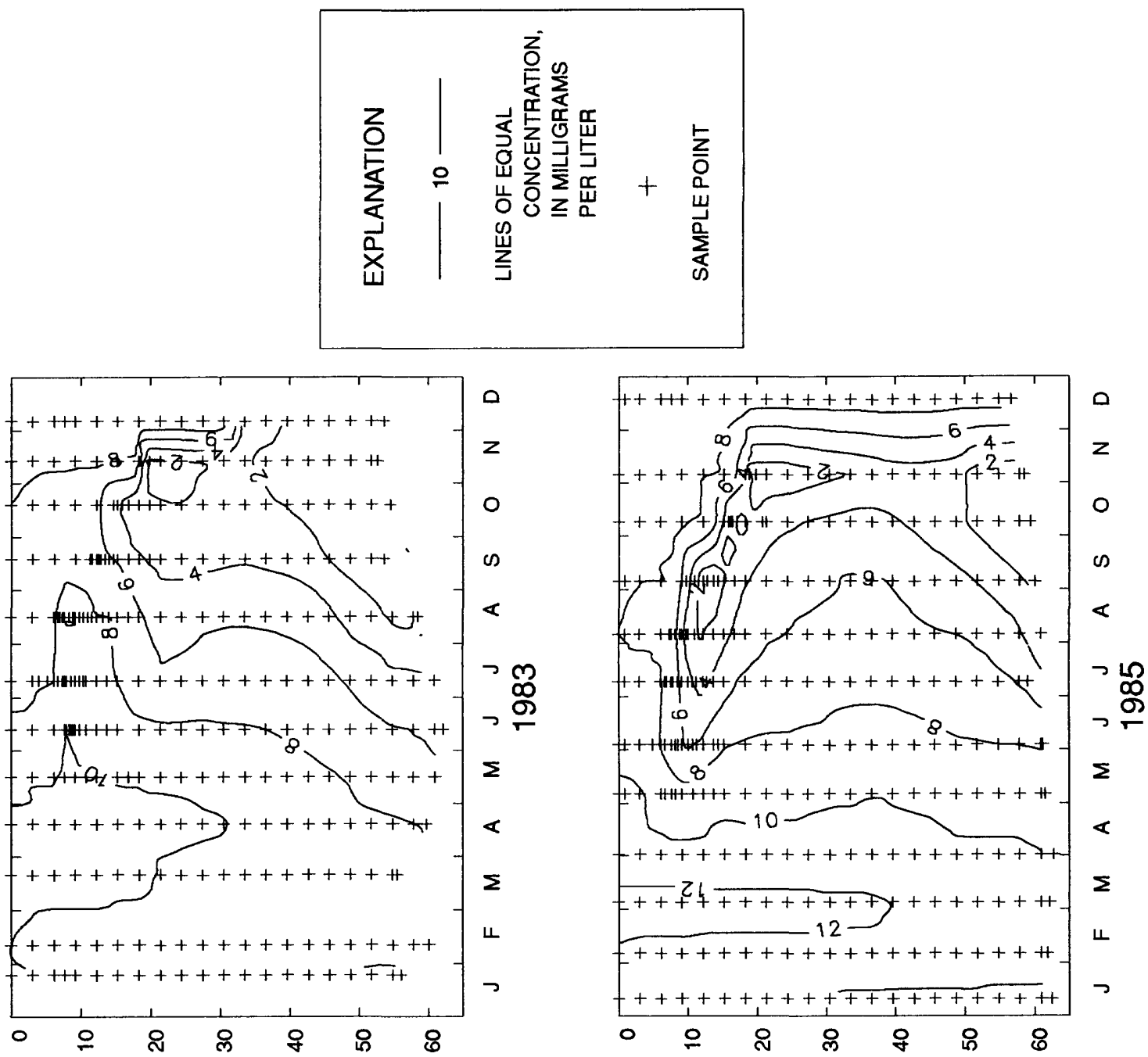

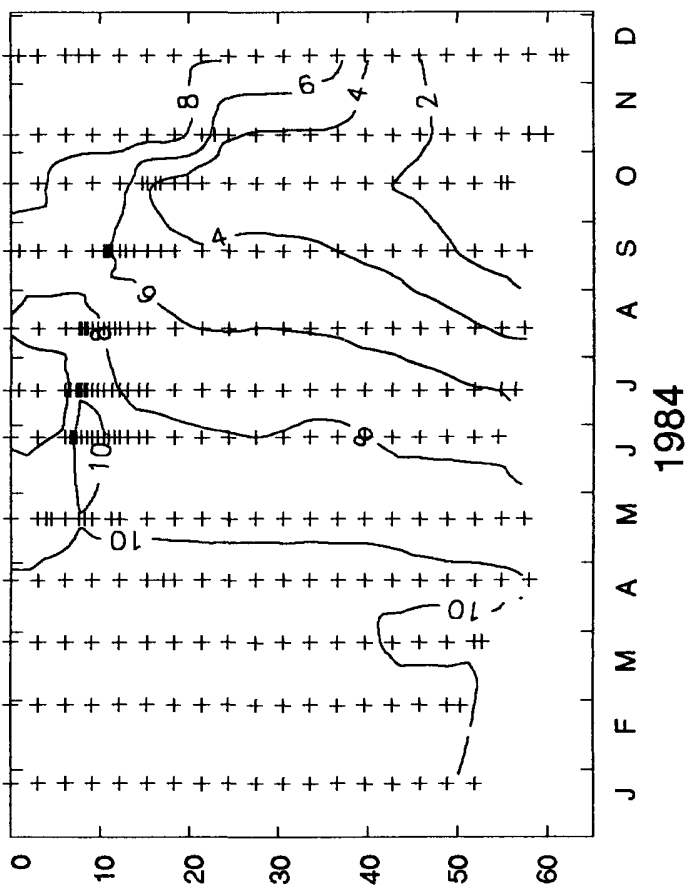

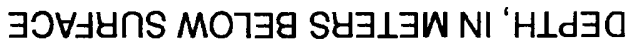



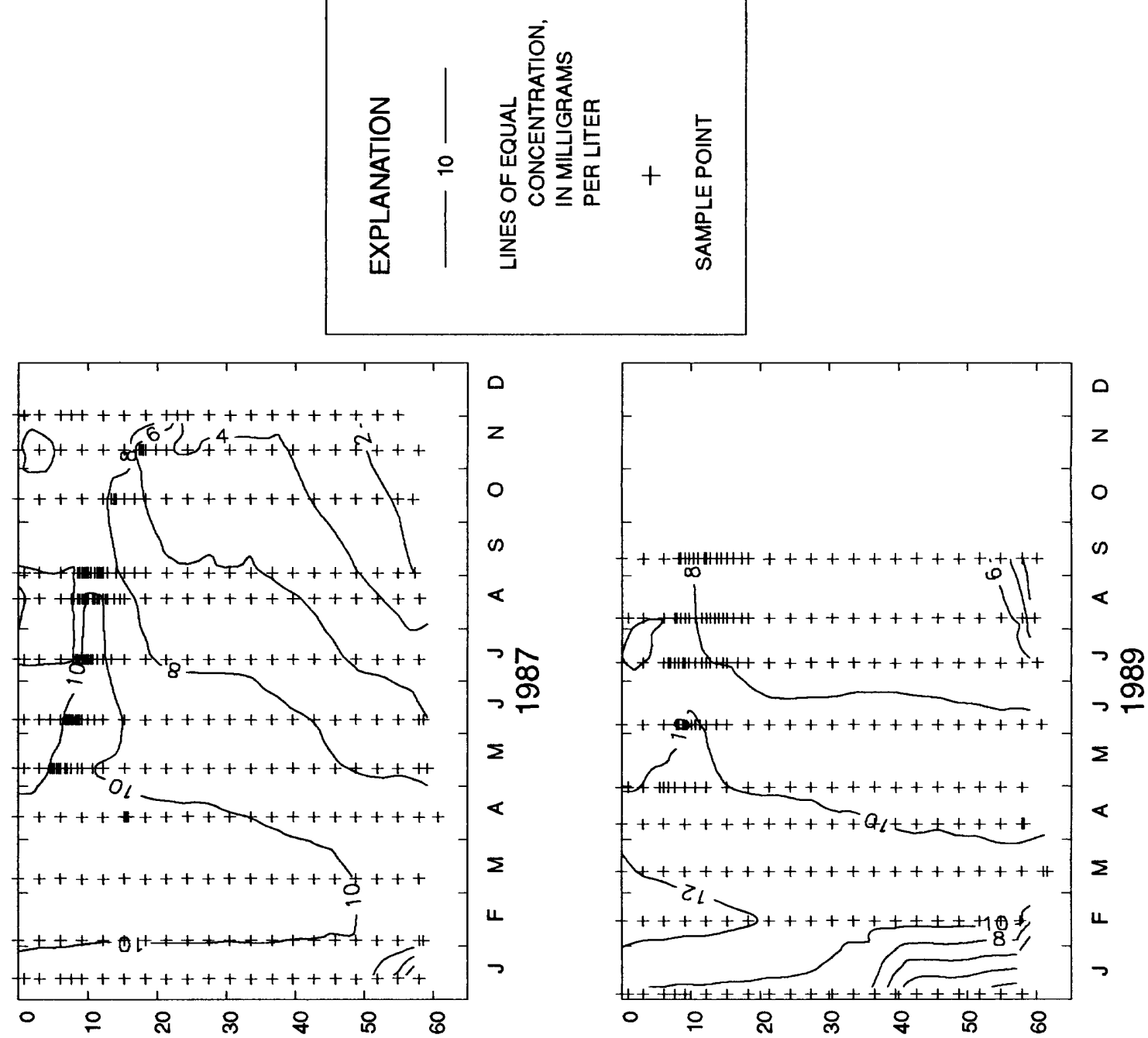

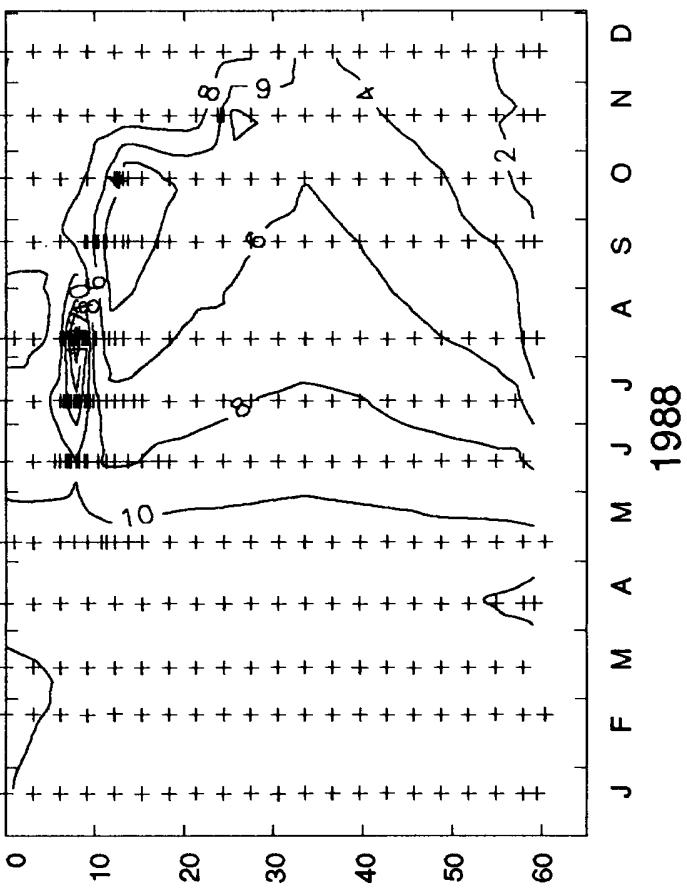

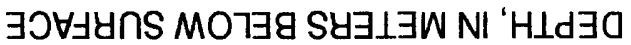



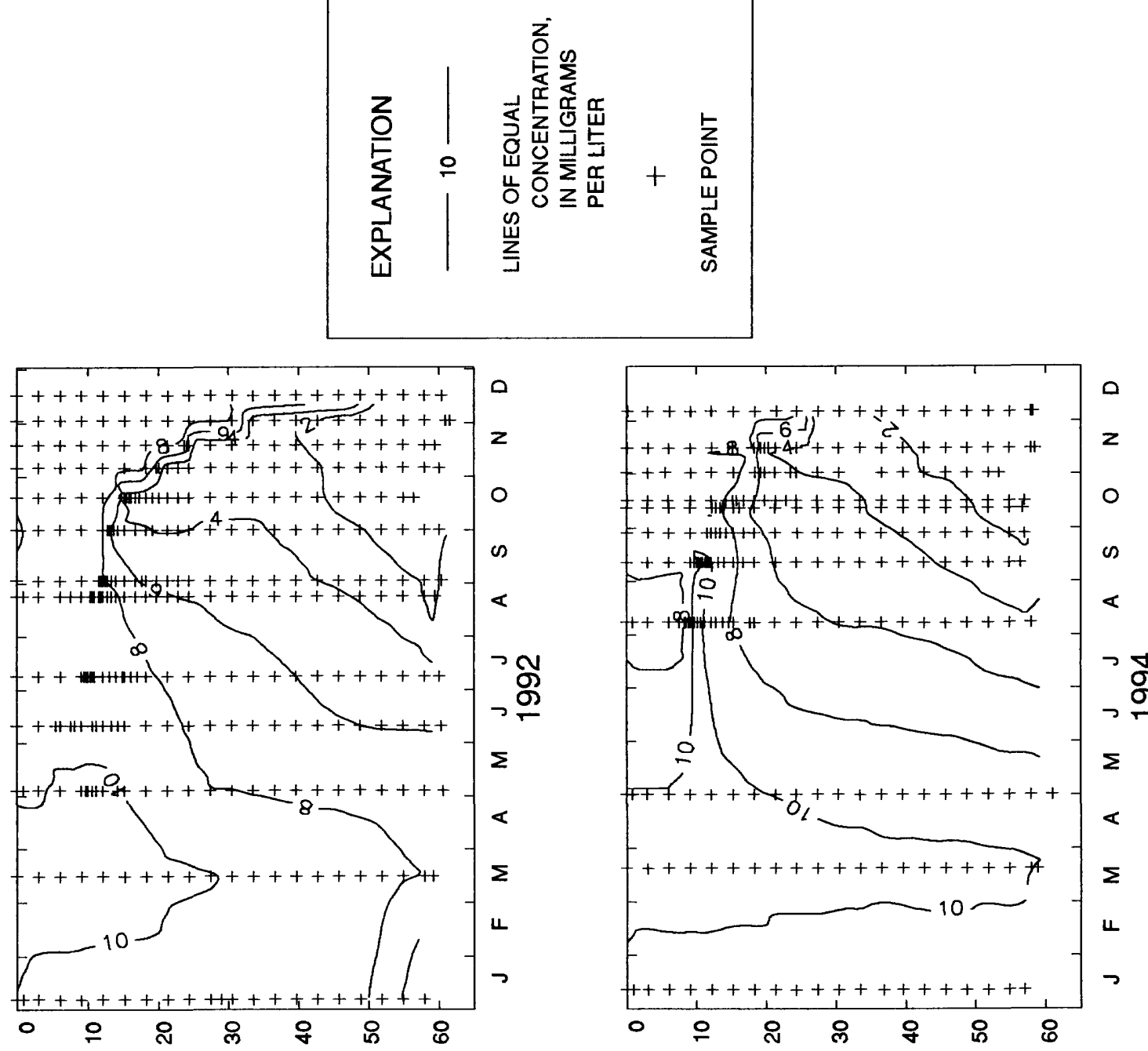

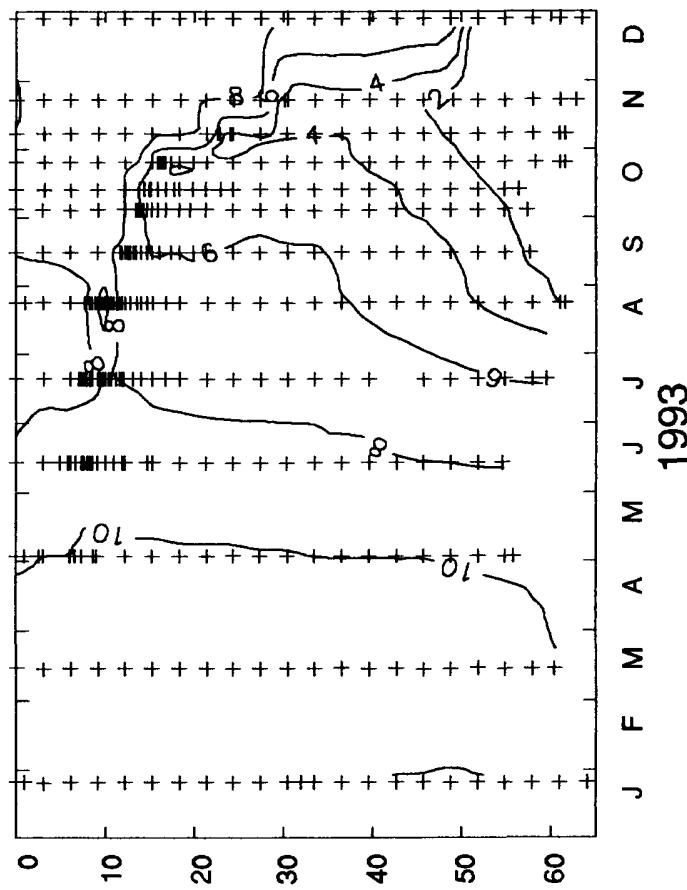

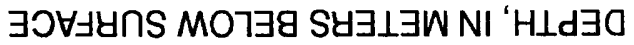




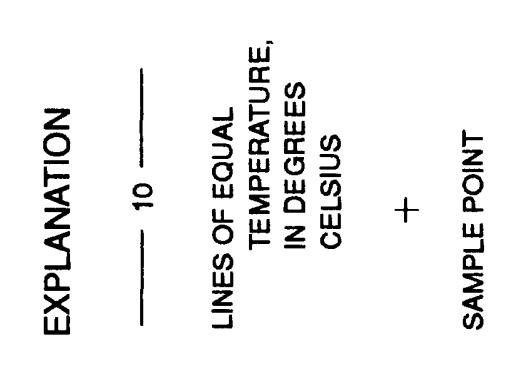
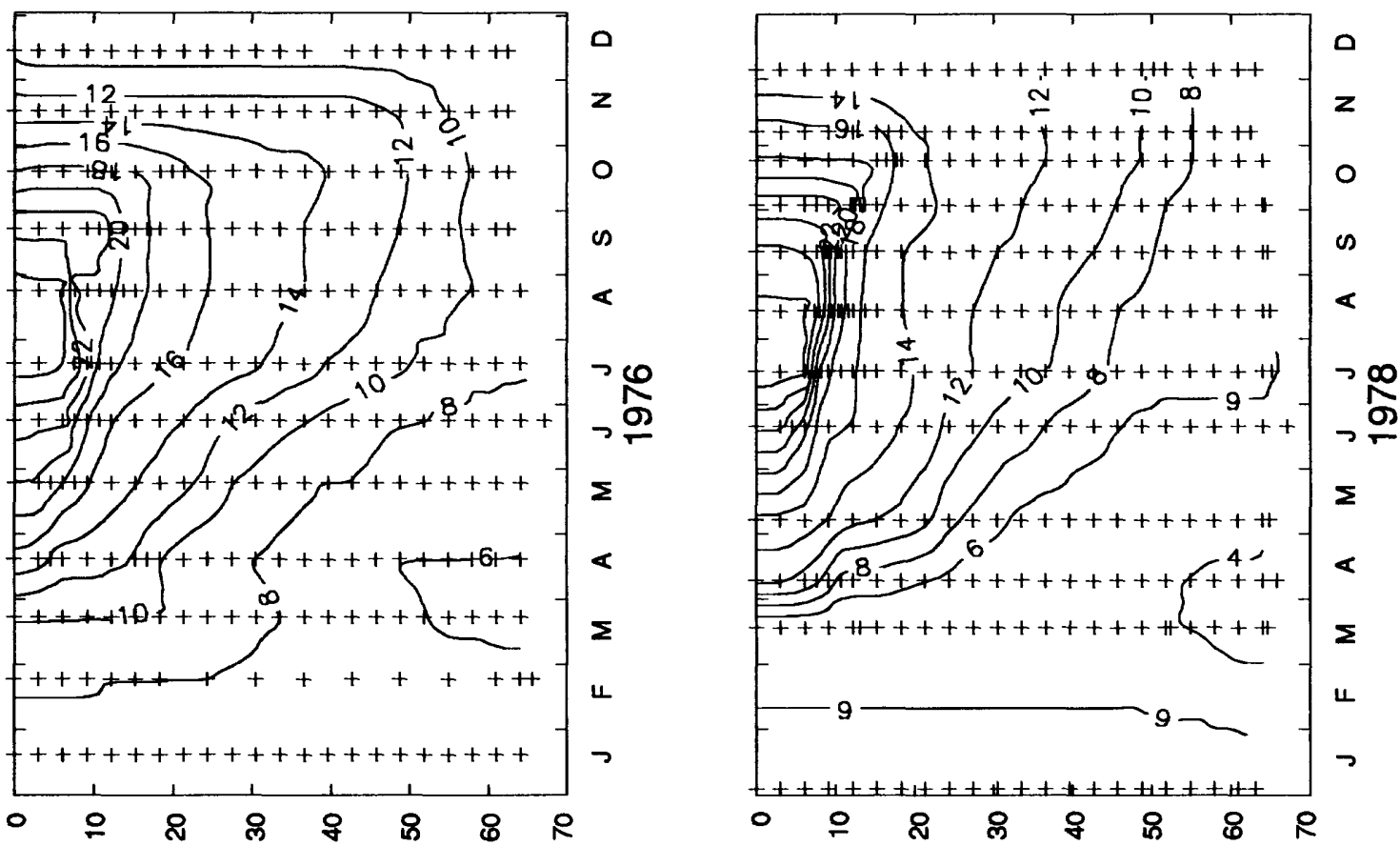

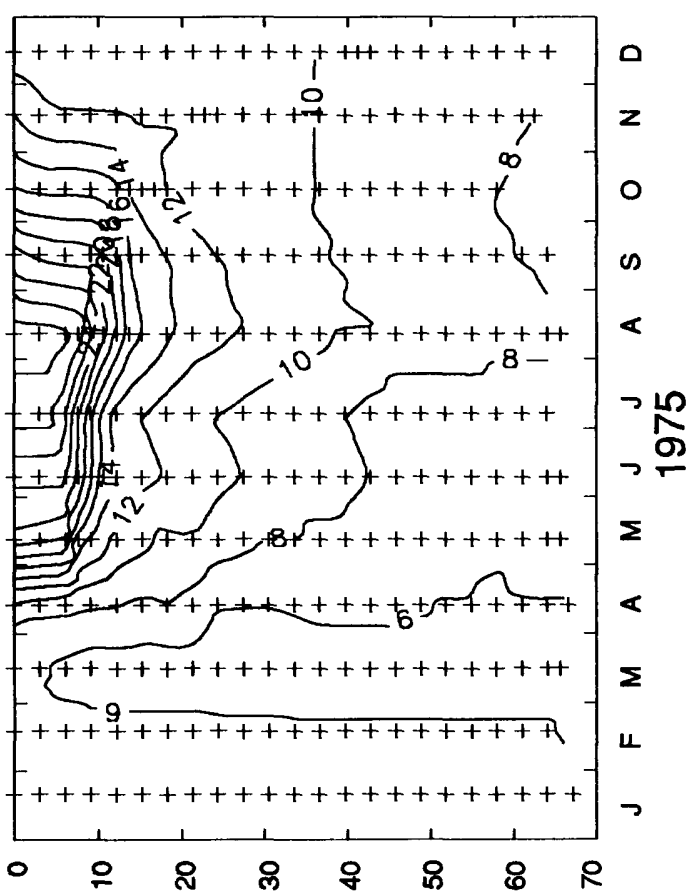

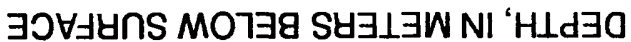

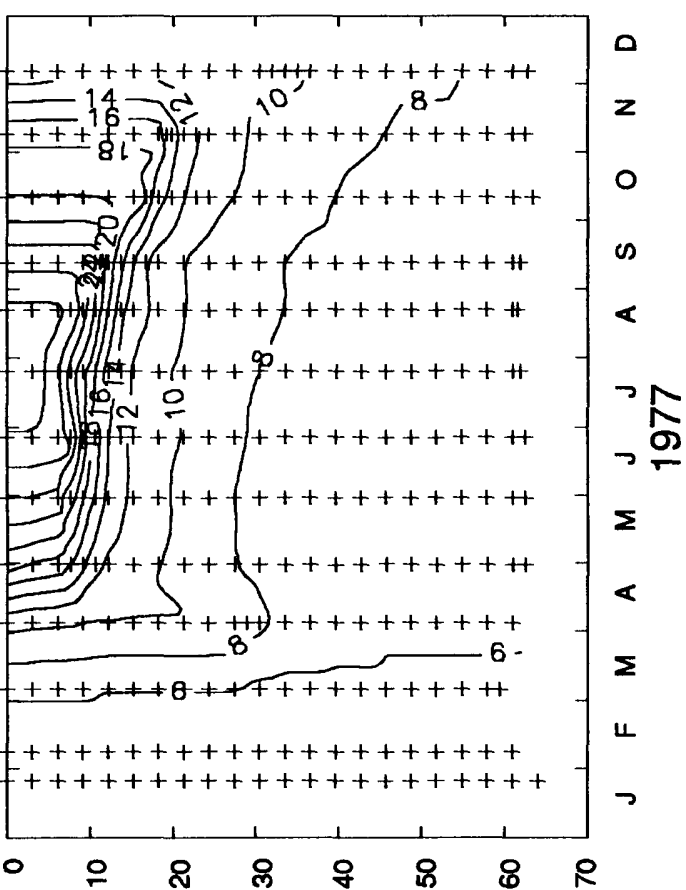

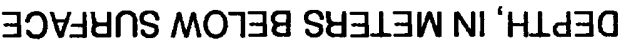




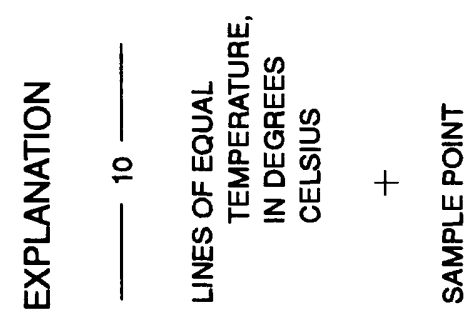
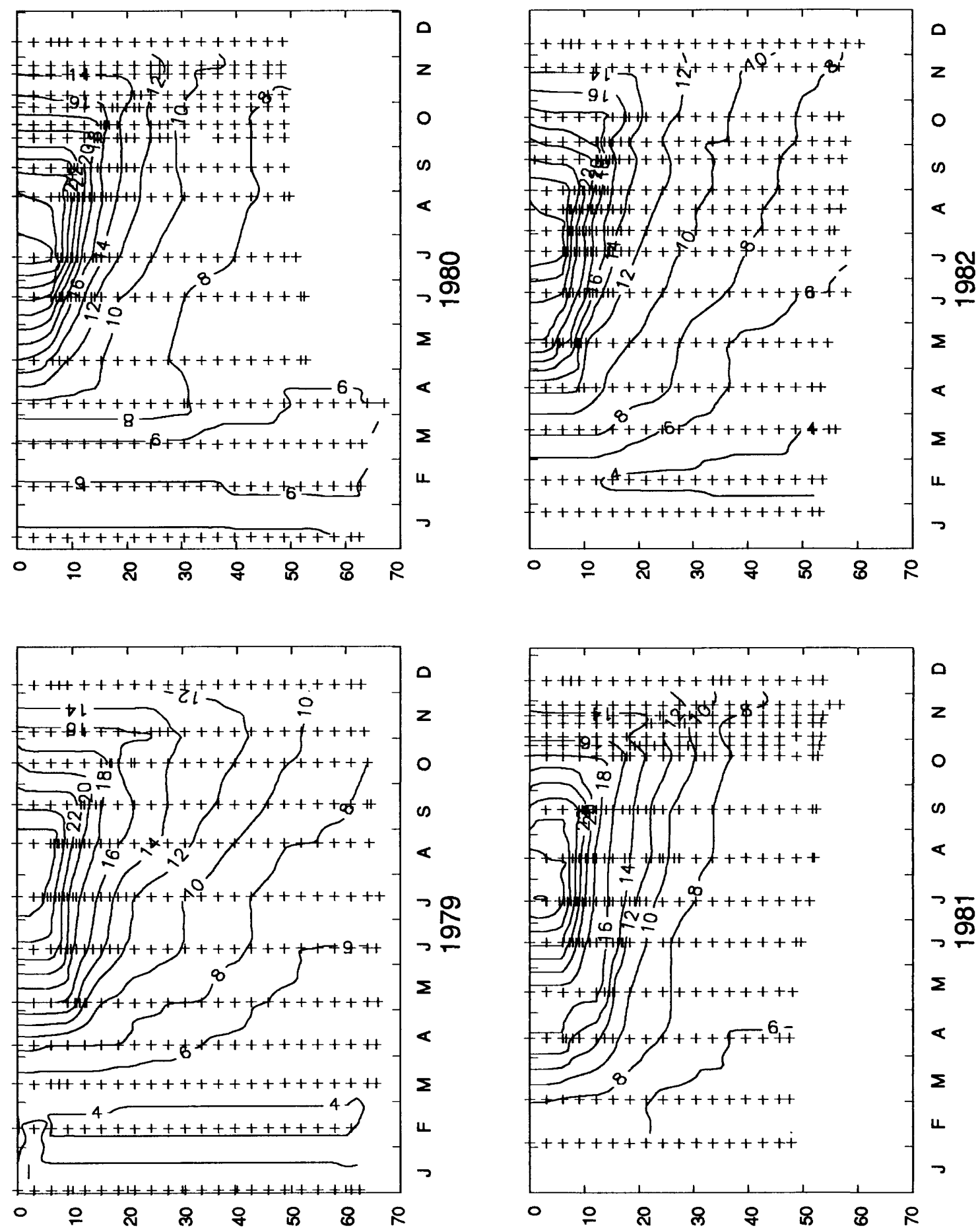

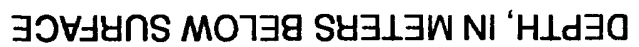
$\exists כ \forall\lrcorner y$ ก MOフ 


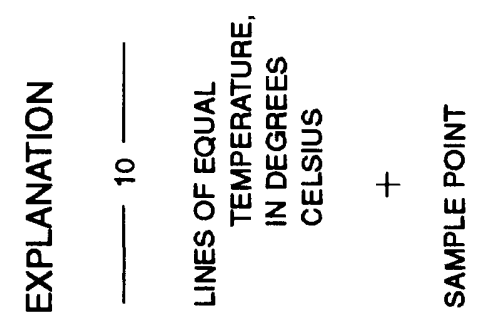
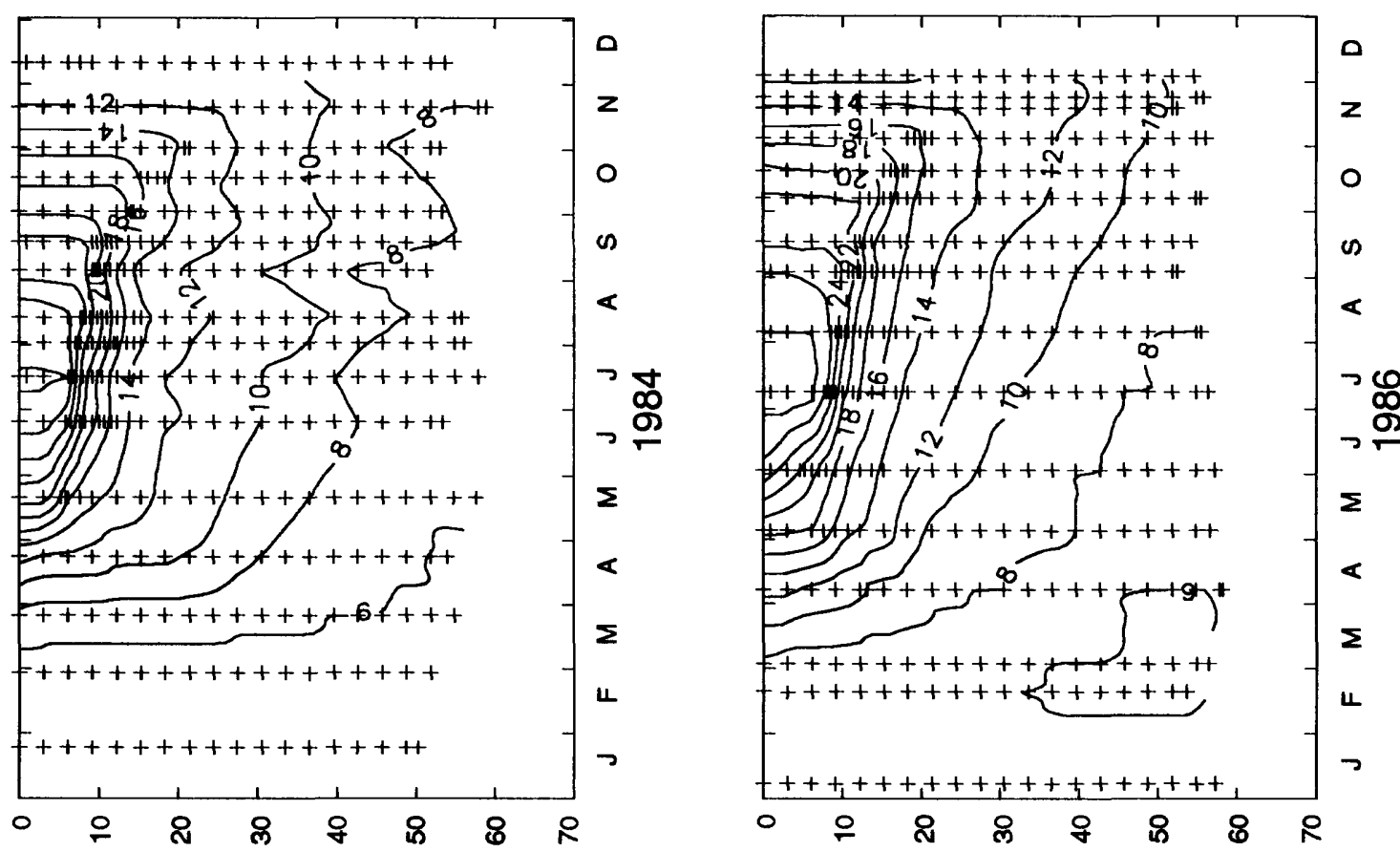

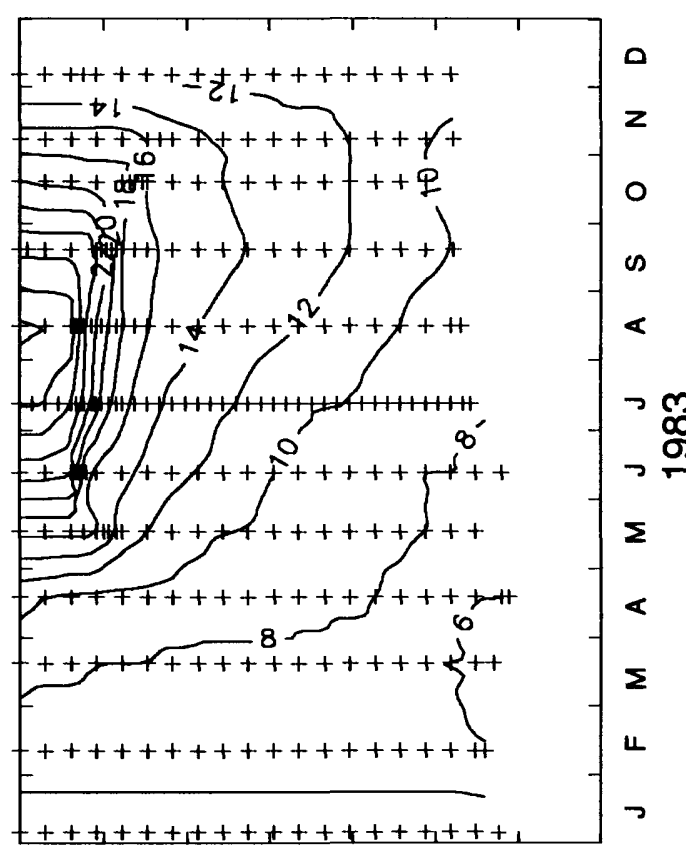

- 으 용요 용

$\exists \supset \forall\lrcorner y$ ก S MO7ヨg S

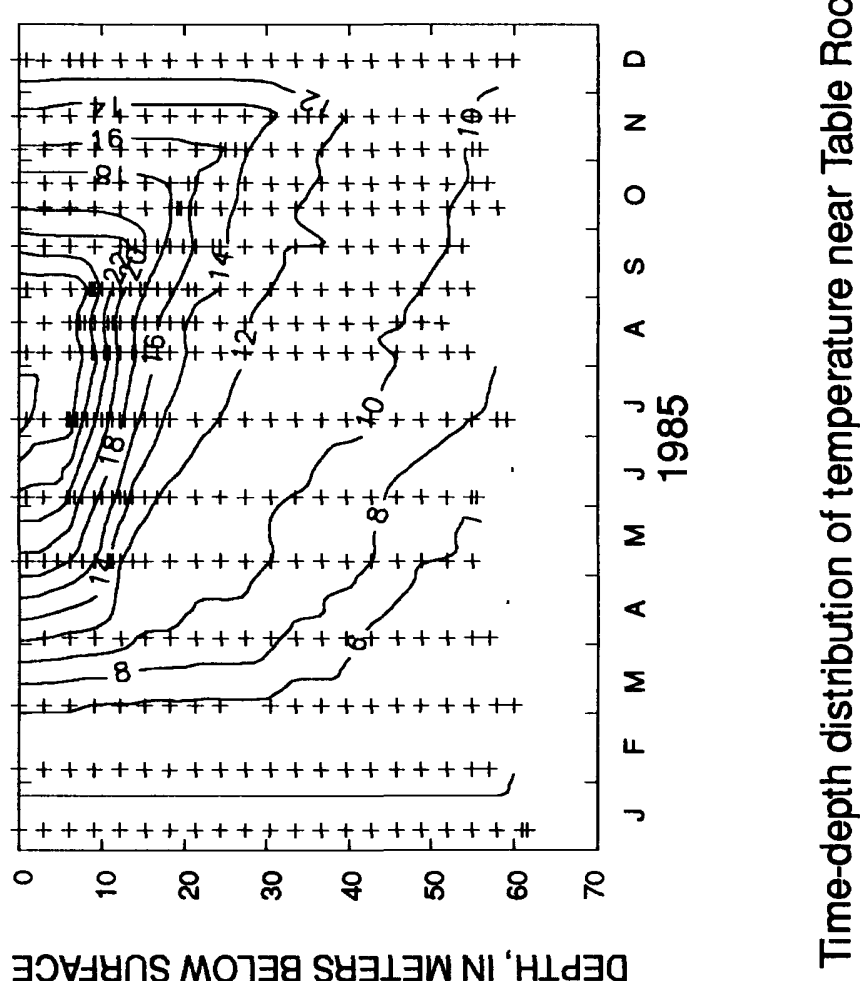

$\exists \supset \forall \exists y \cap S$ MOาヨg S $4 \exists \perp \exists W$ NI ‘ $H \perp d \exists O$ 


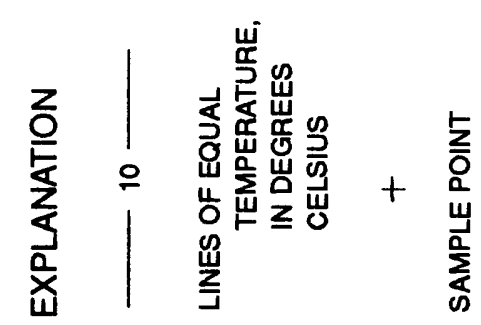
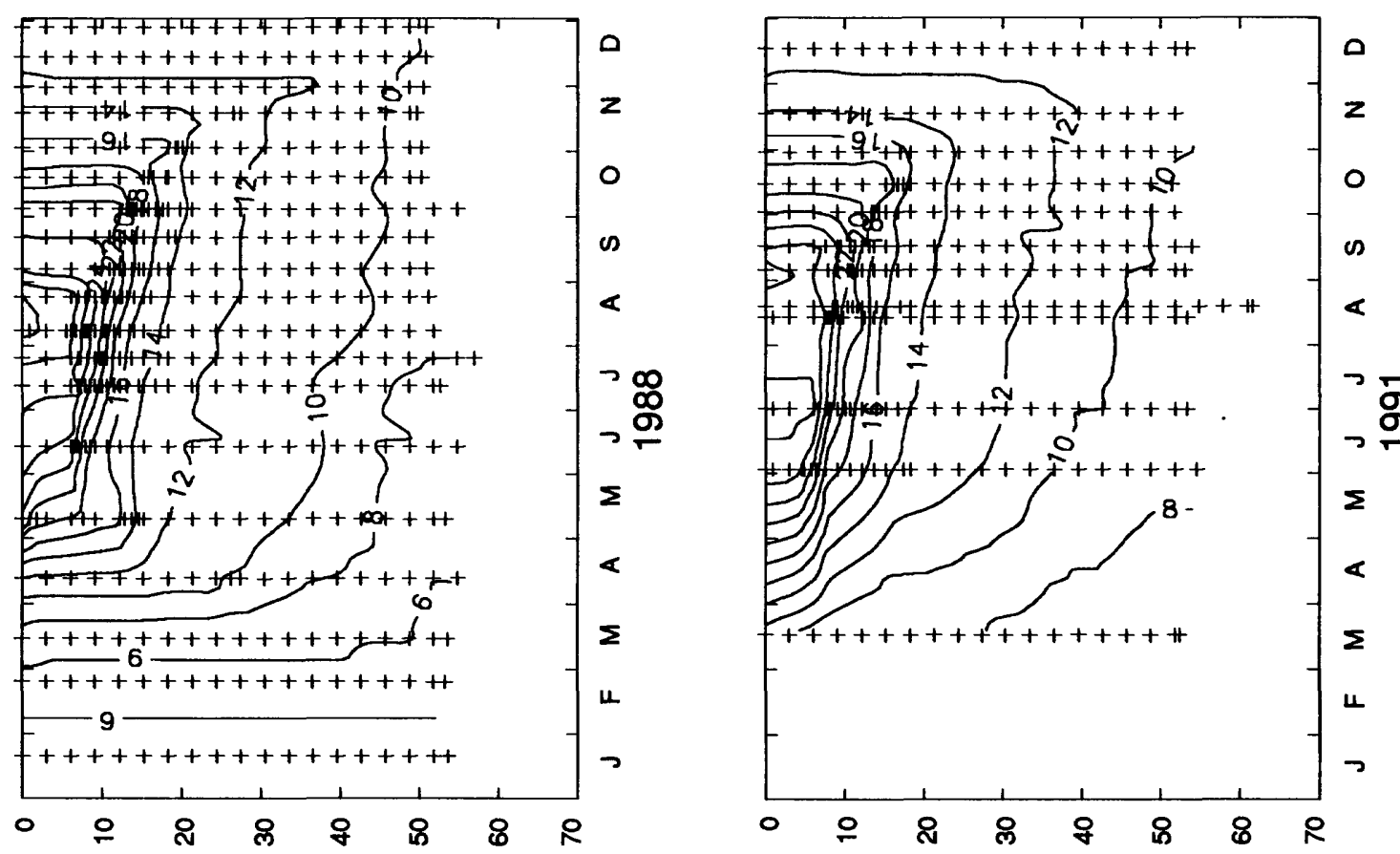

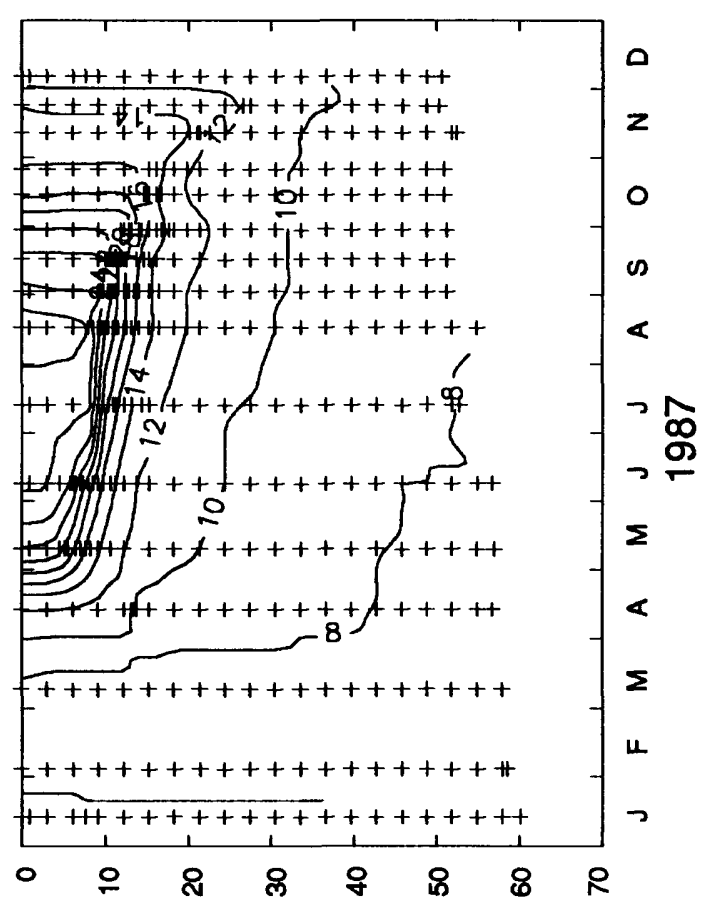

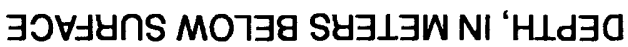

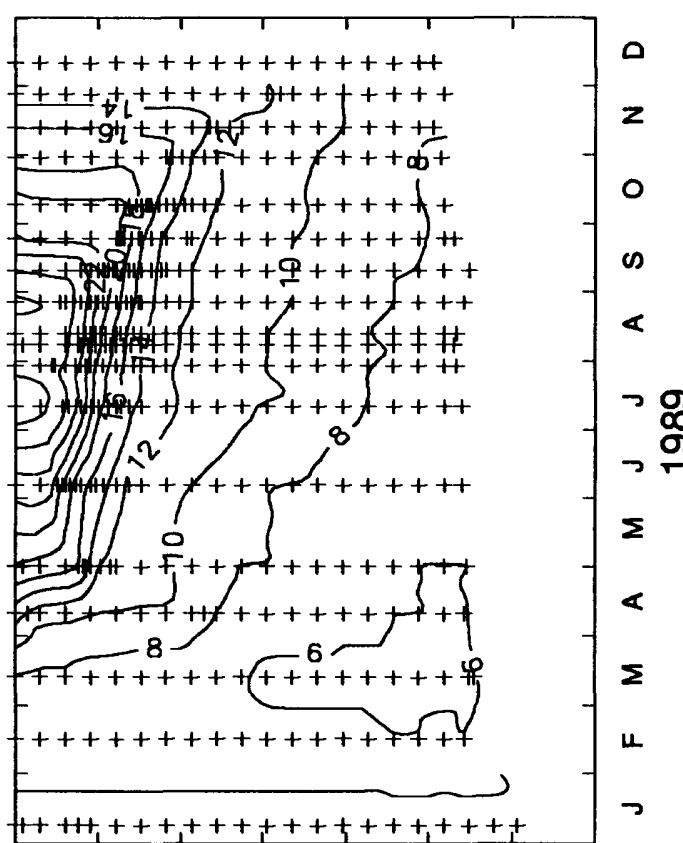

- 으 \& 8 용요 8

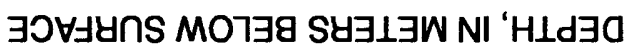




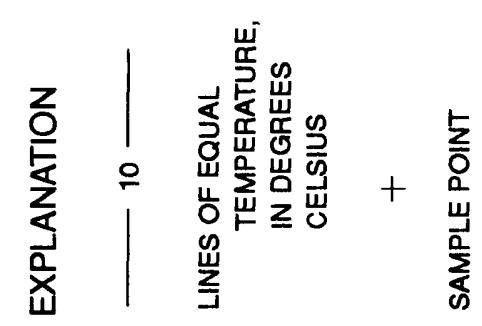

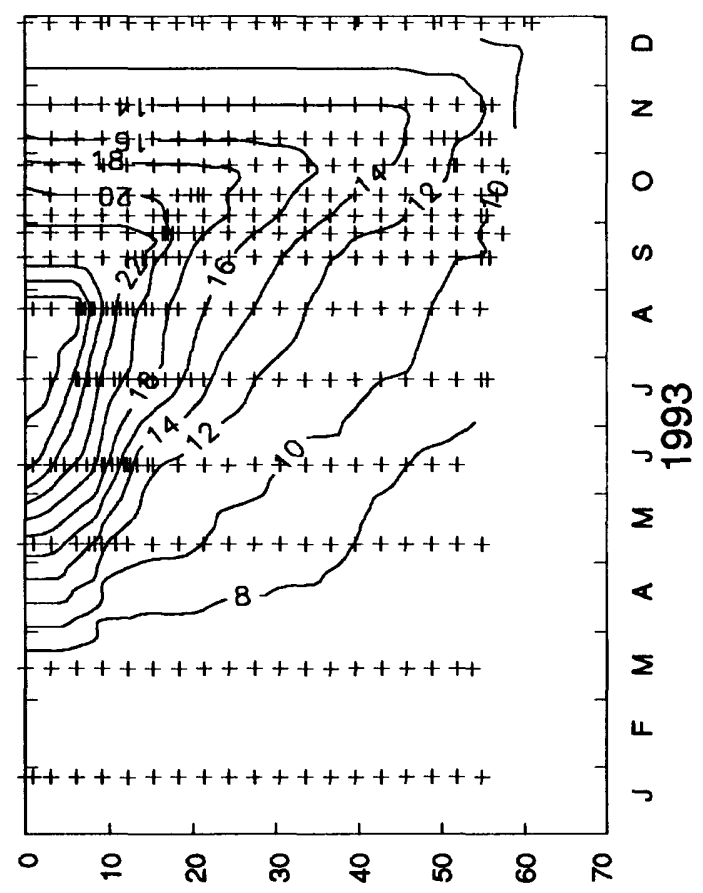

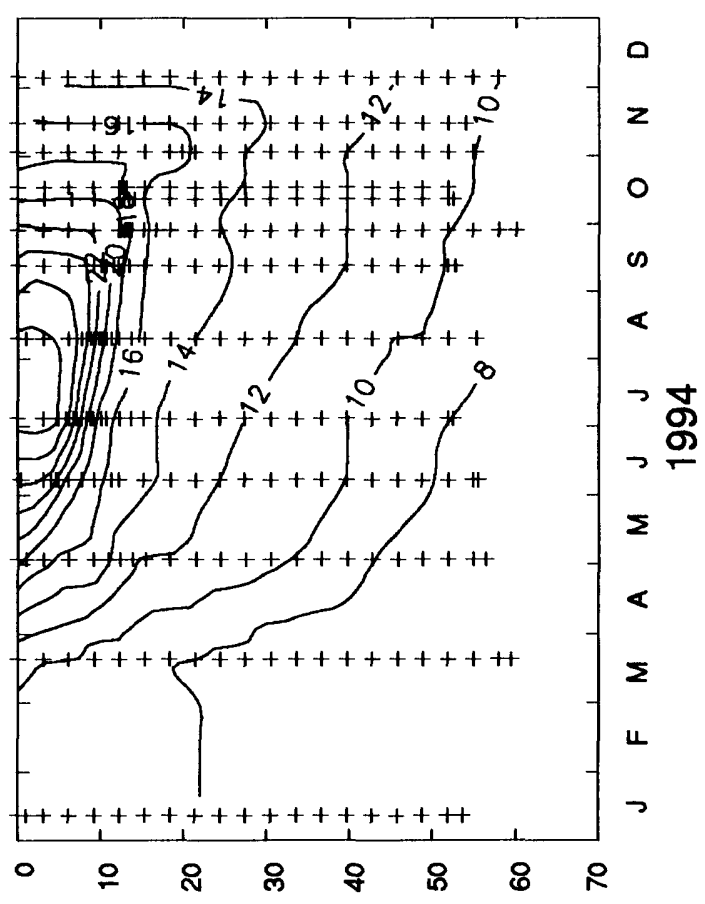

$\exists \supset \forall\lrcorner y n S$ MO 


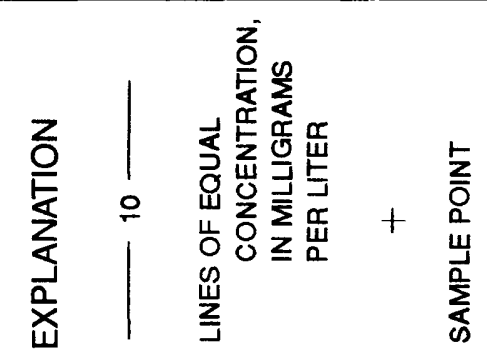
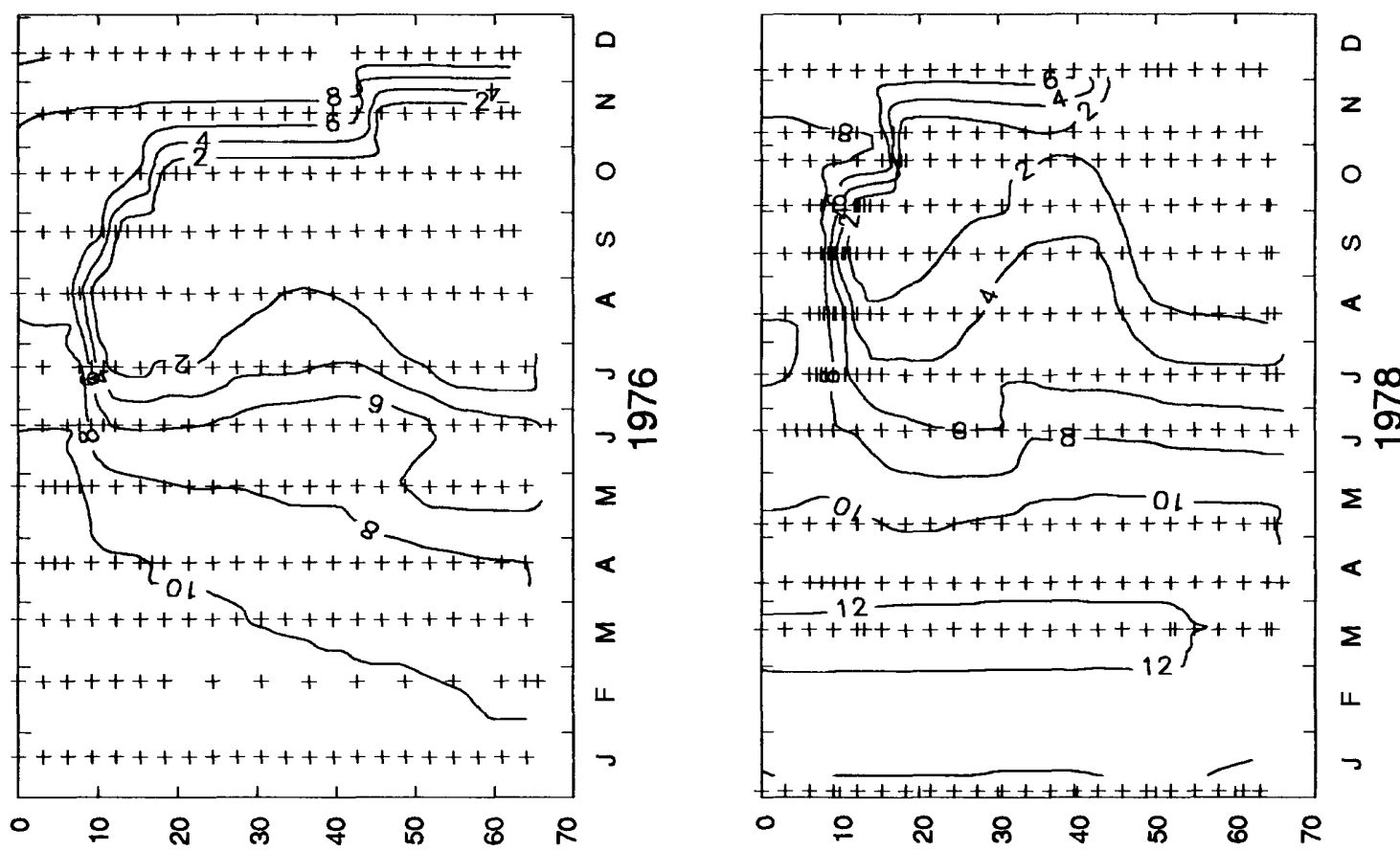

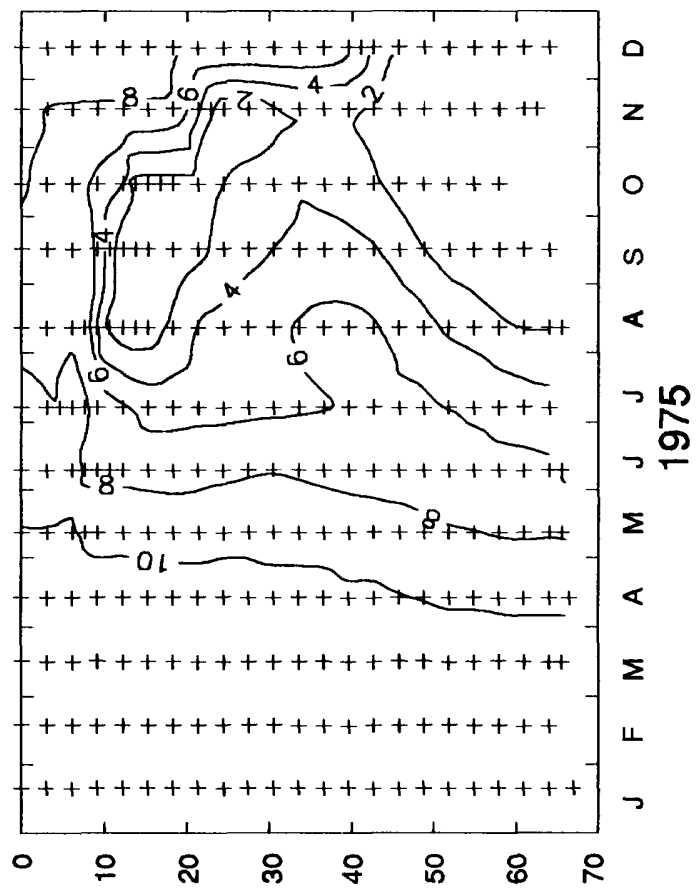

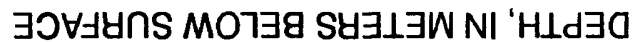

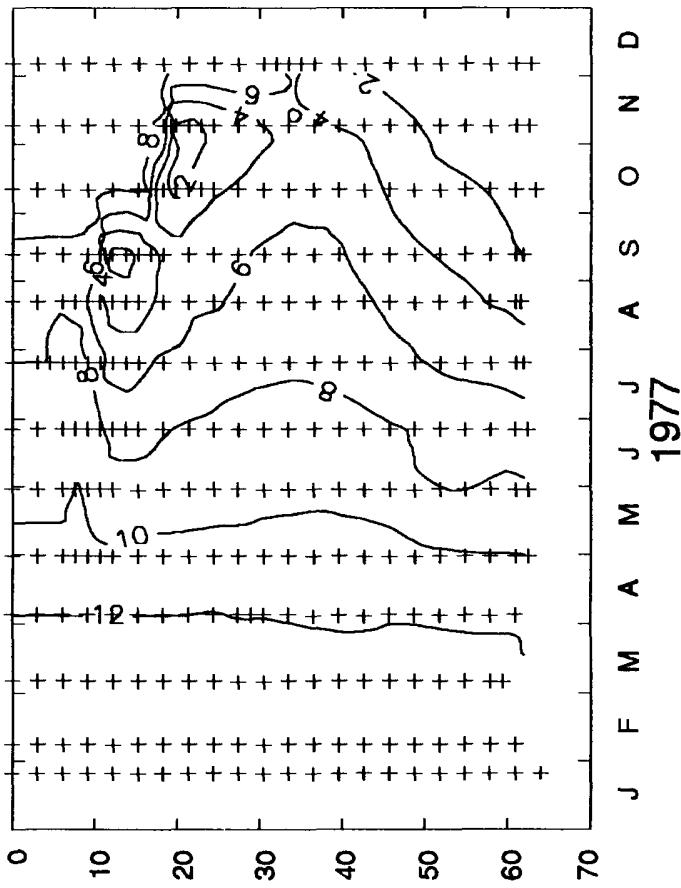

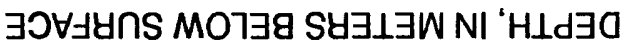



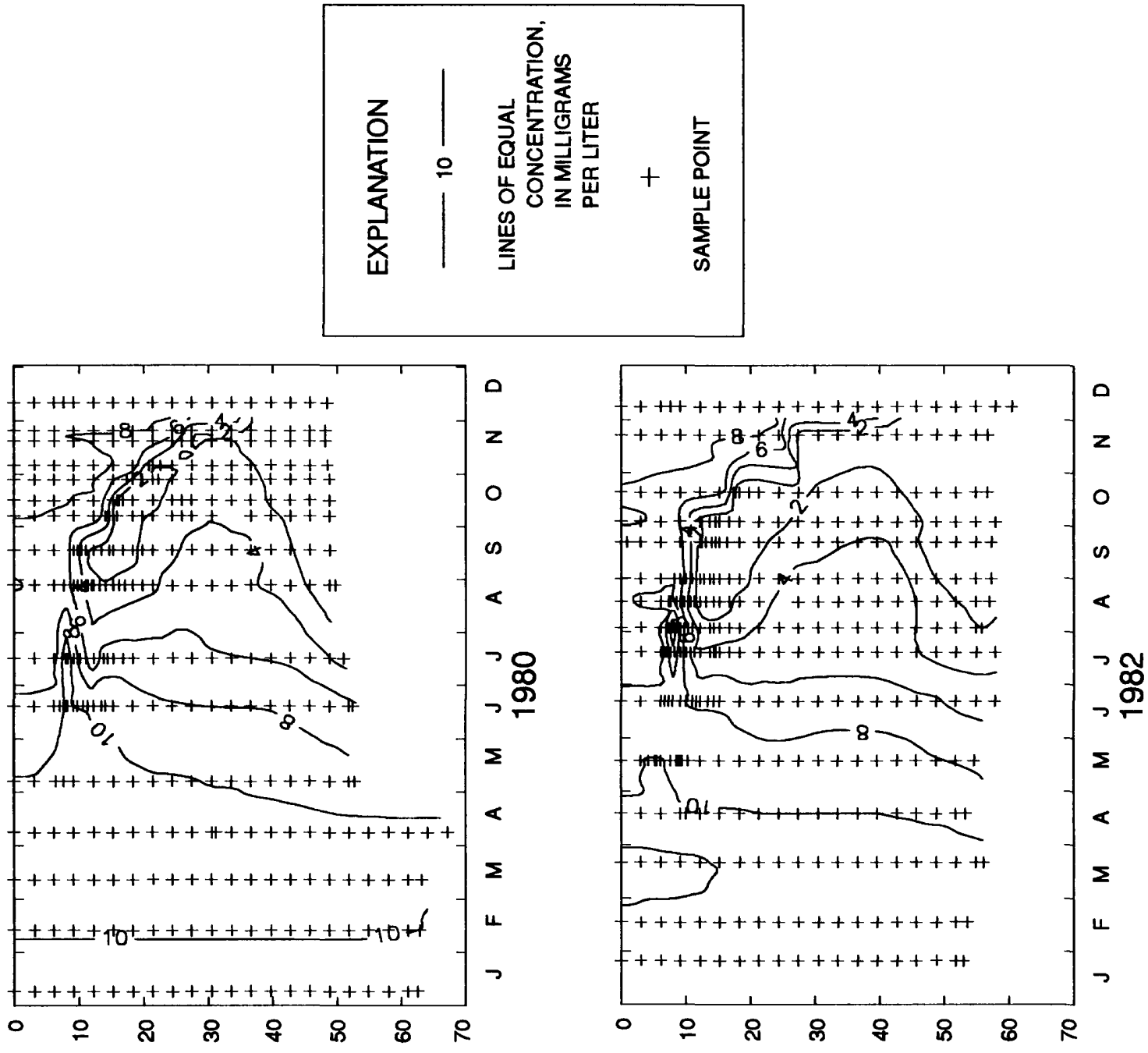

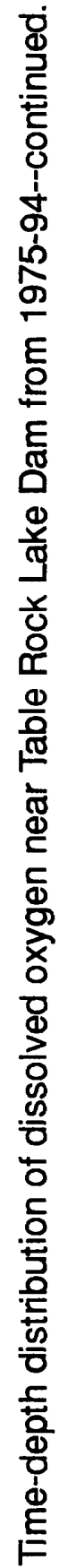

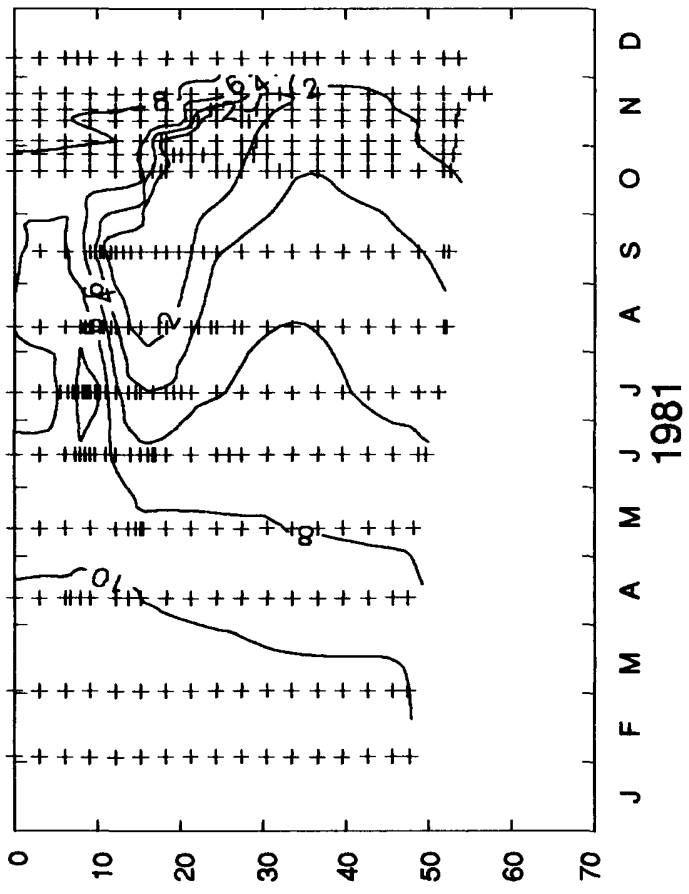

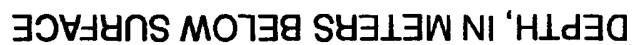




$$
\text { IIn! }
$$
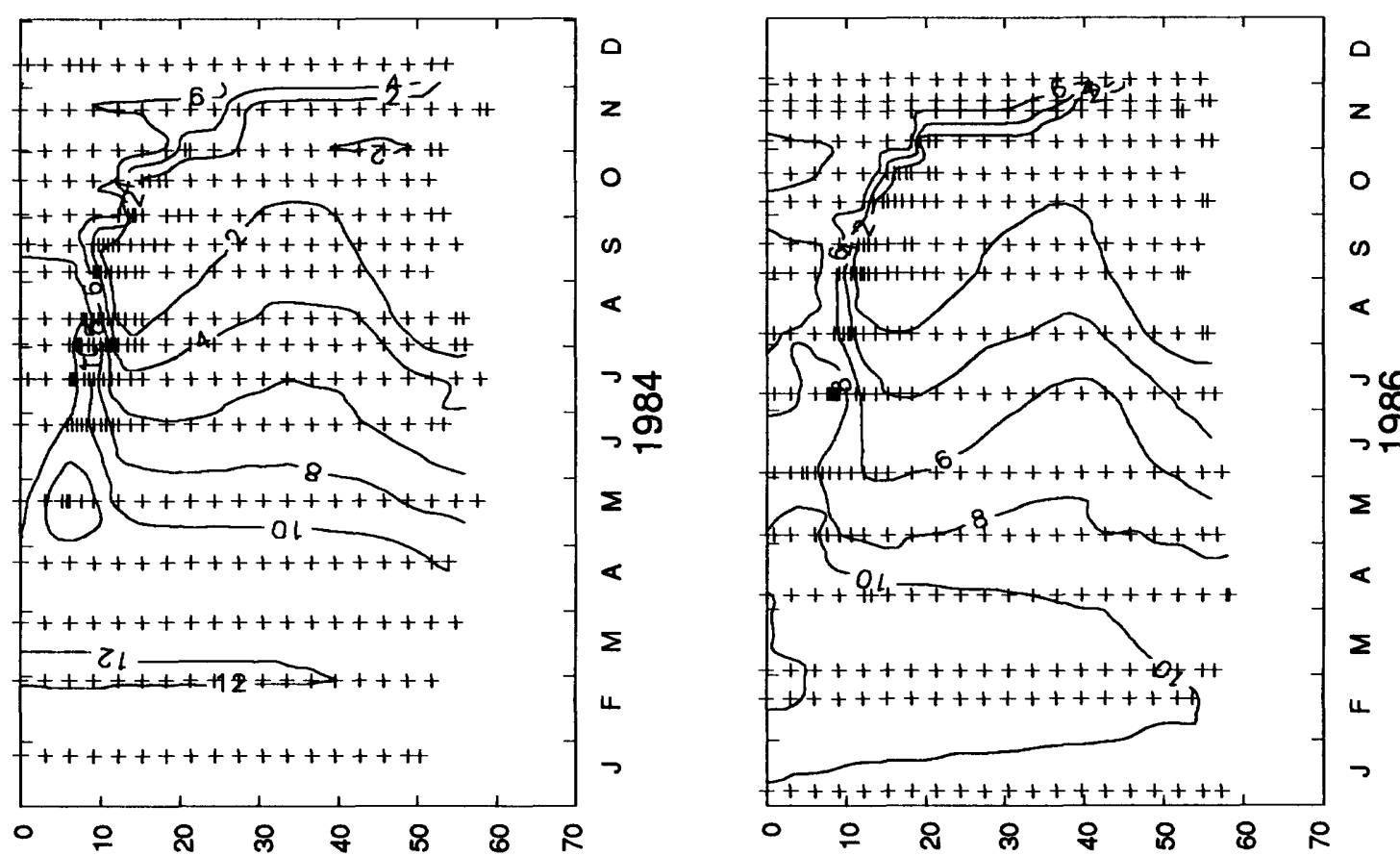

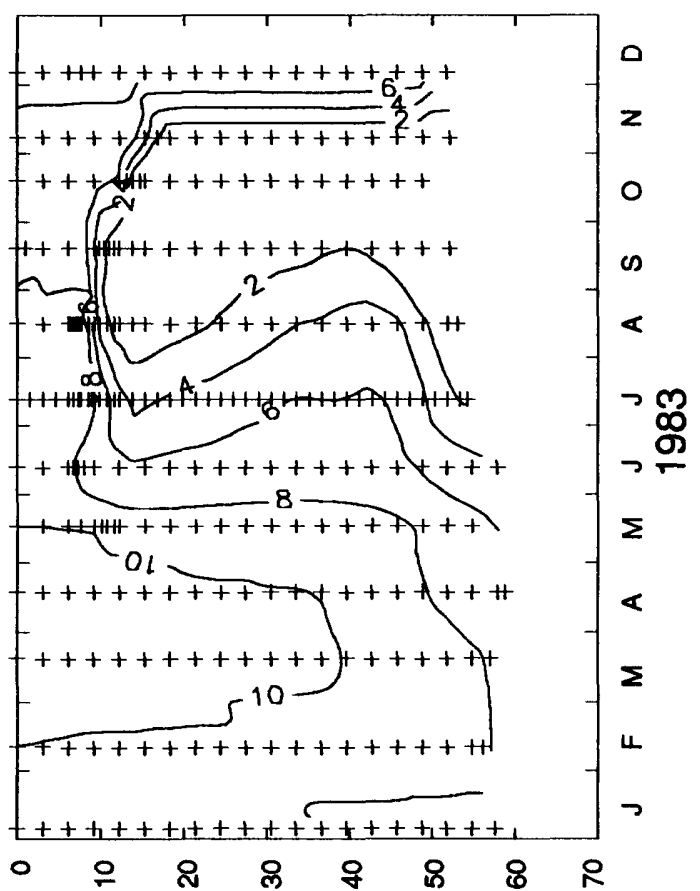

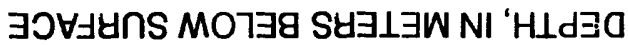

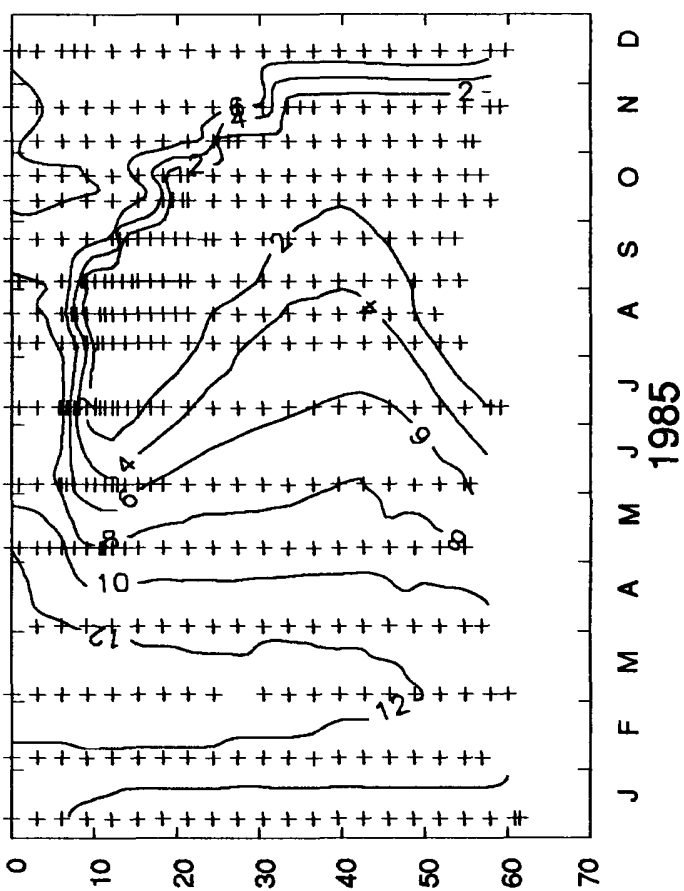

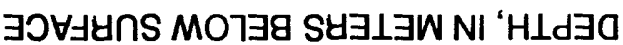



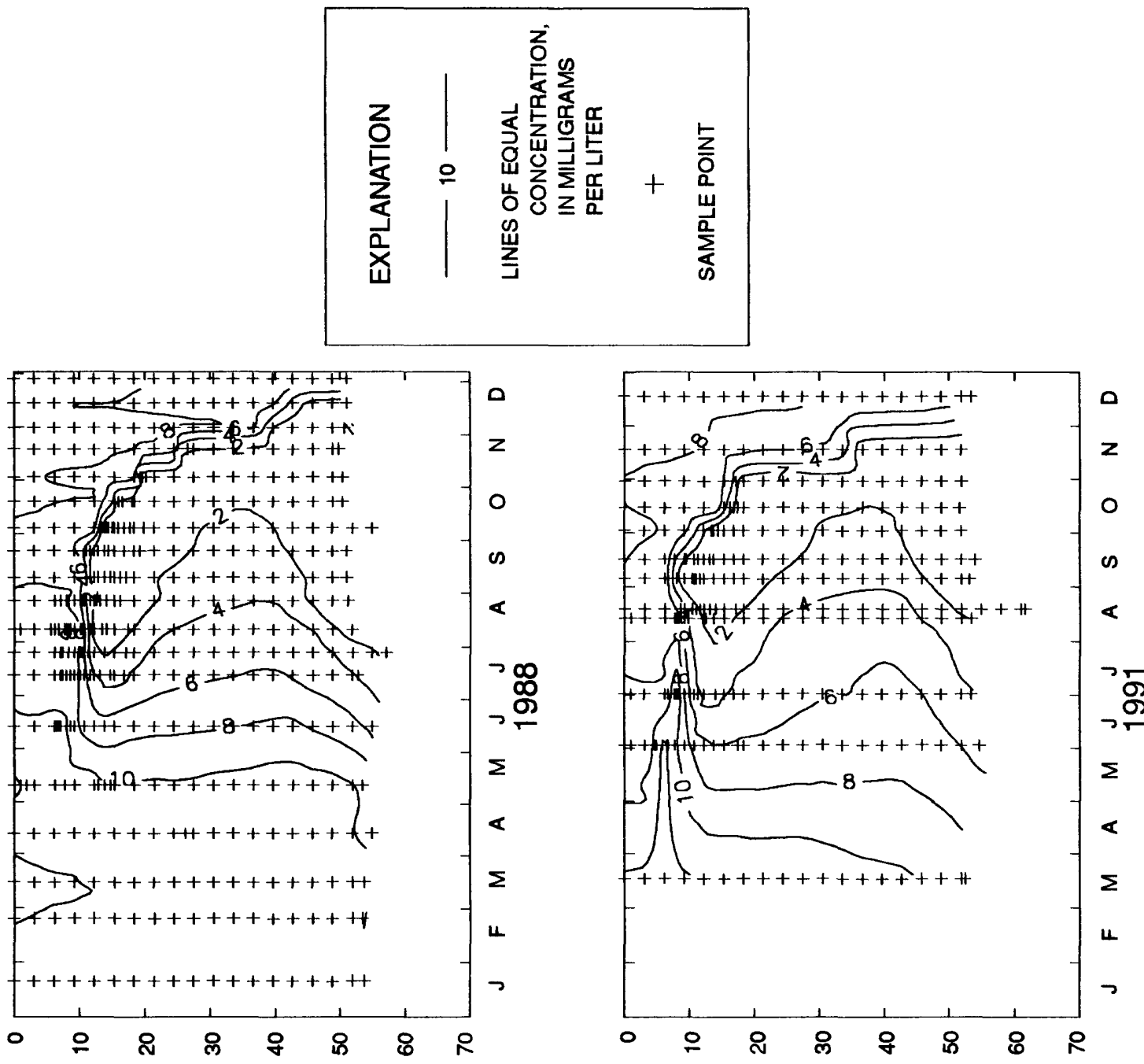

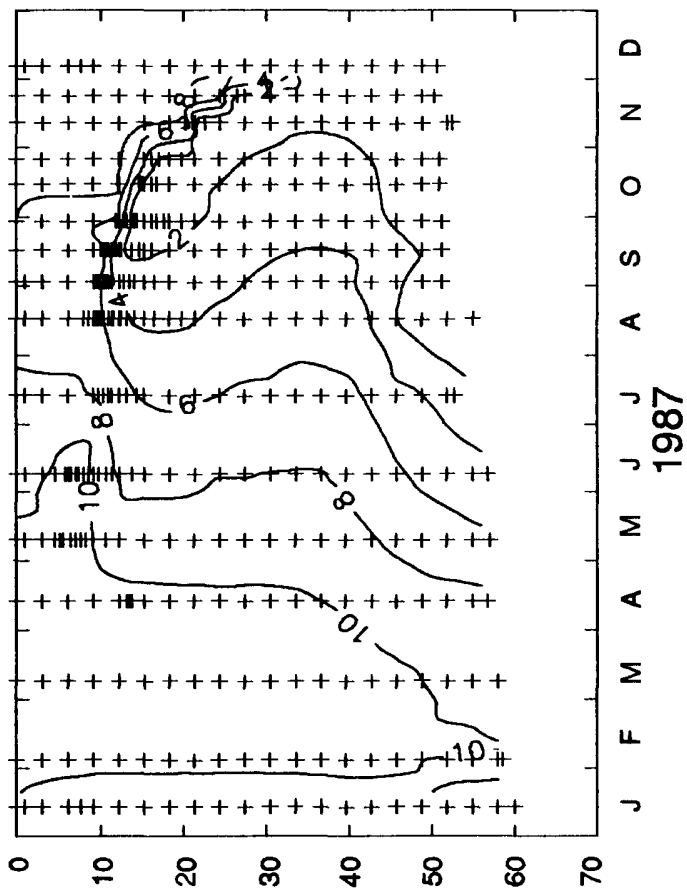

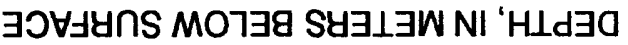

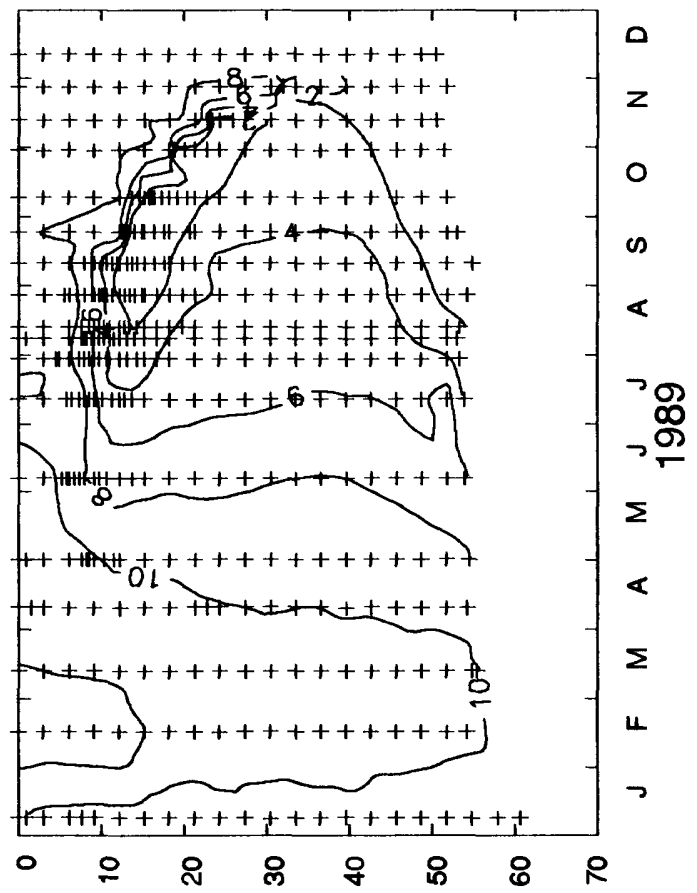

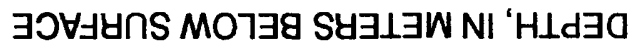




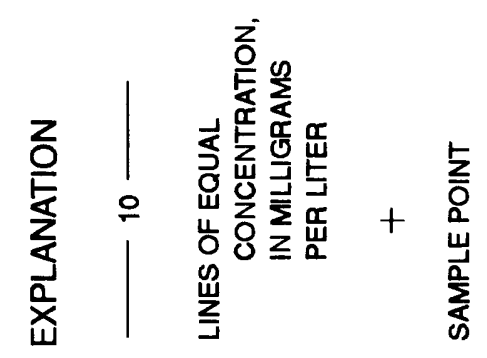

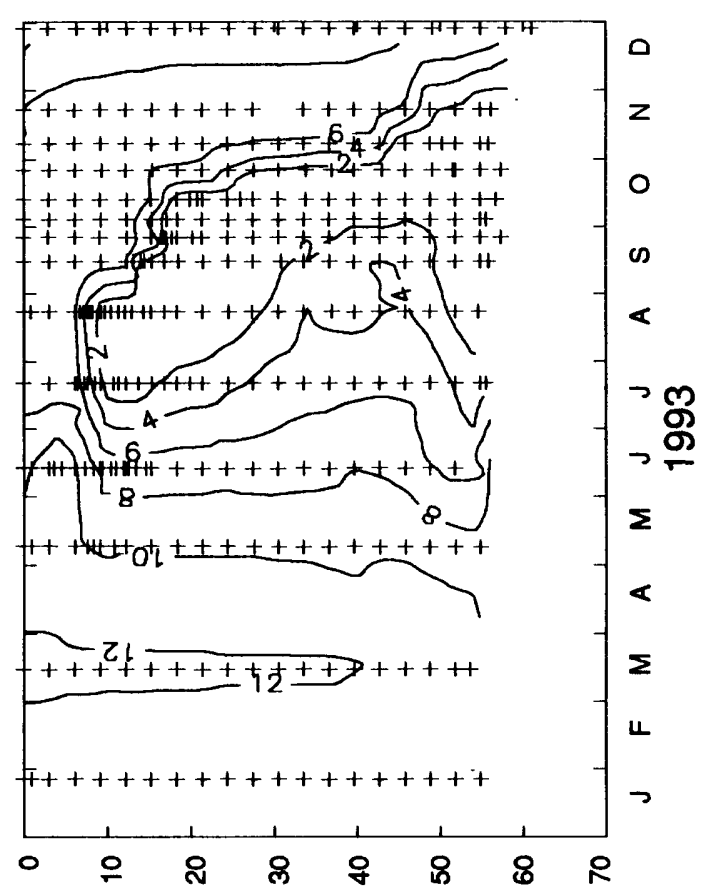

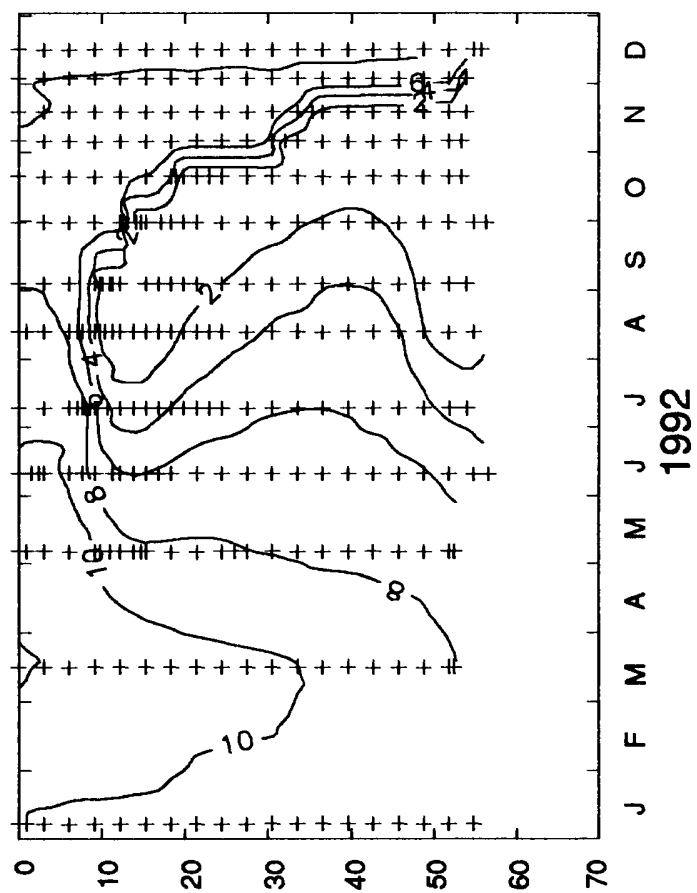

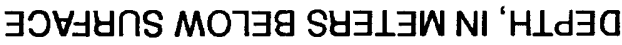

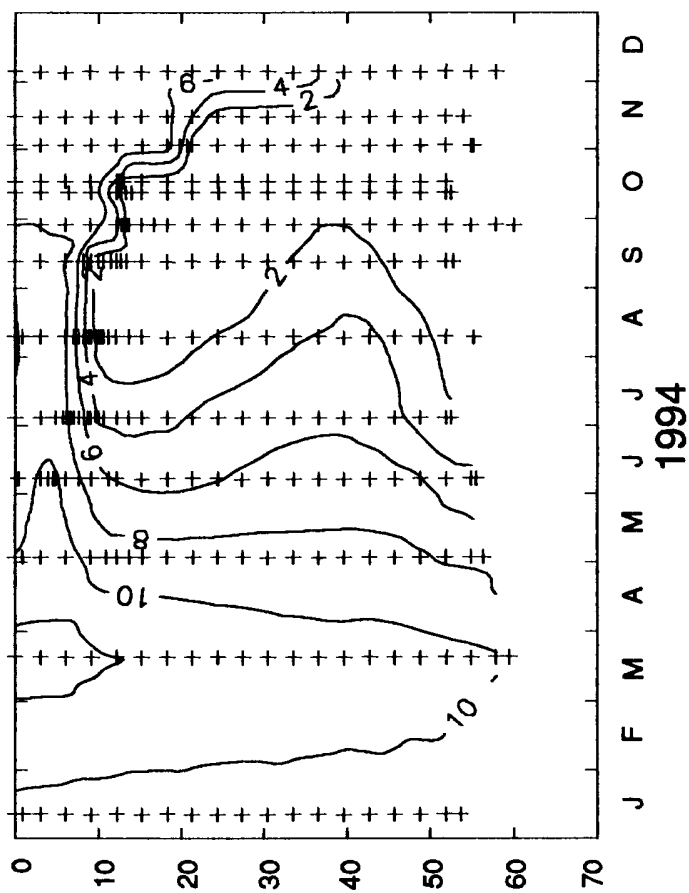

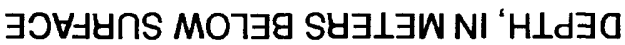




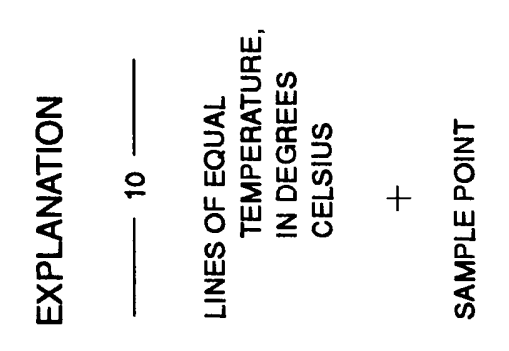
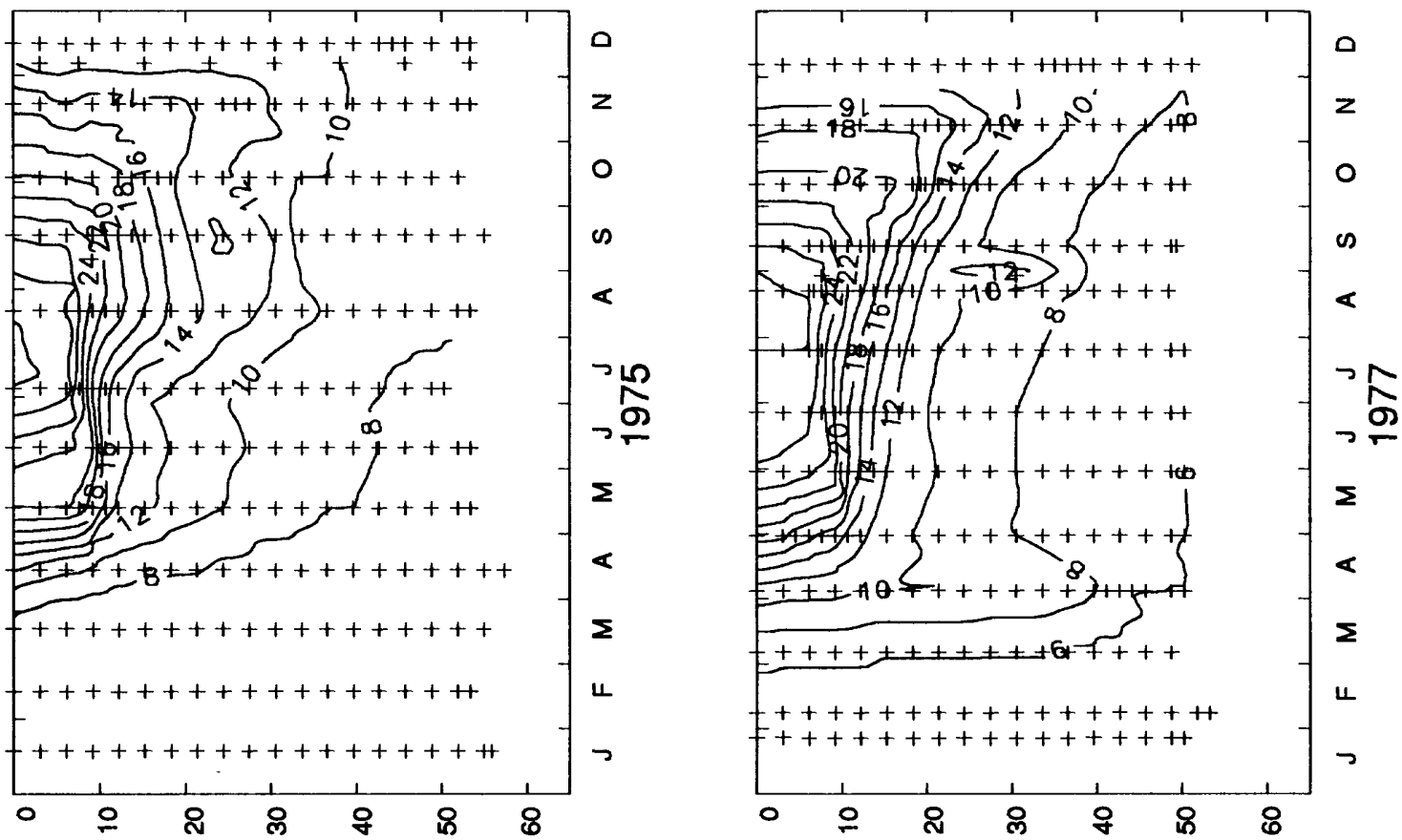

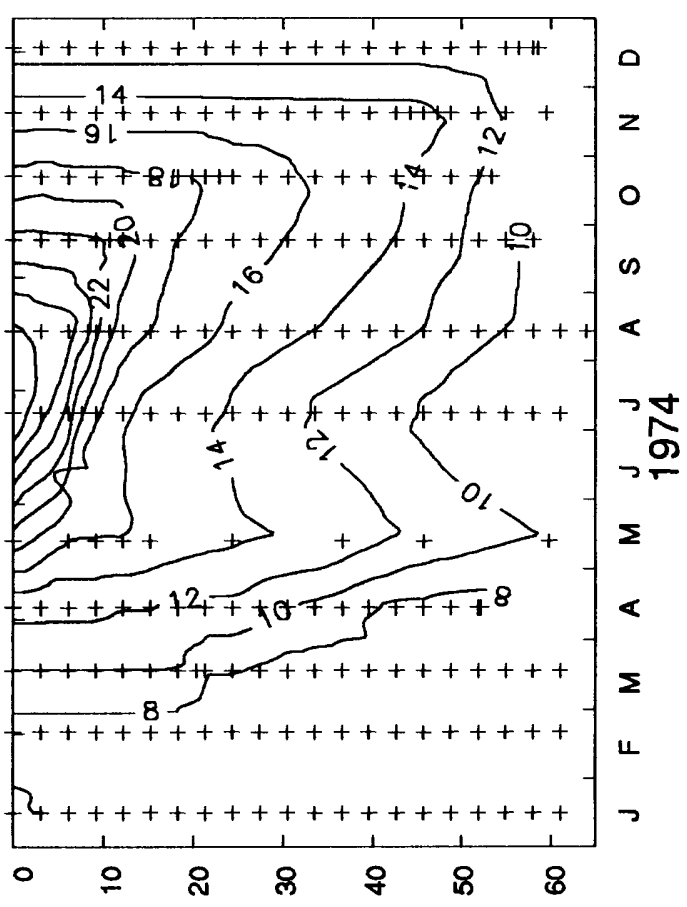

$\exists O \forall \exists y$ ก S MOTヨg S

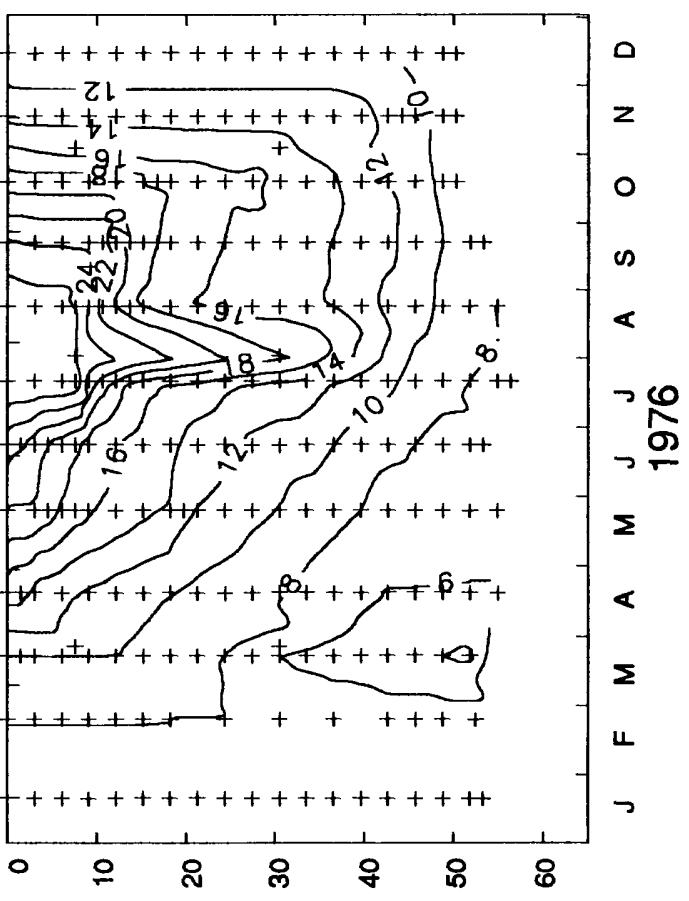

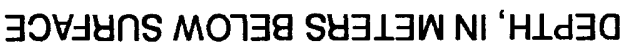

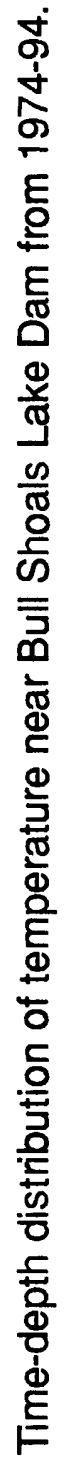




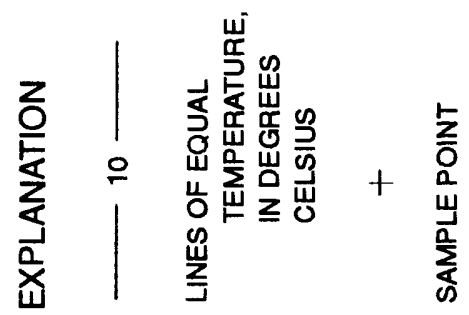
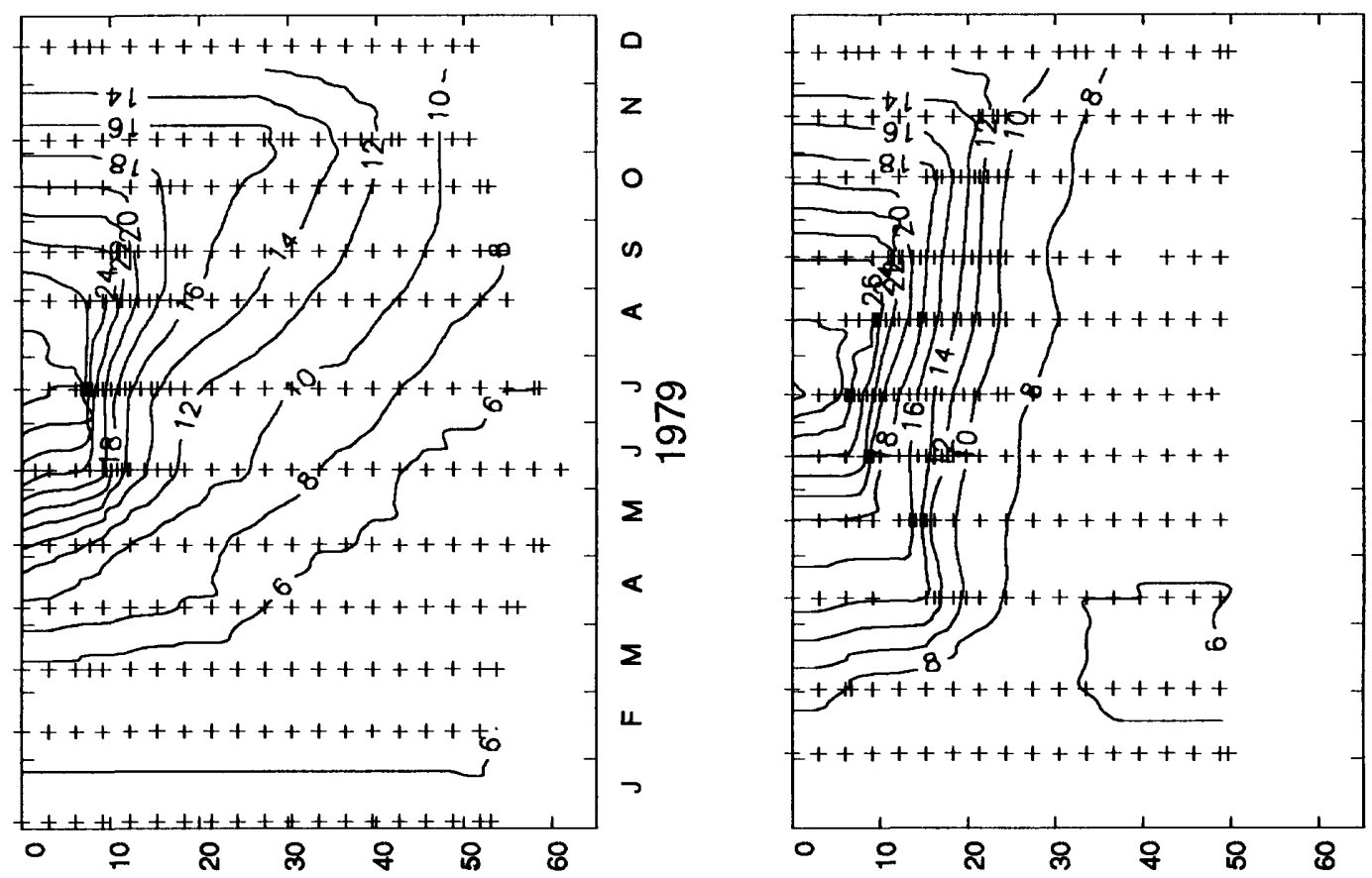

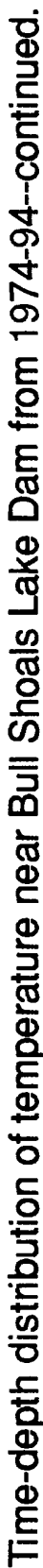

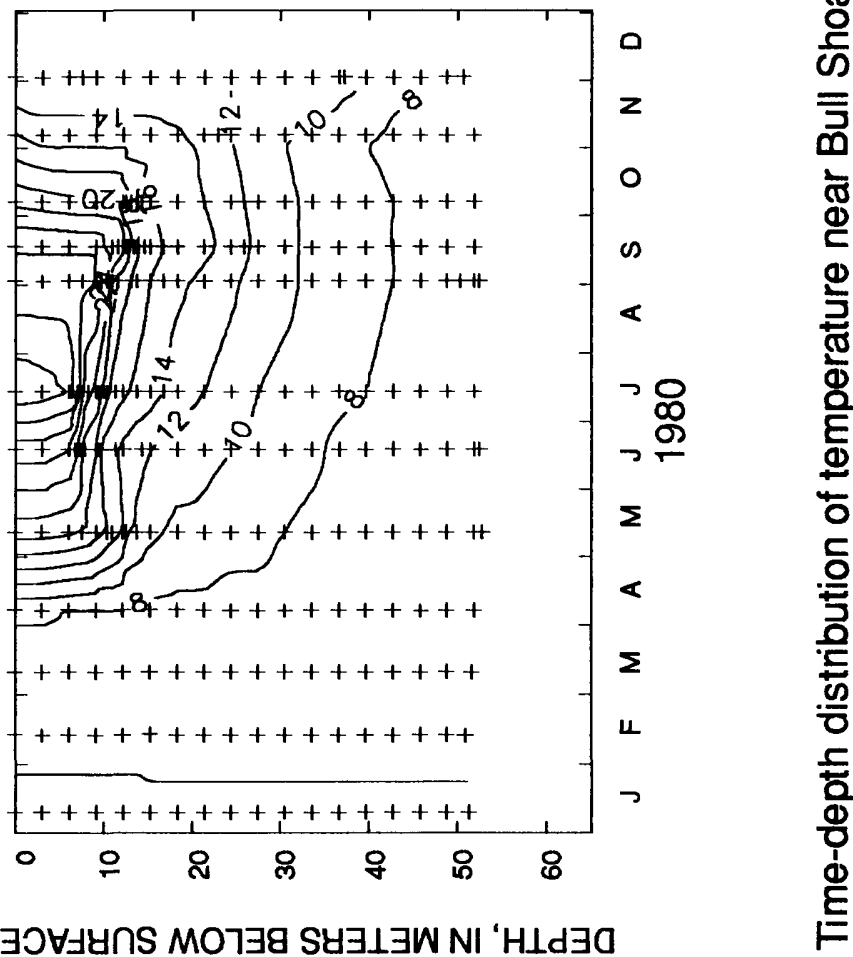




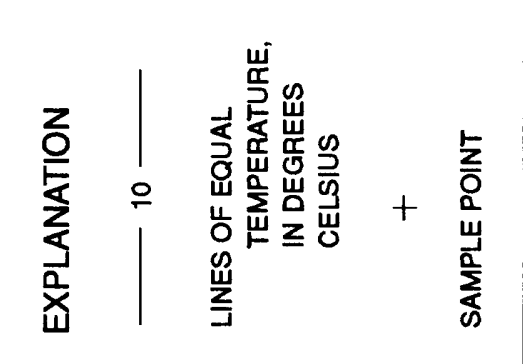
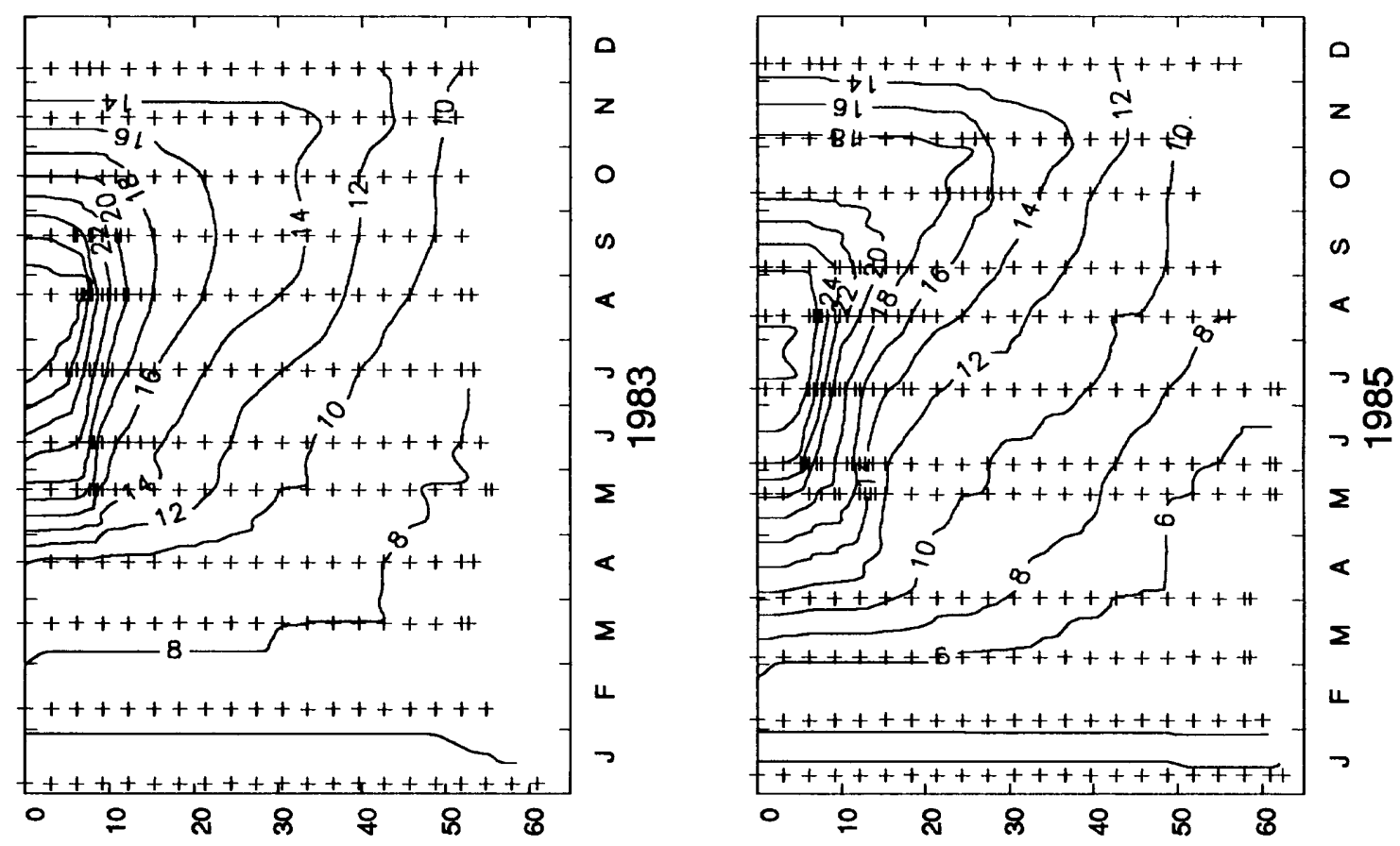

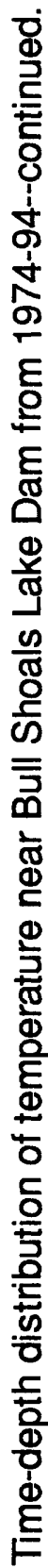

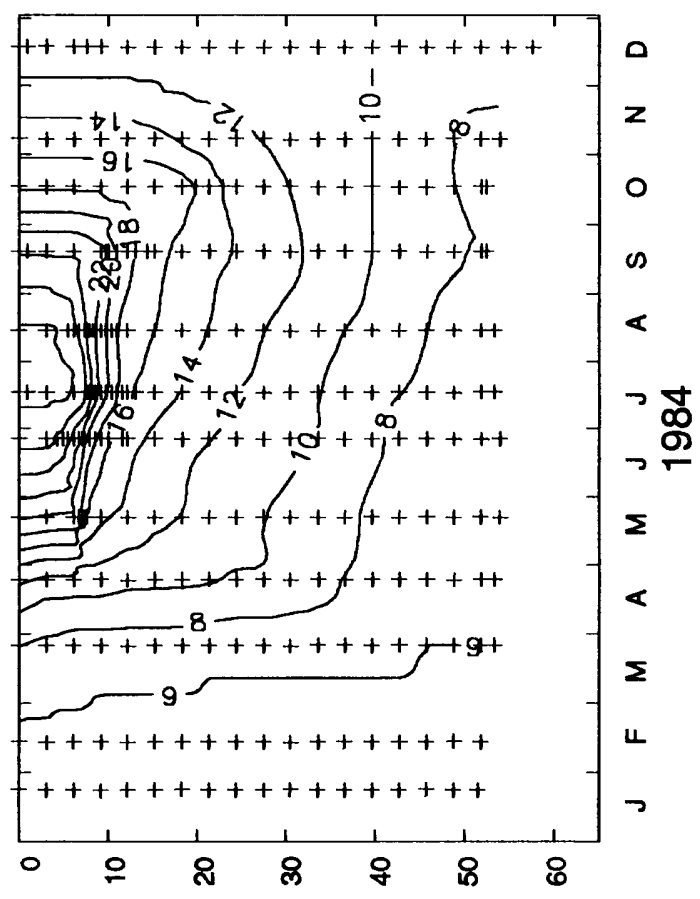

$\exists \supset \forall \exists y \cap S$ MOTヨg S 

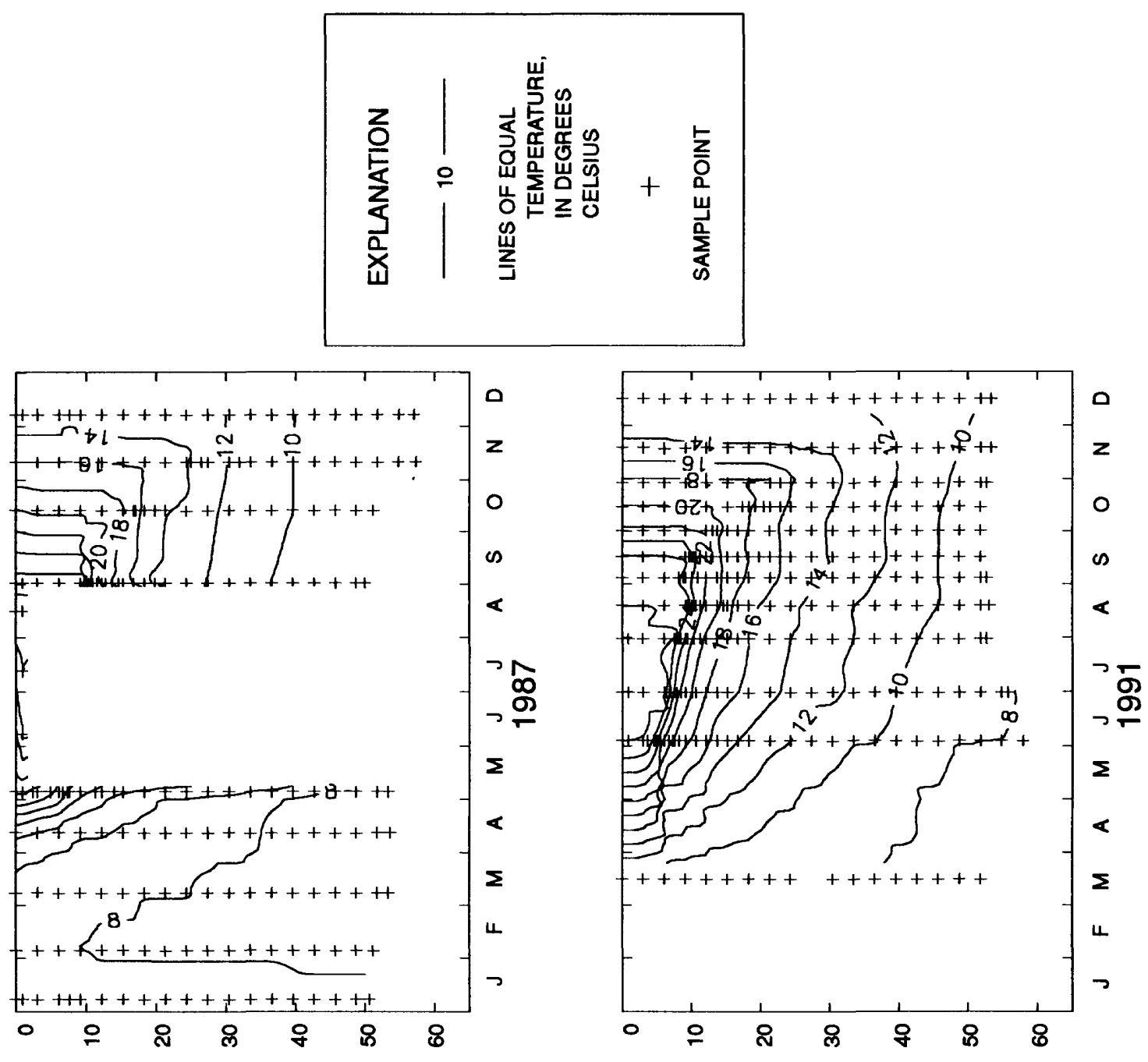

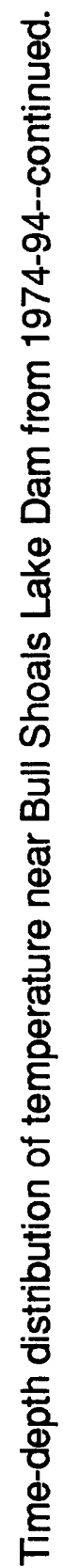

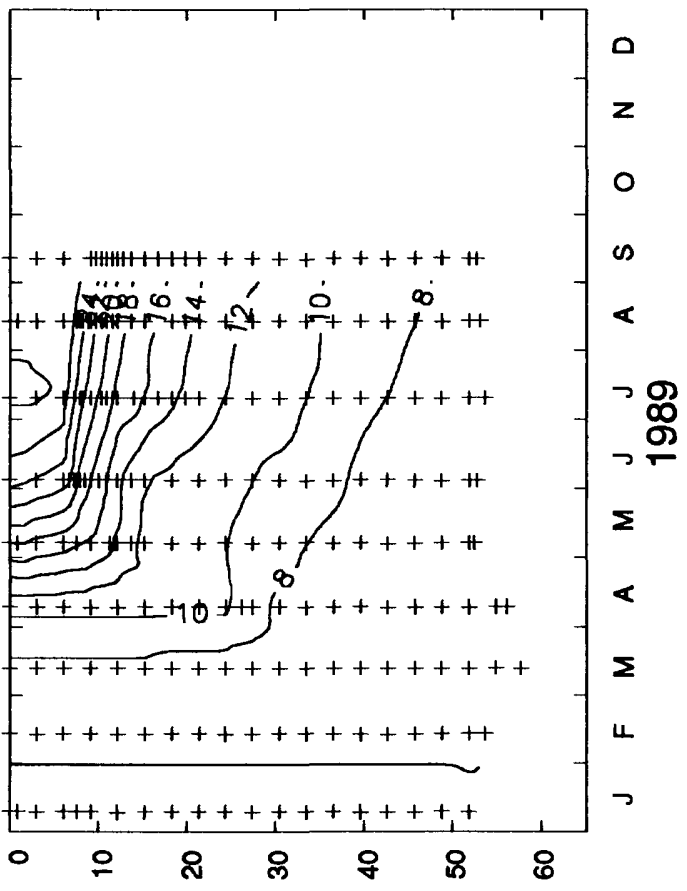

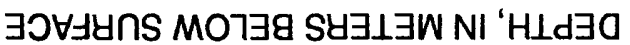




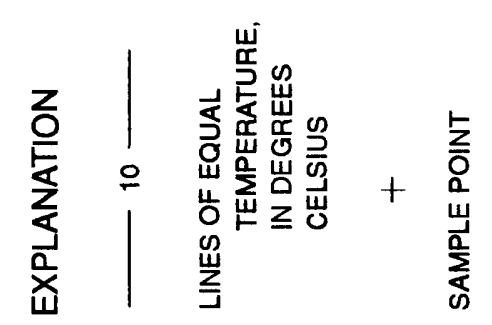

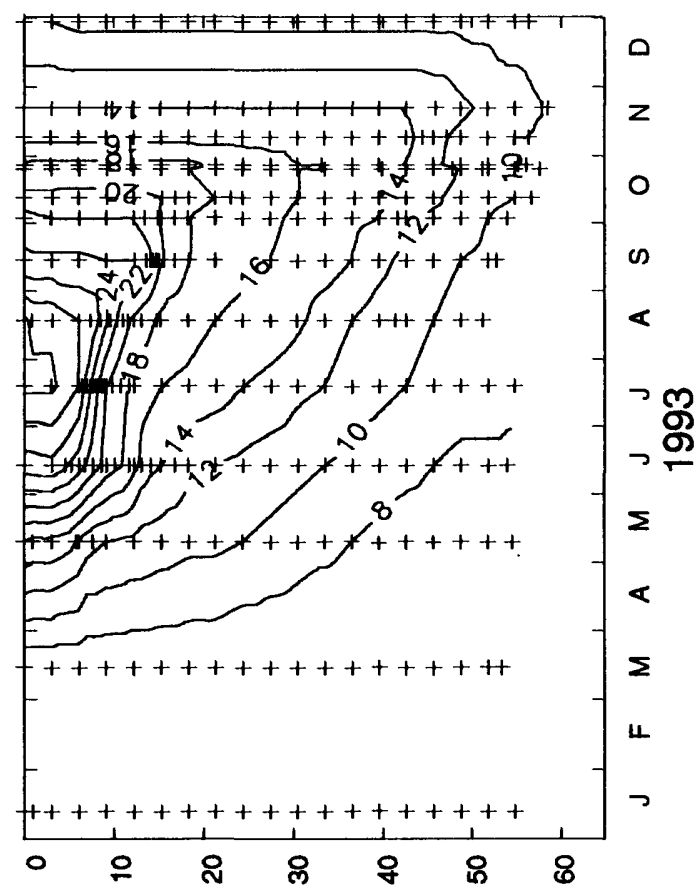

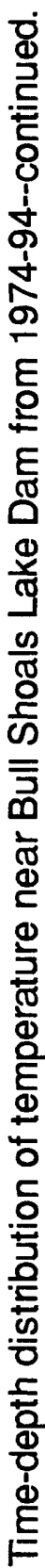

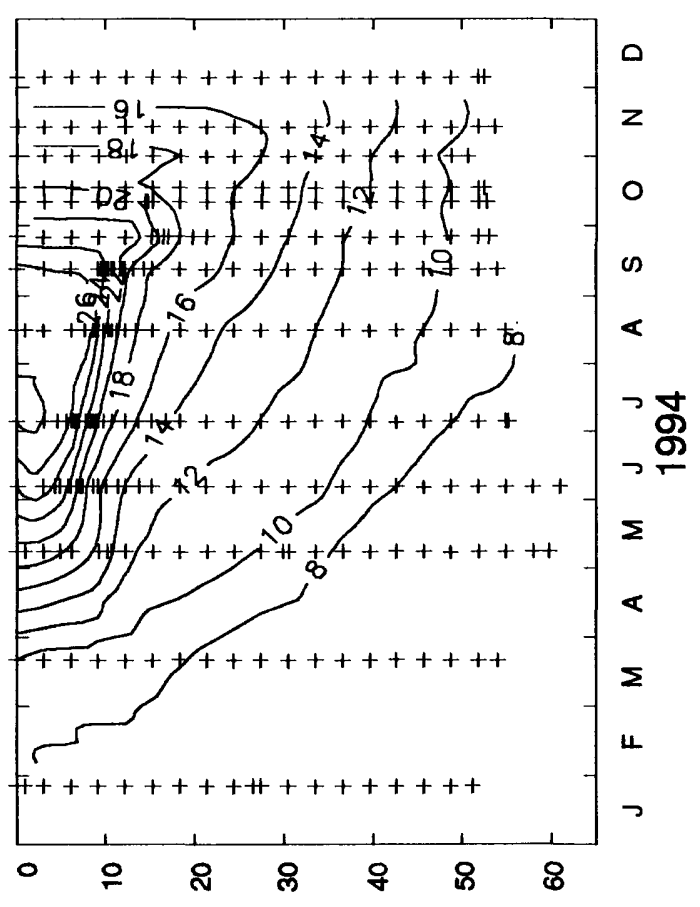

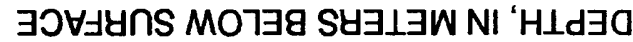




$$
\text { H H }
$$
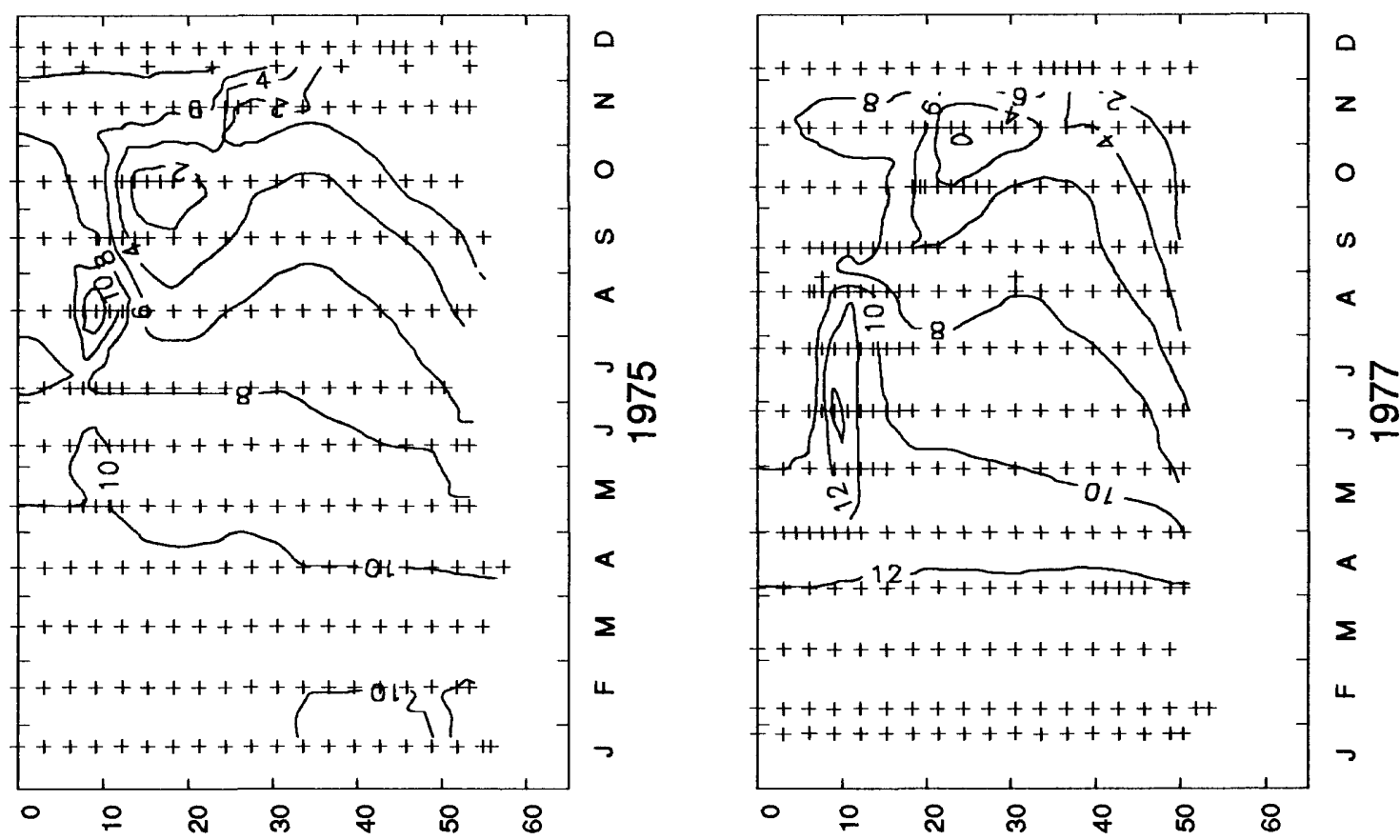

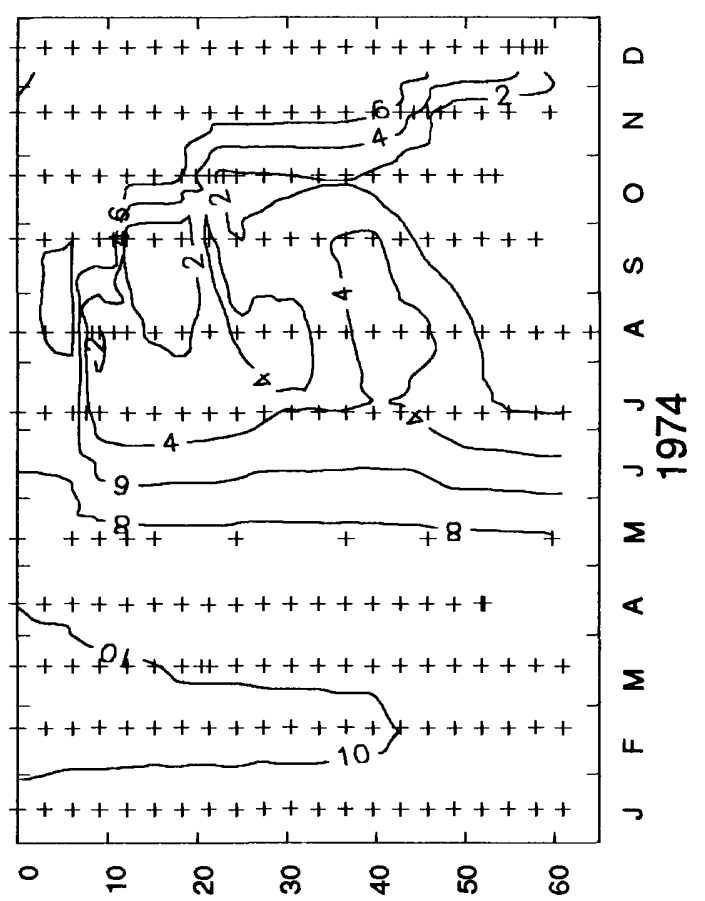

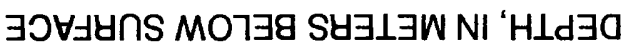

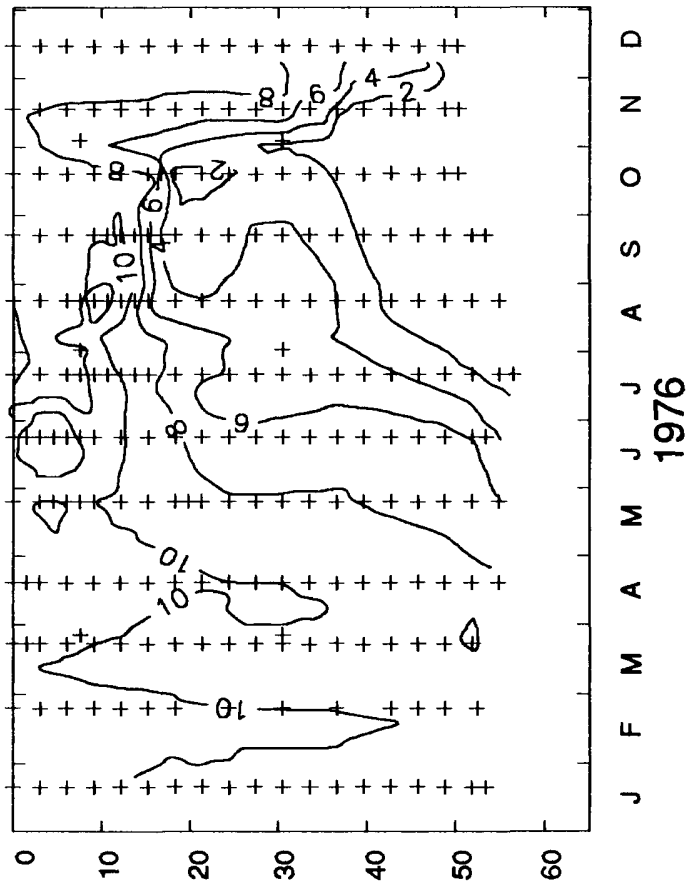

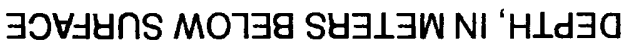




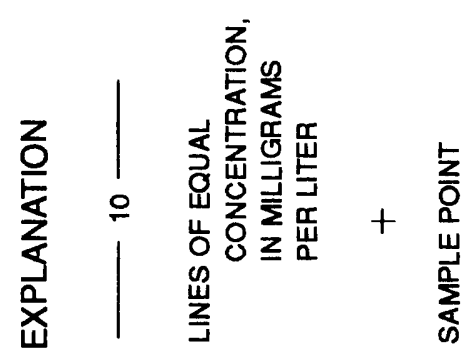
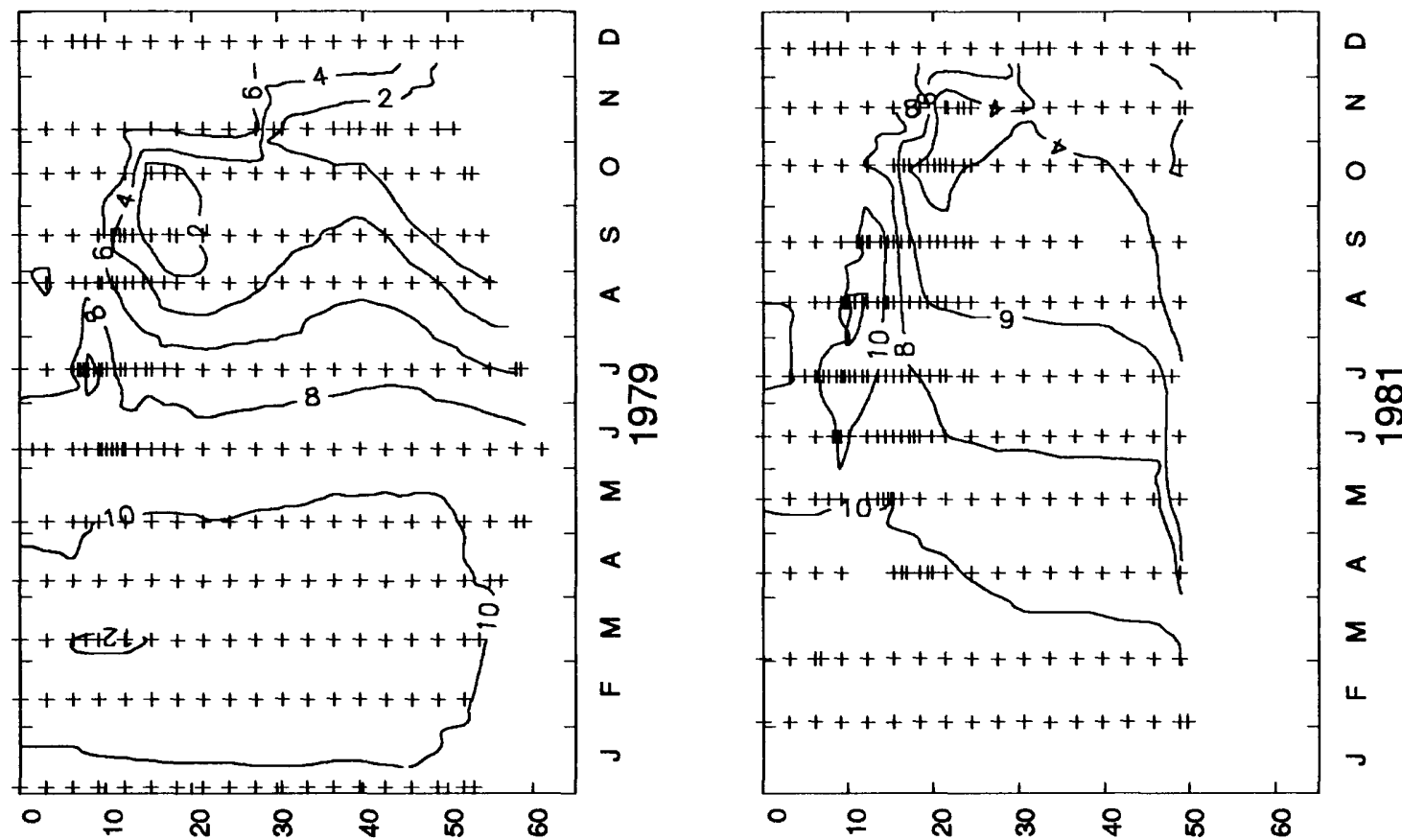

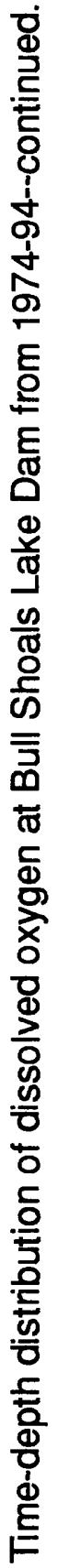



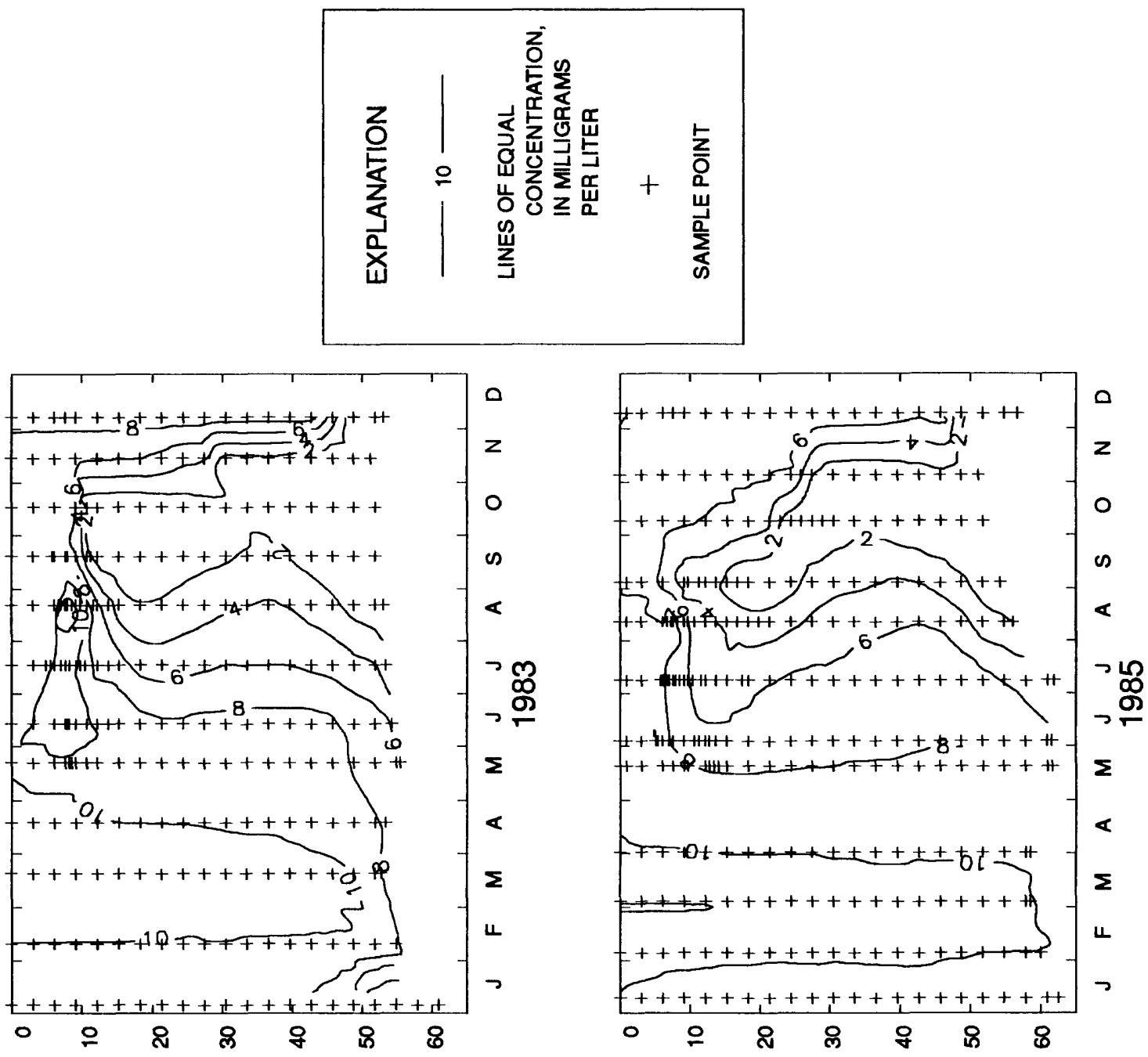

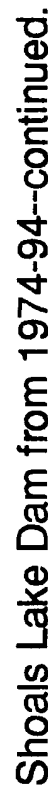

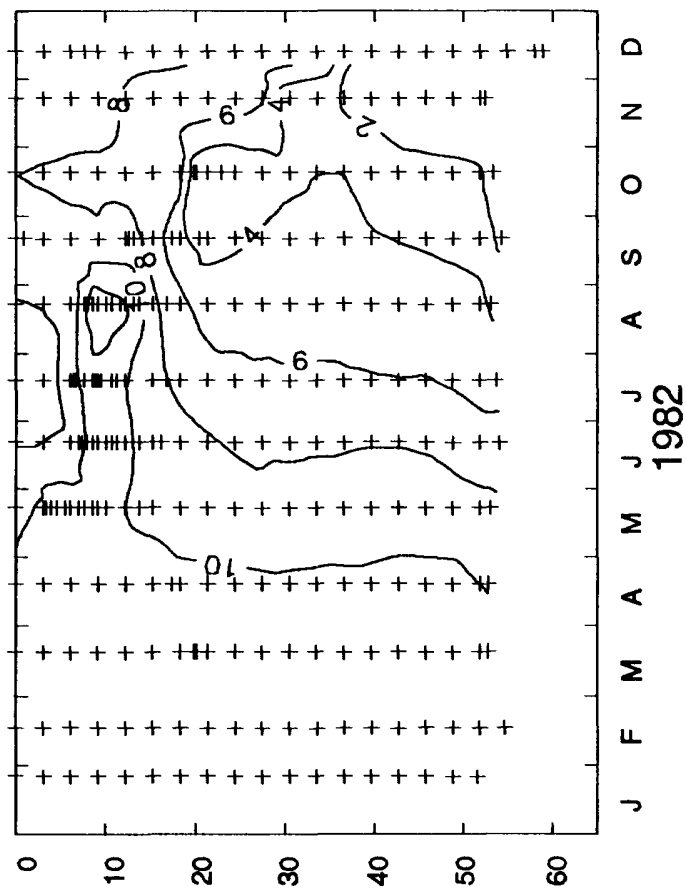

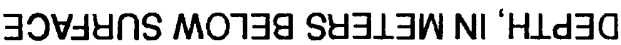

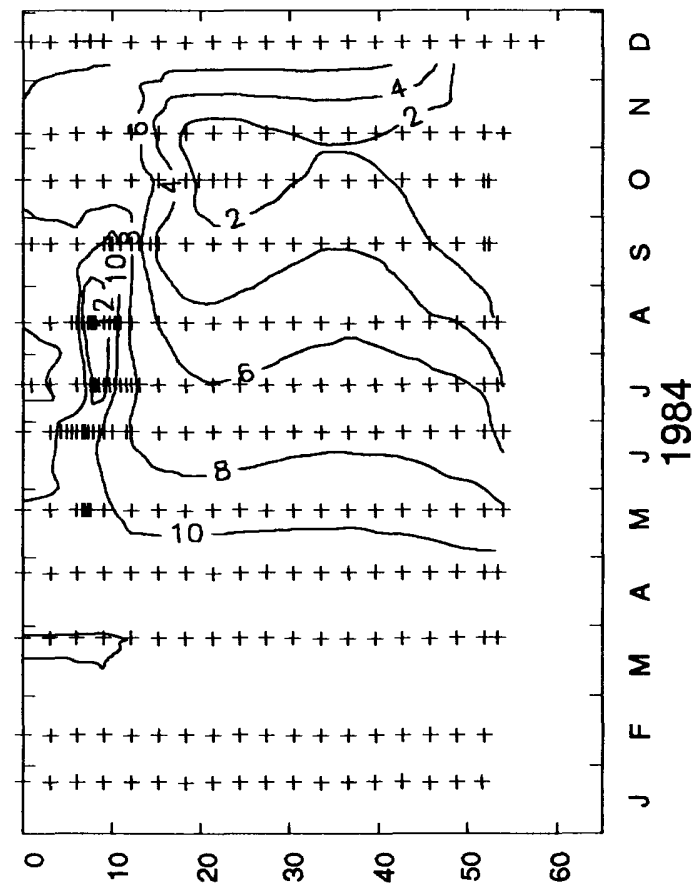

$\exists \supset \forall \exists y \cap S$ MOTヨg S 


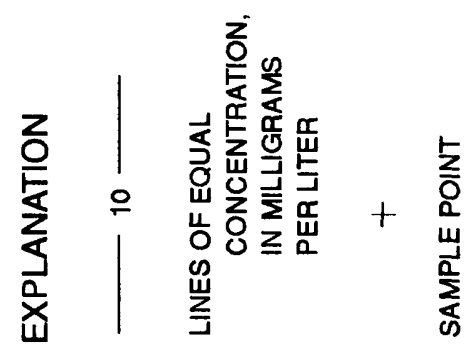
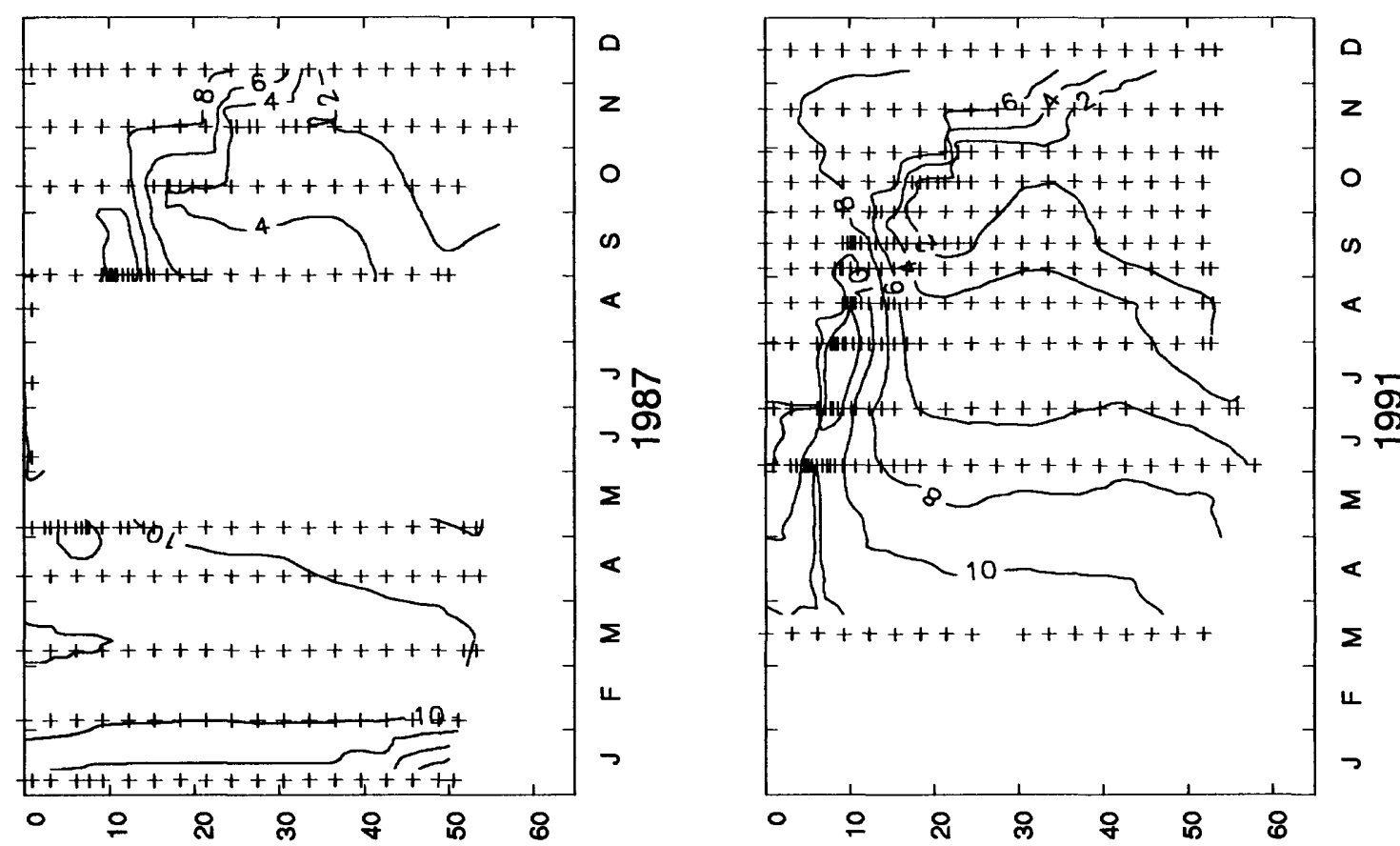

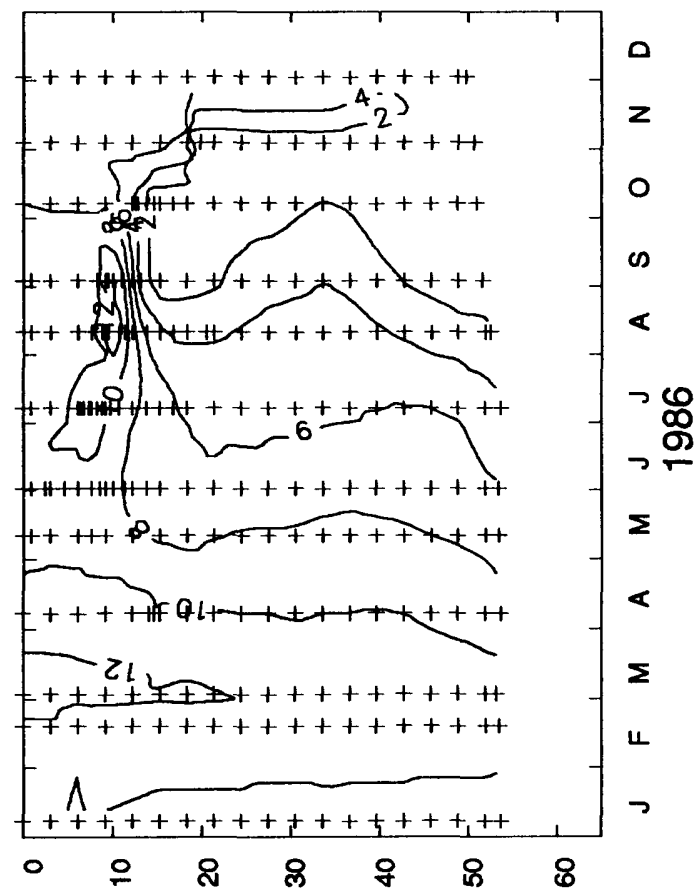

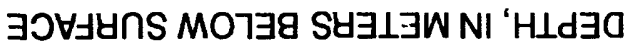

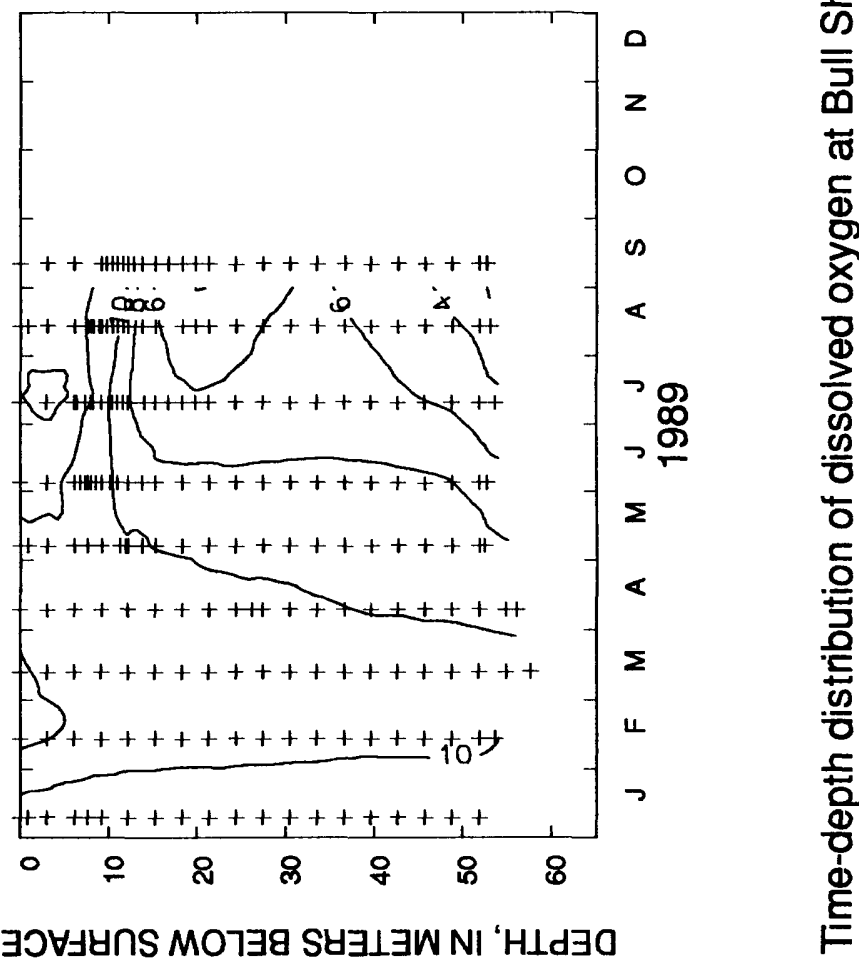



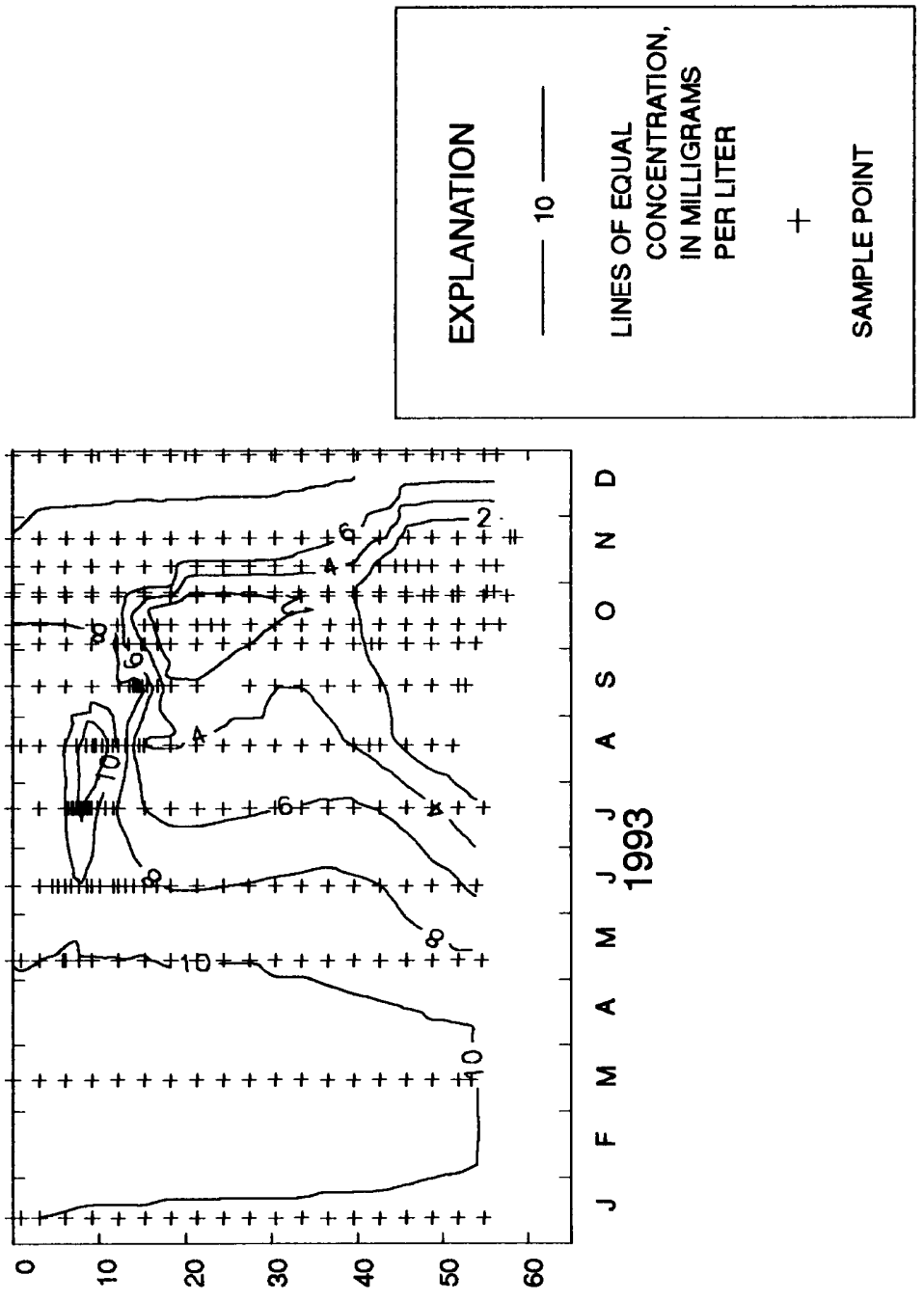

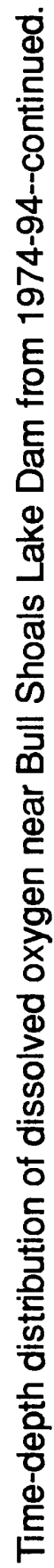

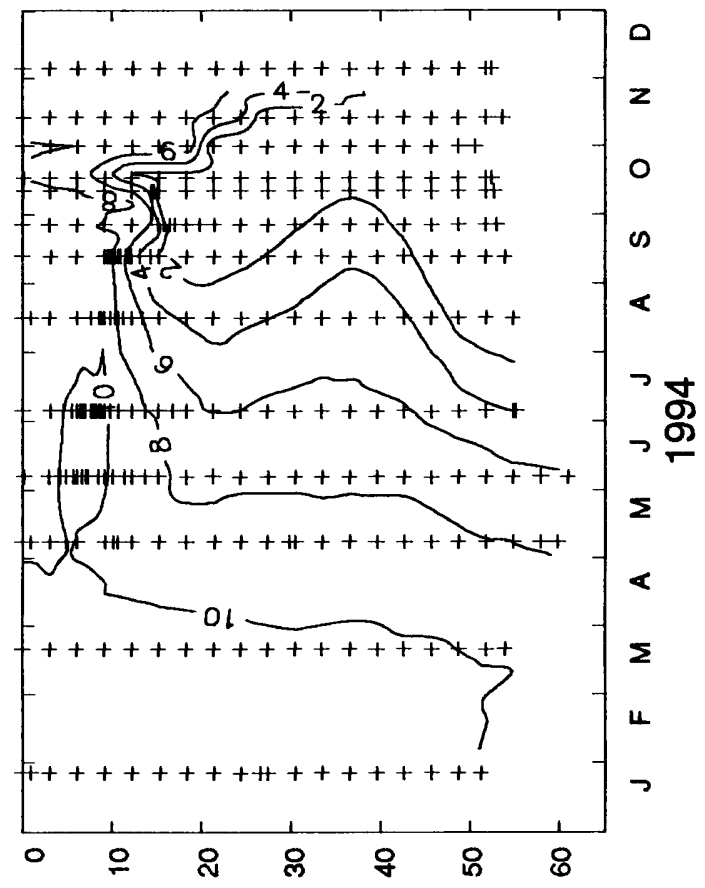

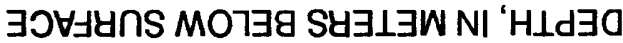




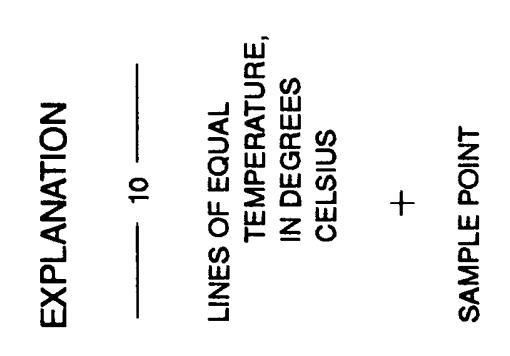
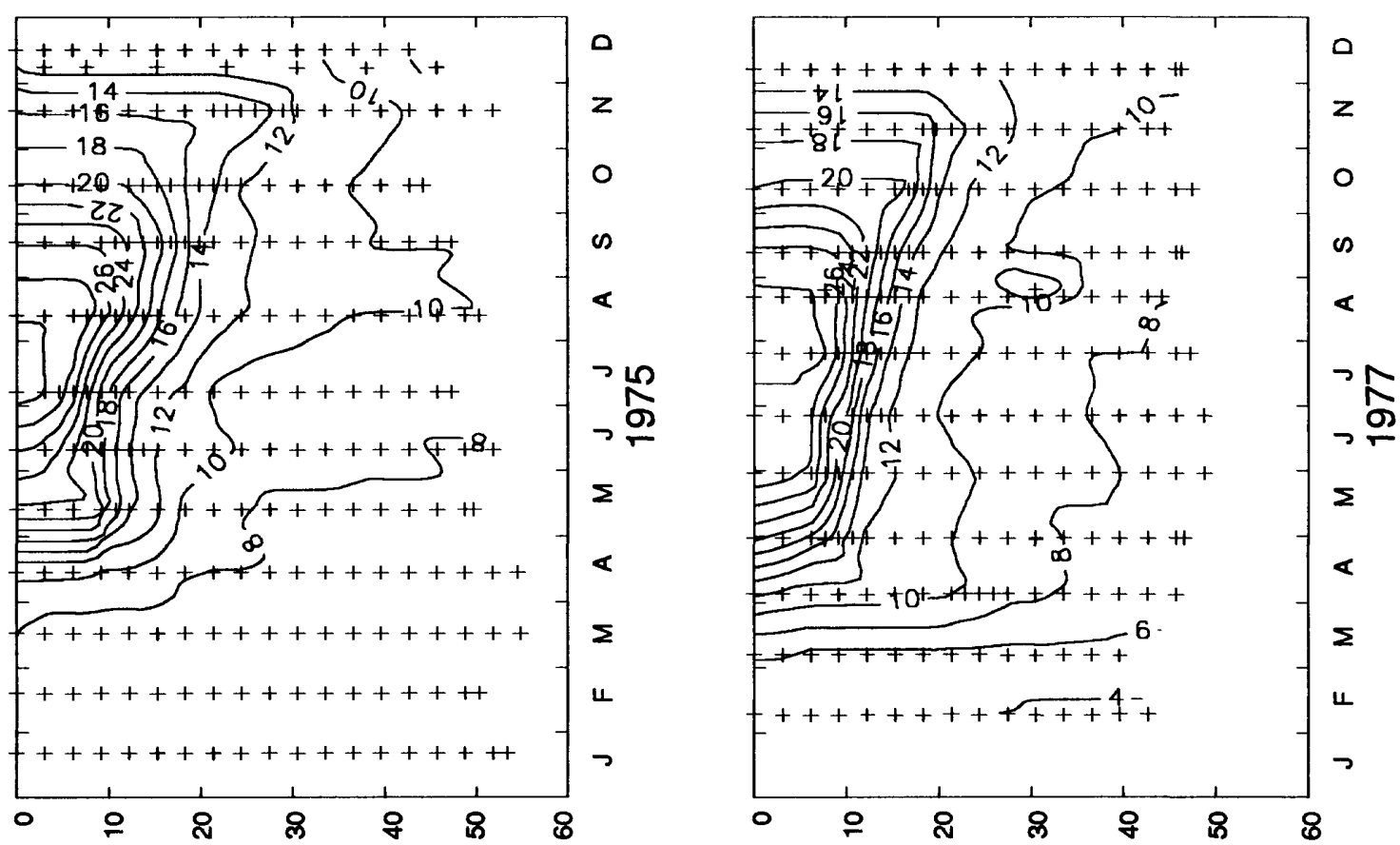

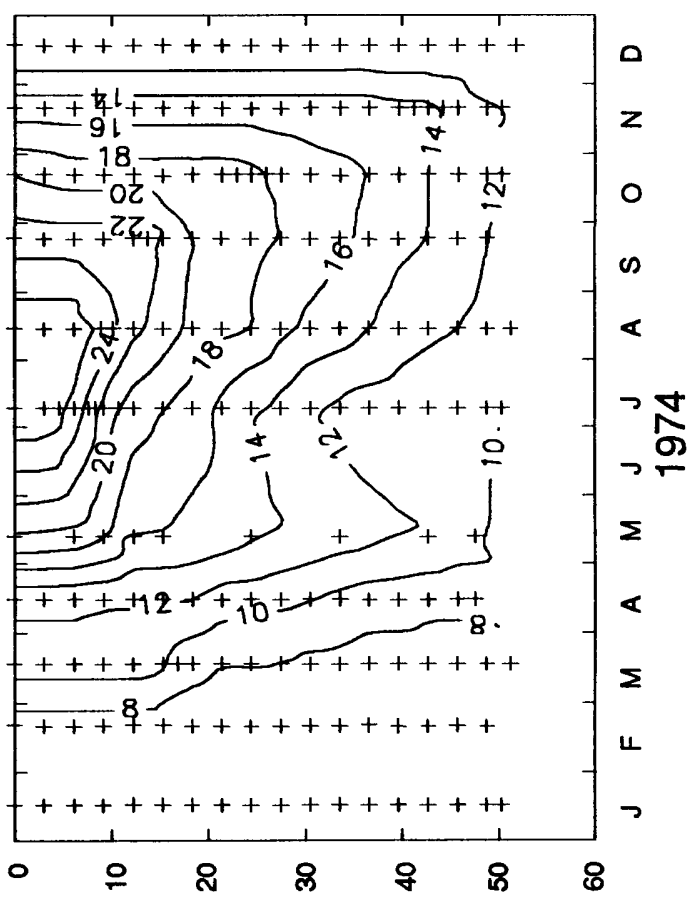

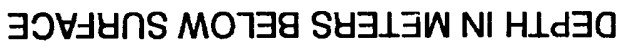

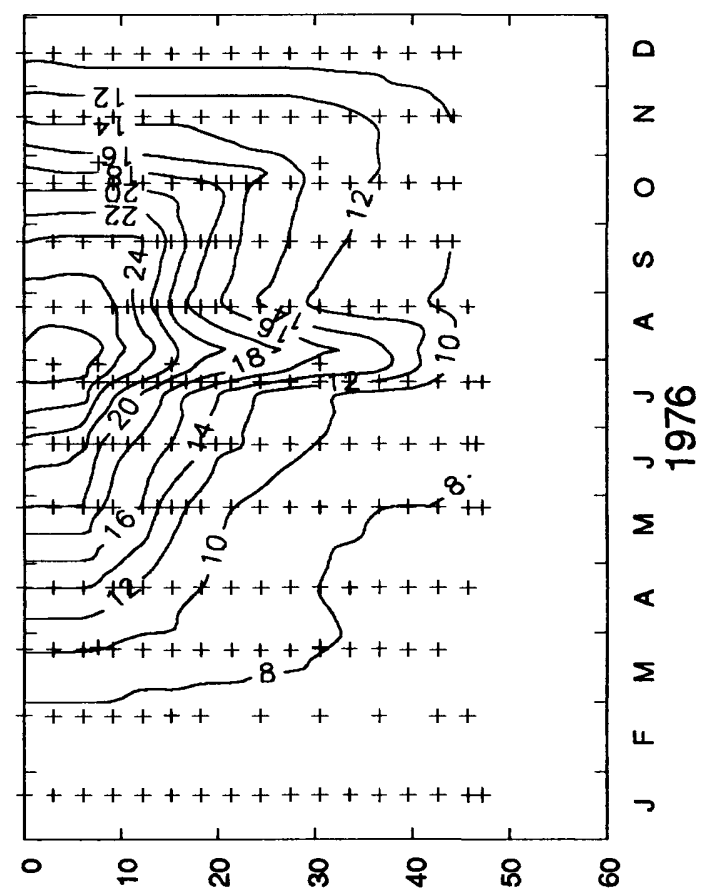

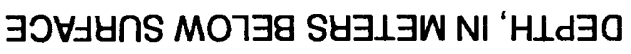



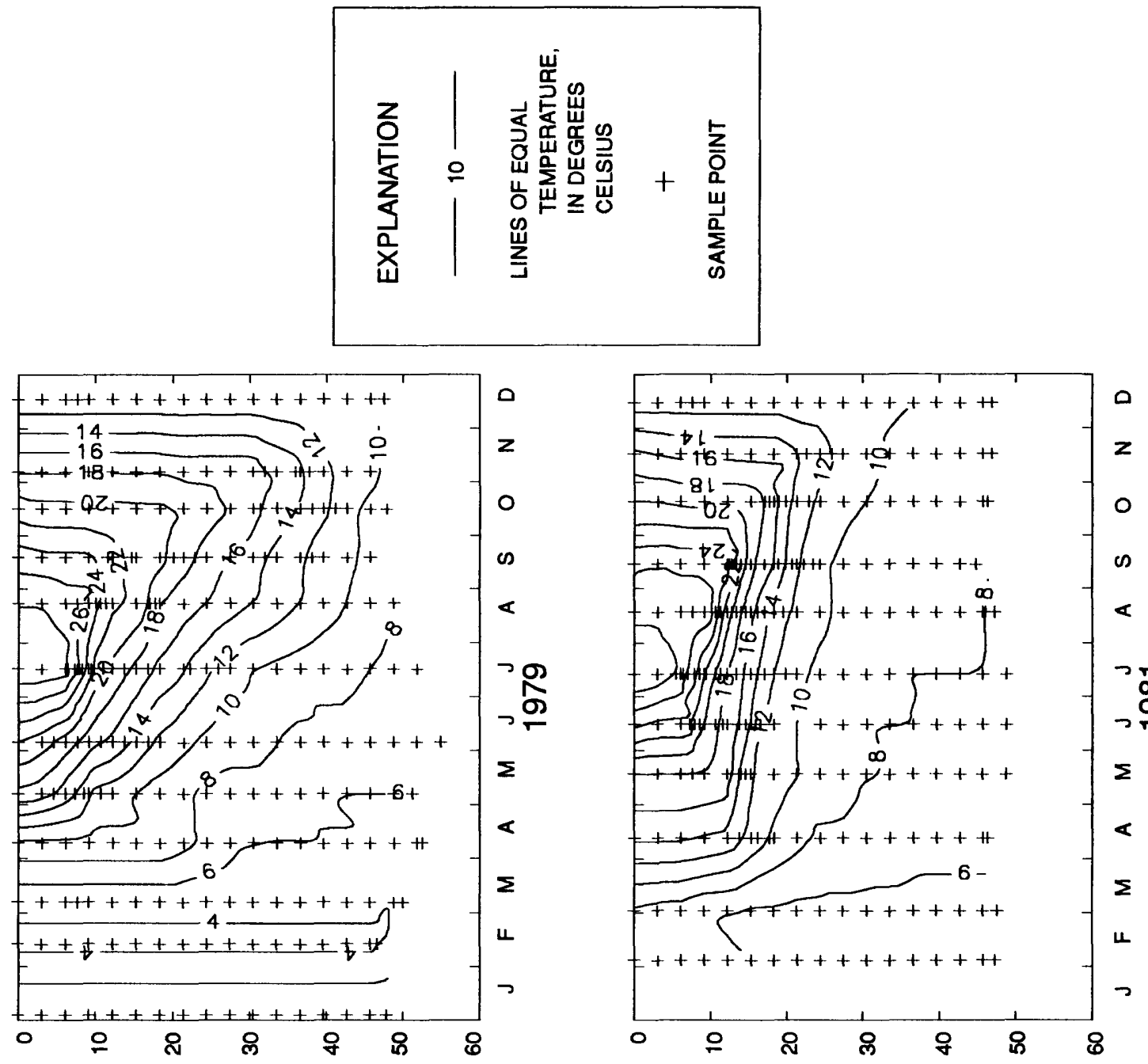

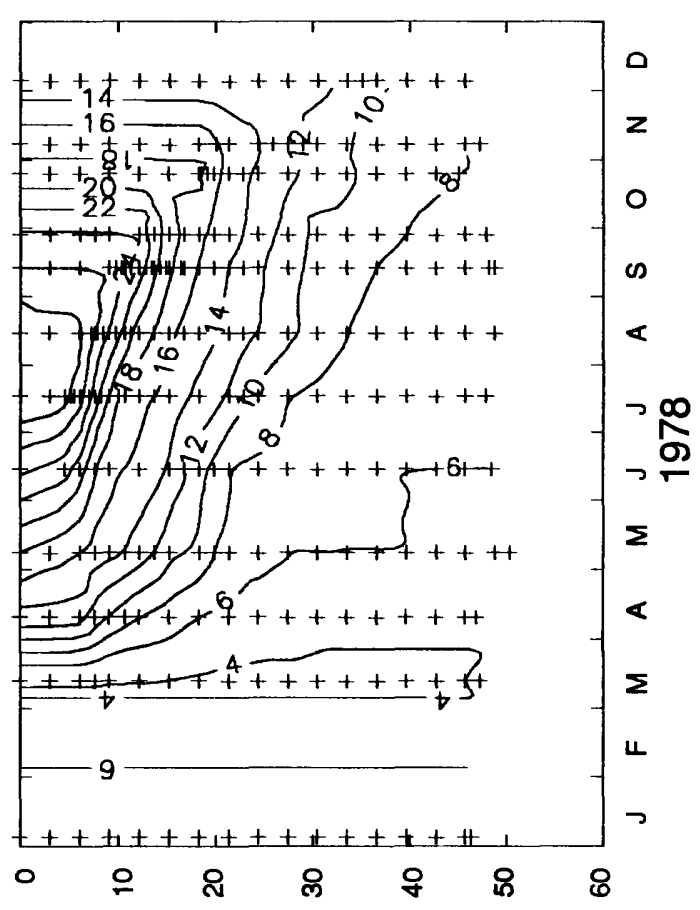

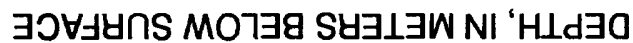

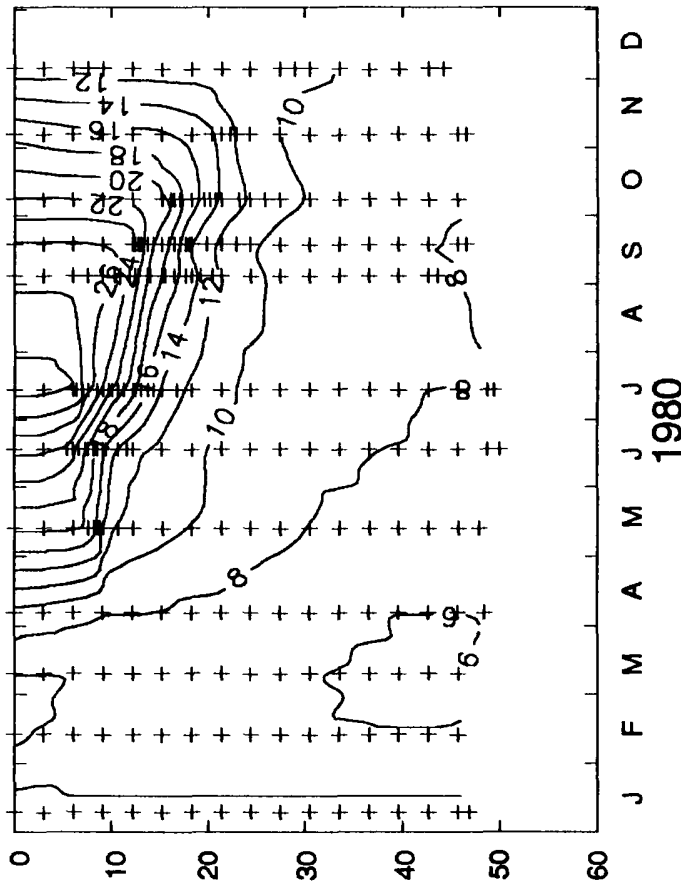

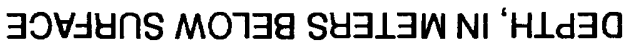




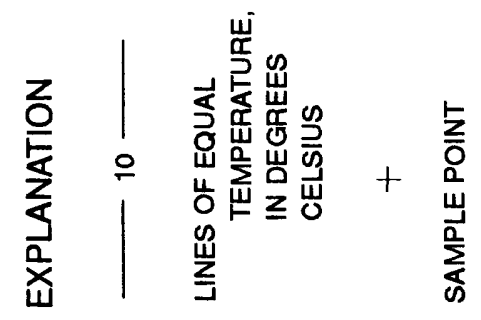
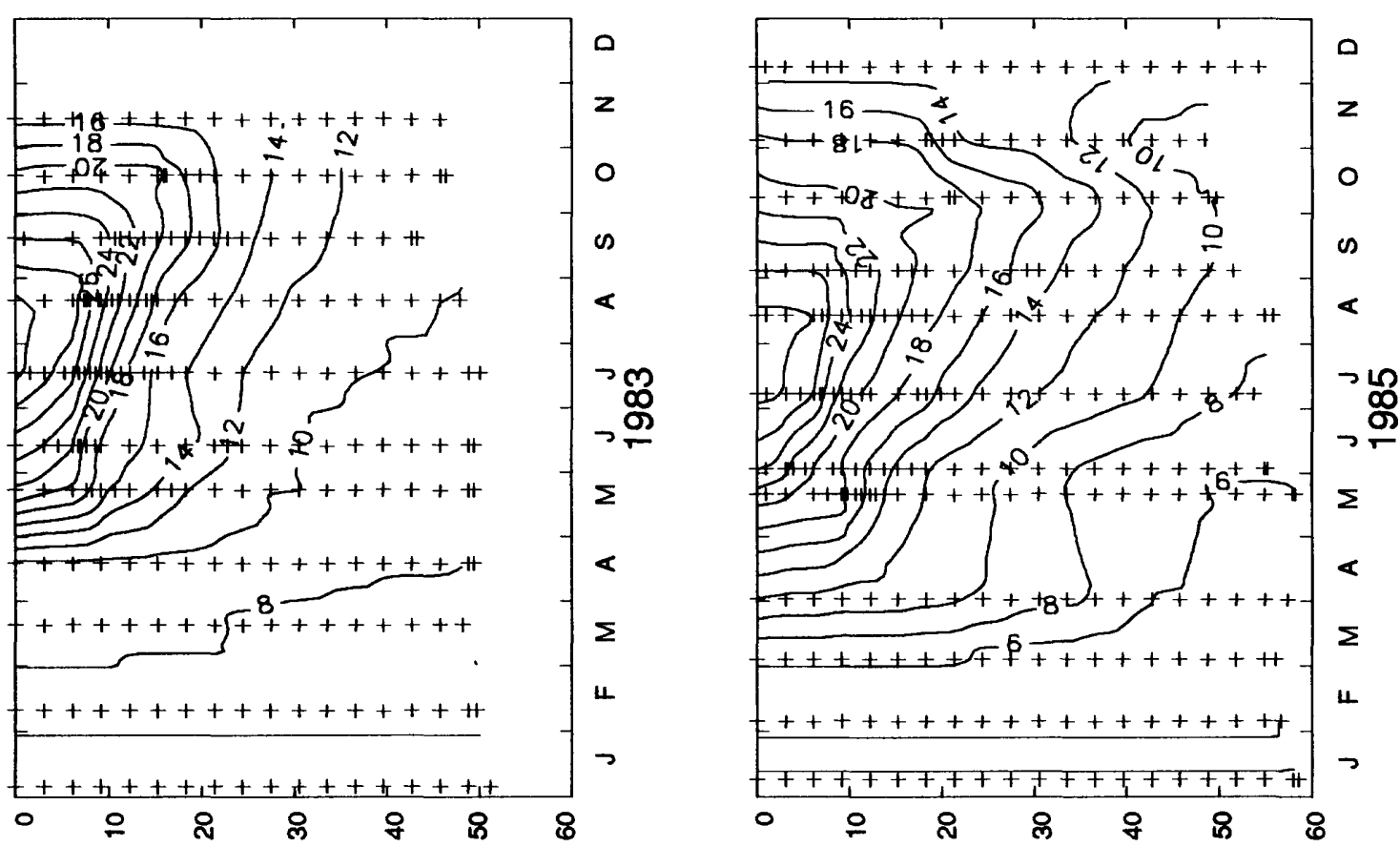

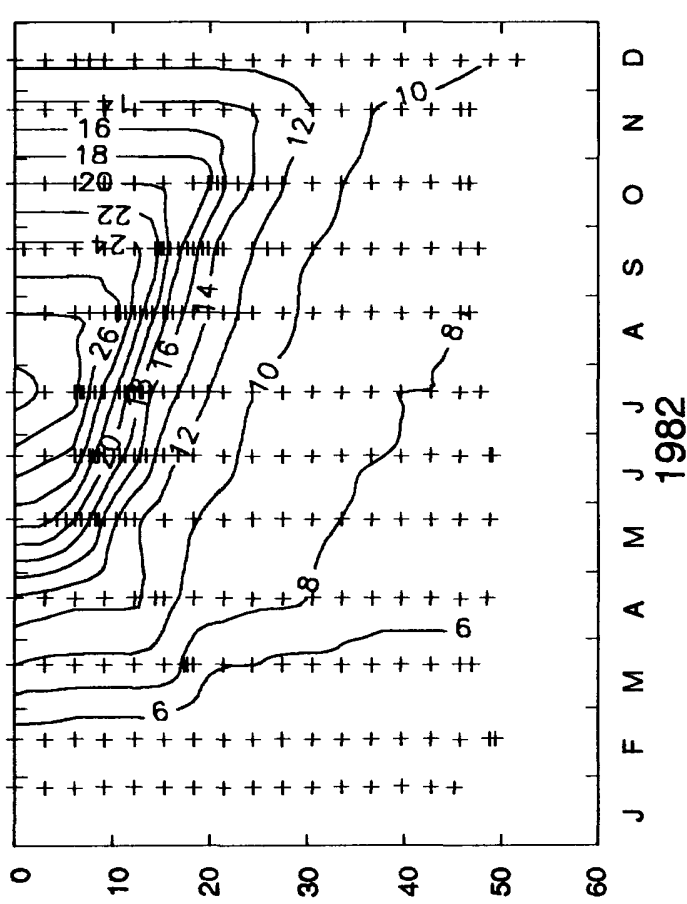

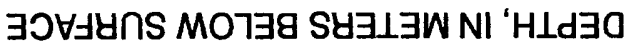

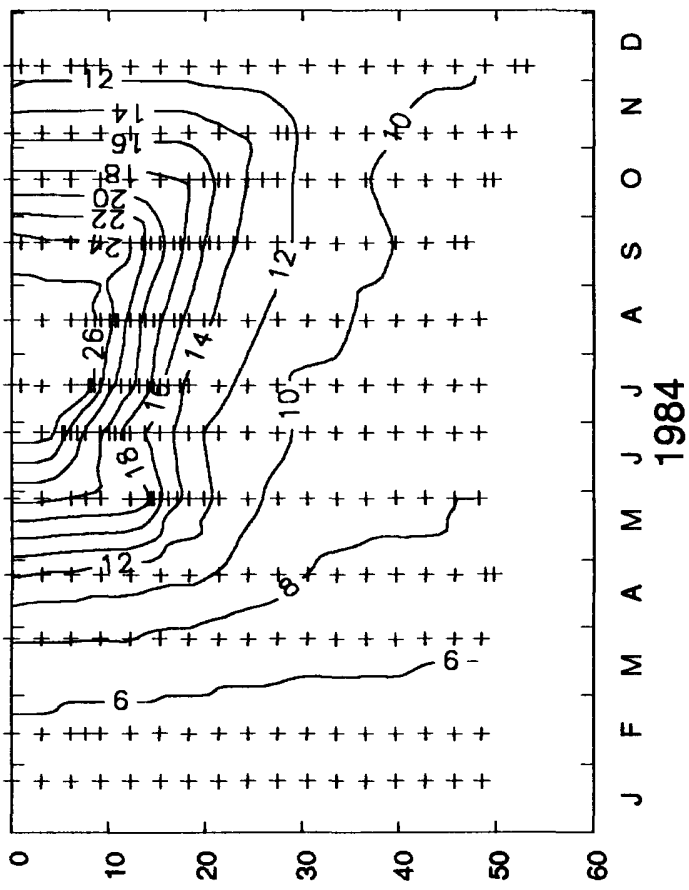

$\exists \supset \forall\lrcorner y \cap S$ MOフヨg S 


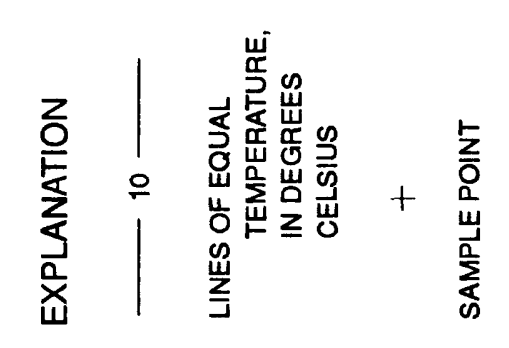
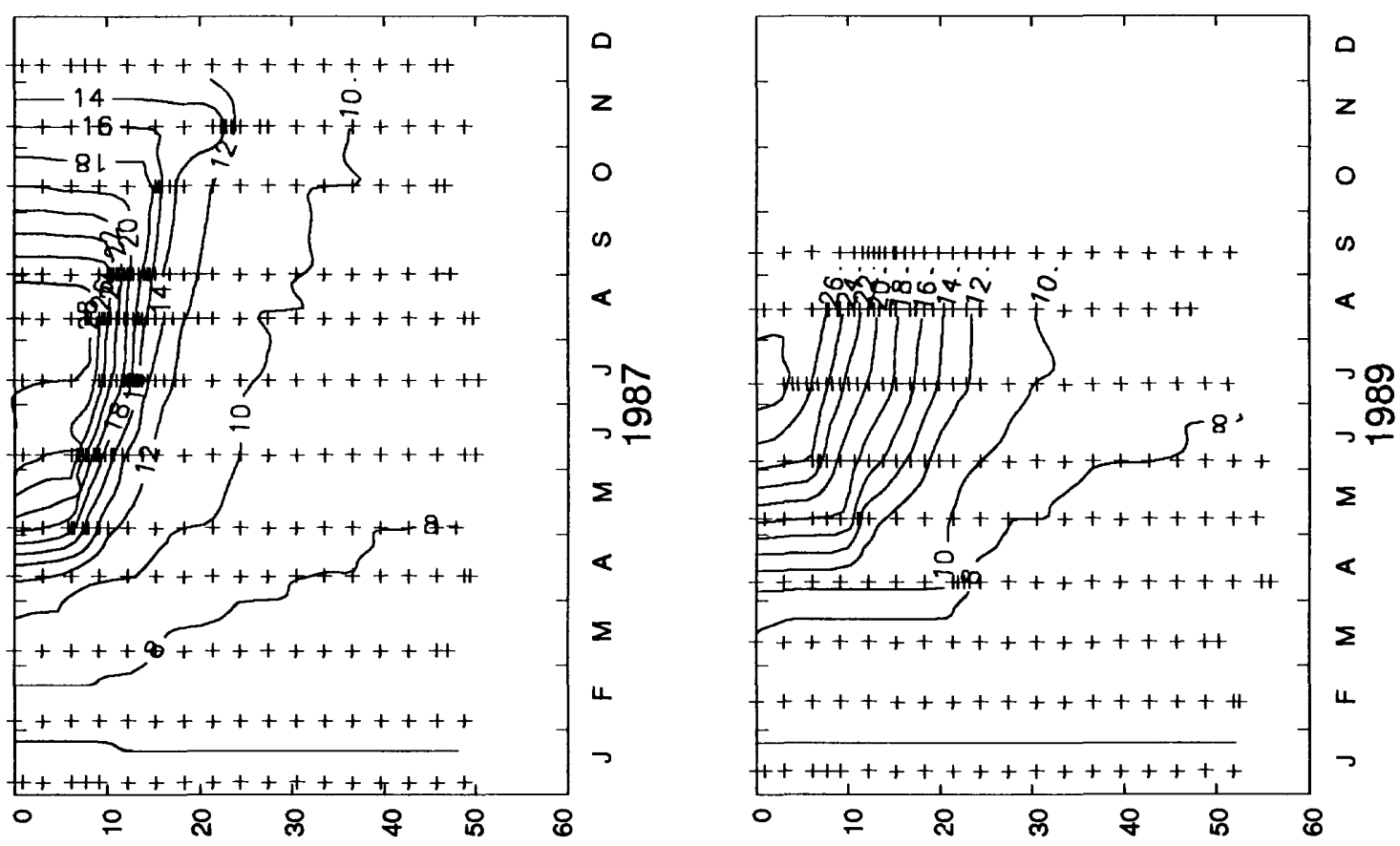

守
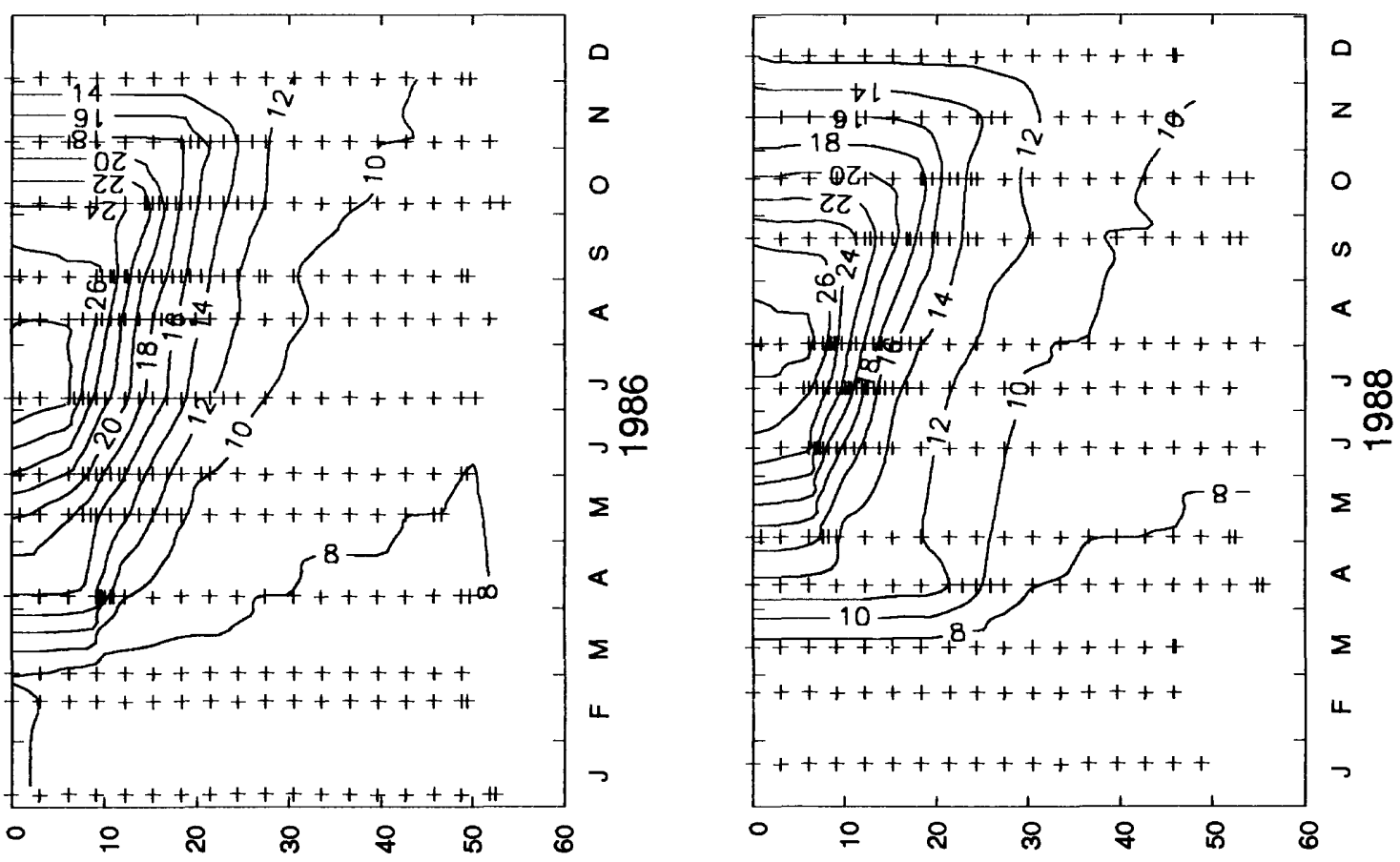

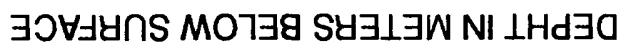

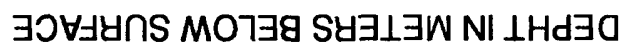



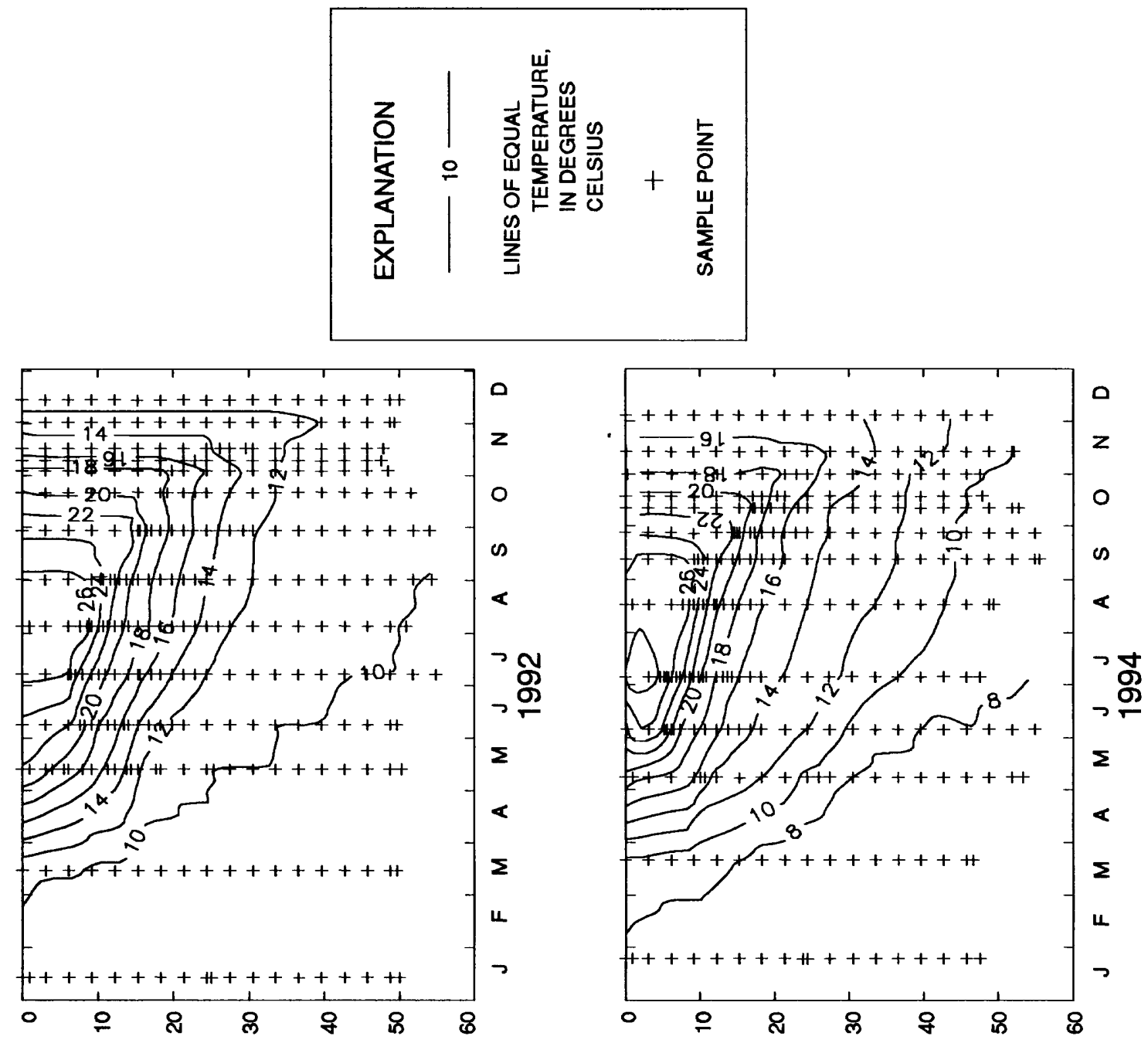

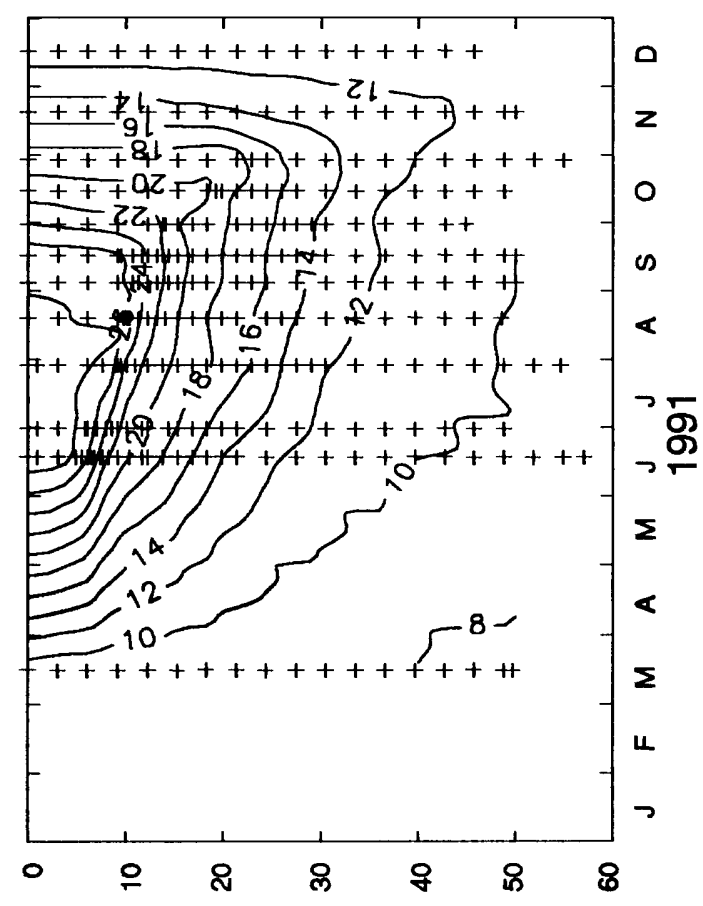

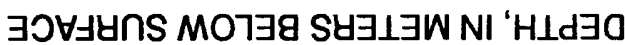

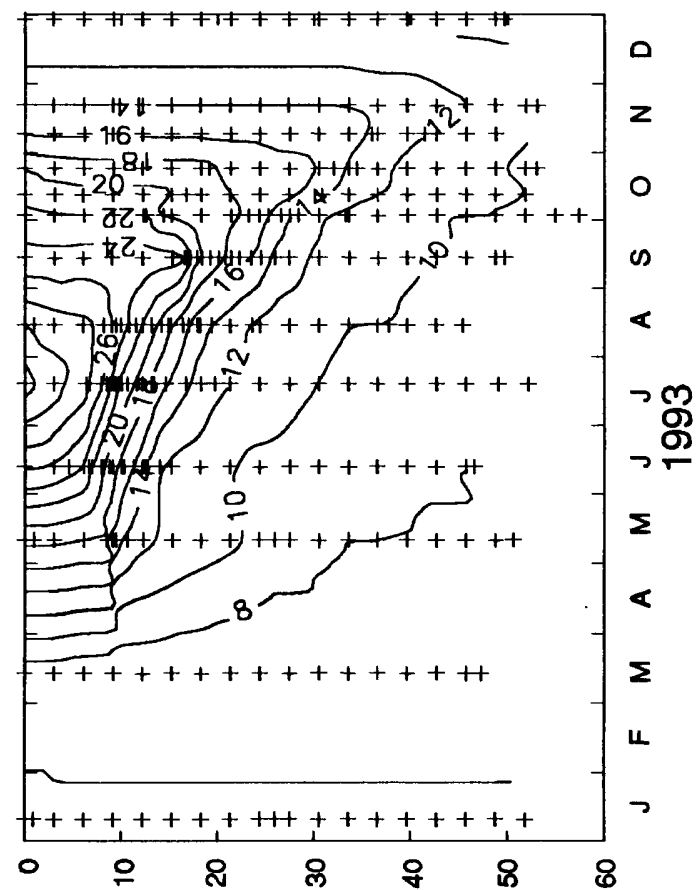

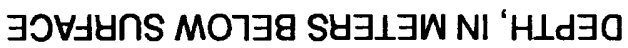



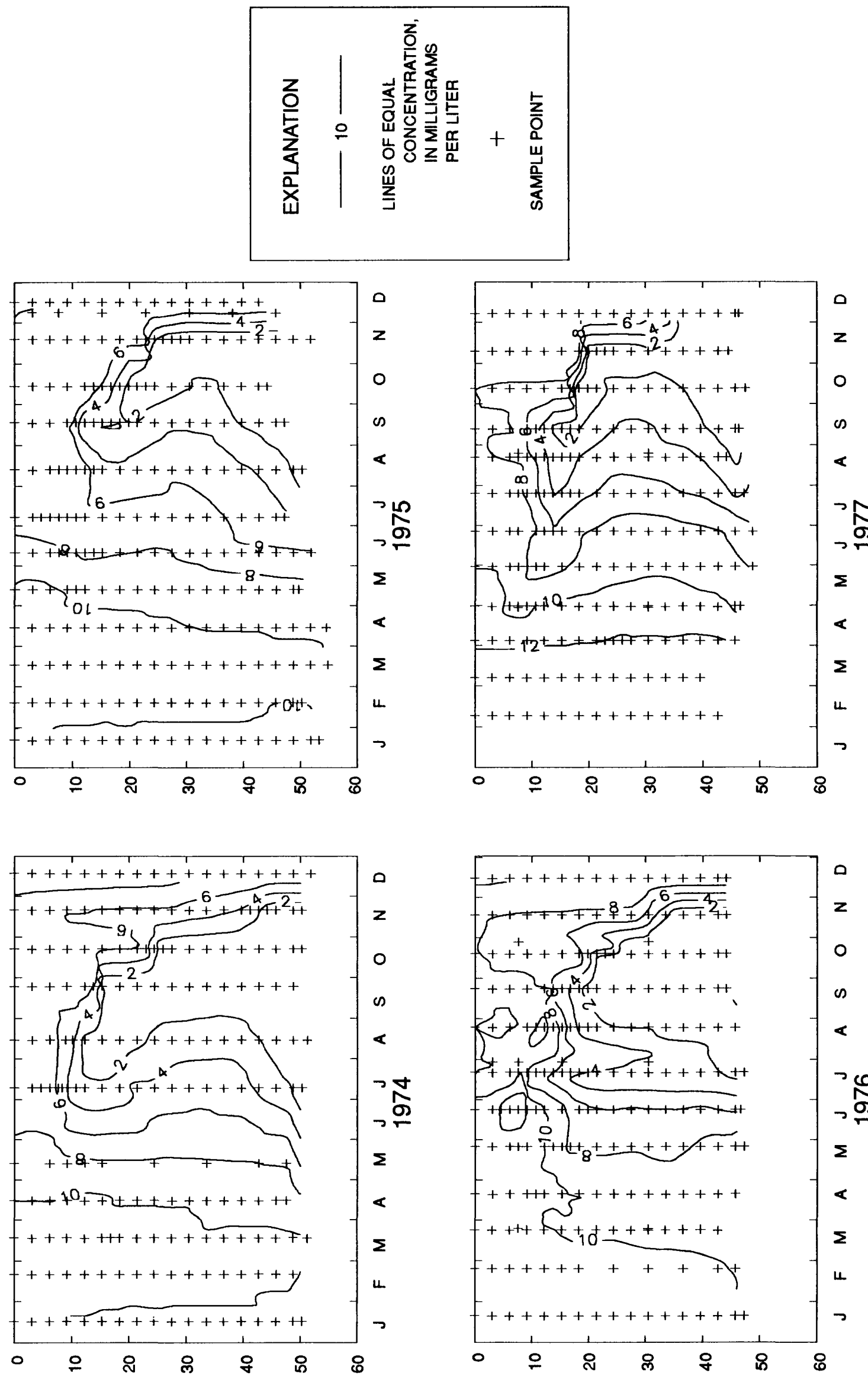

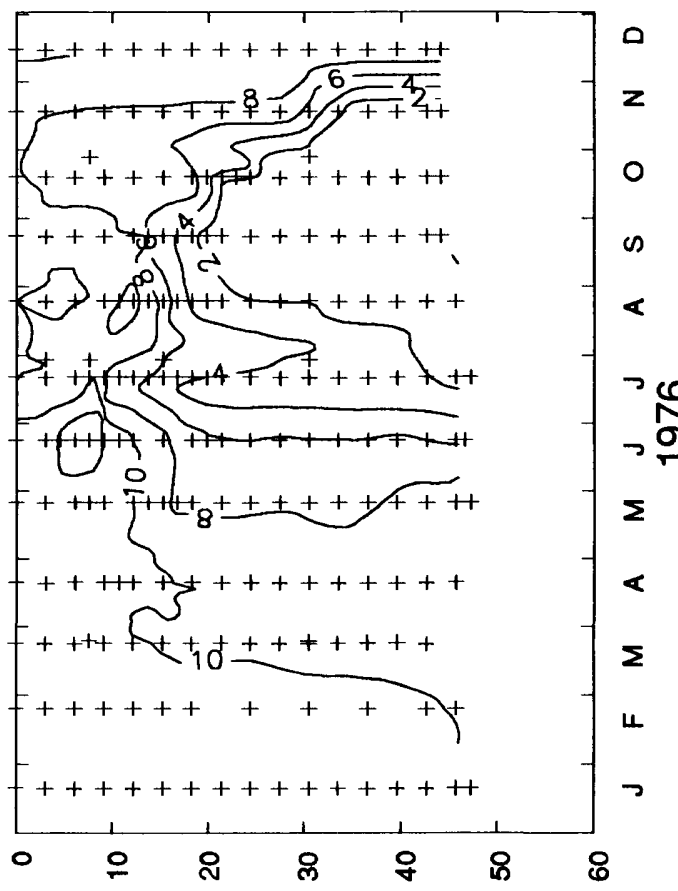

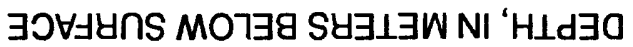



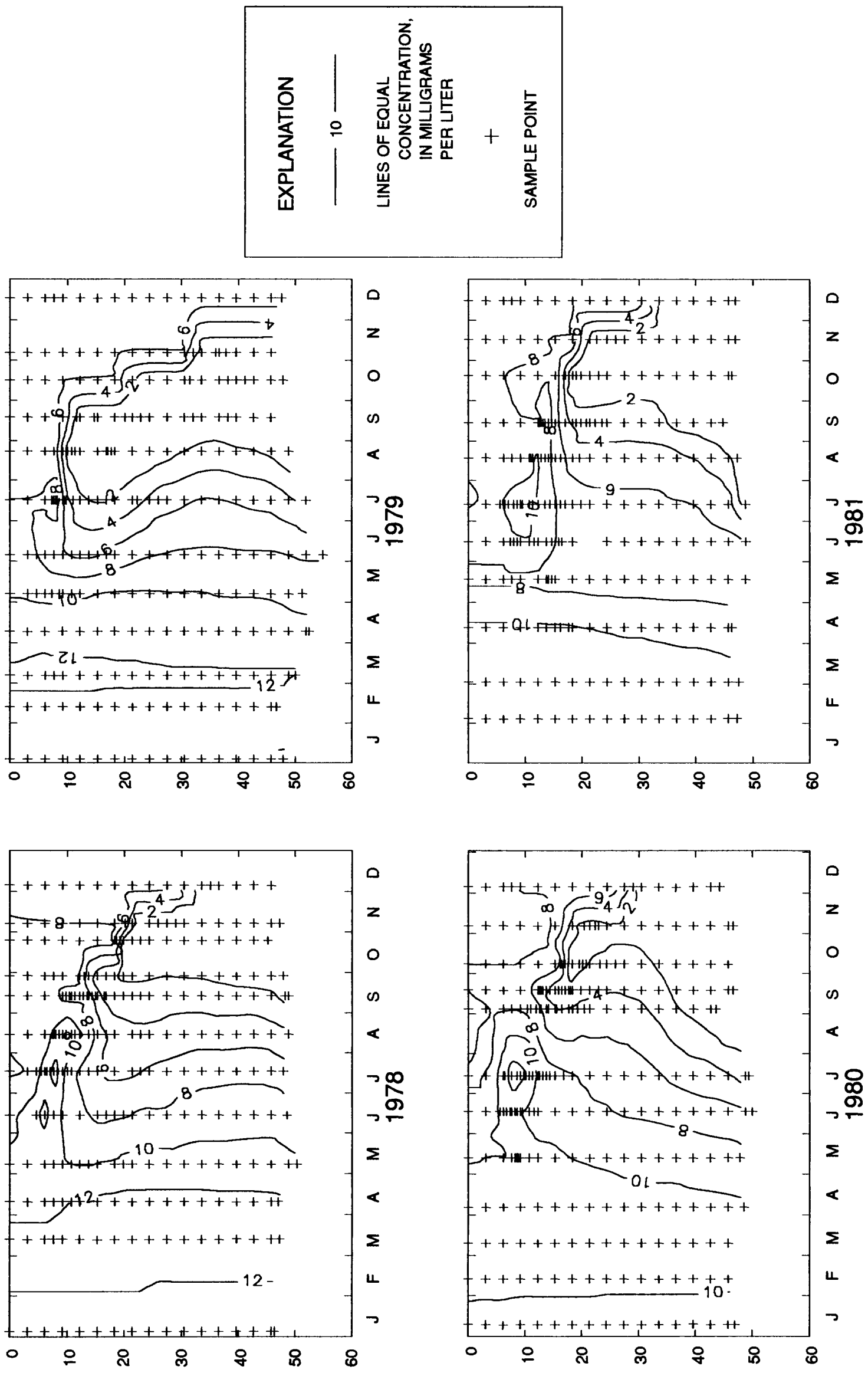

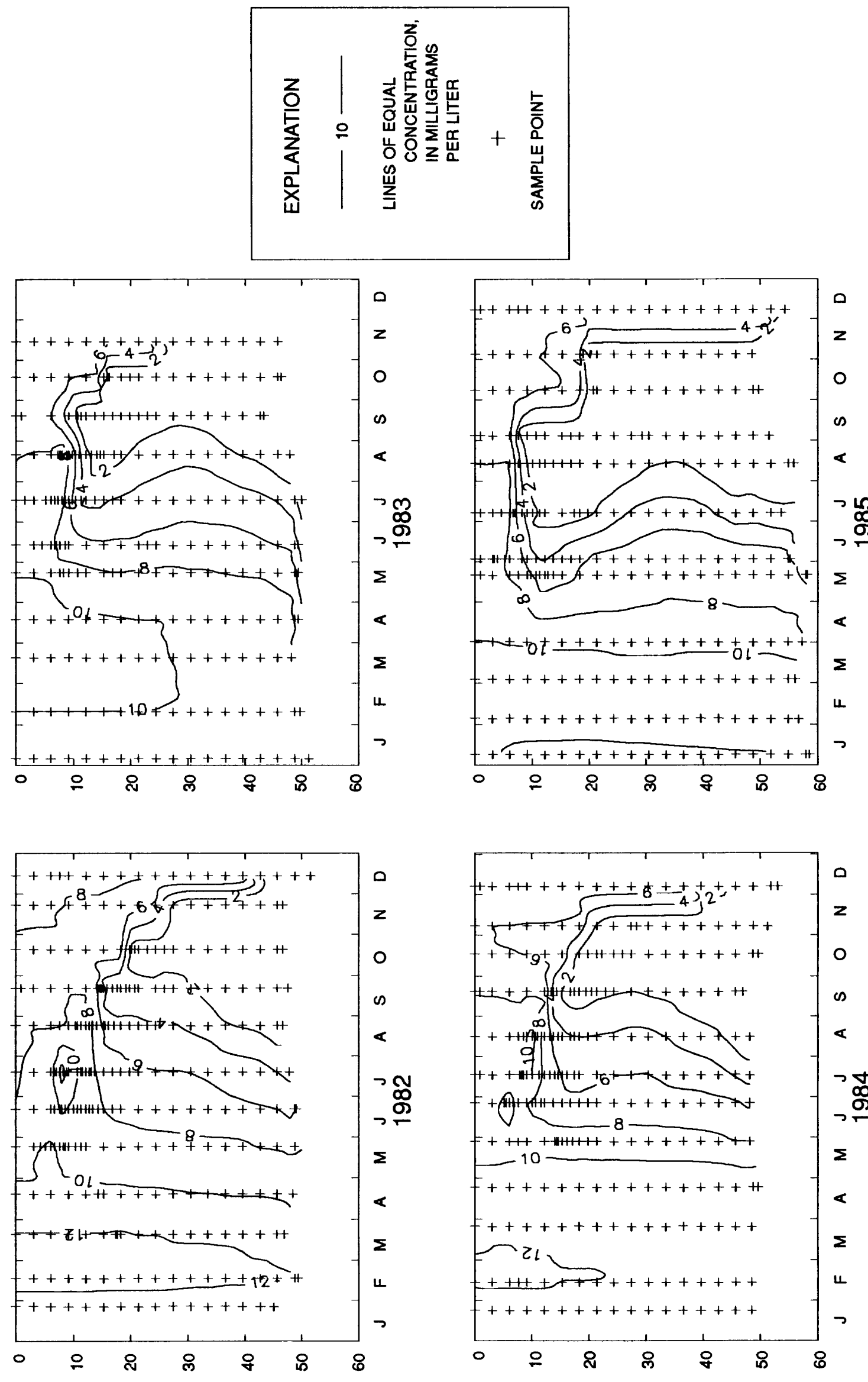

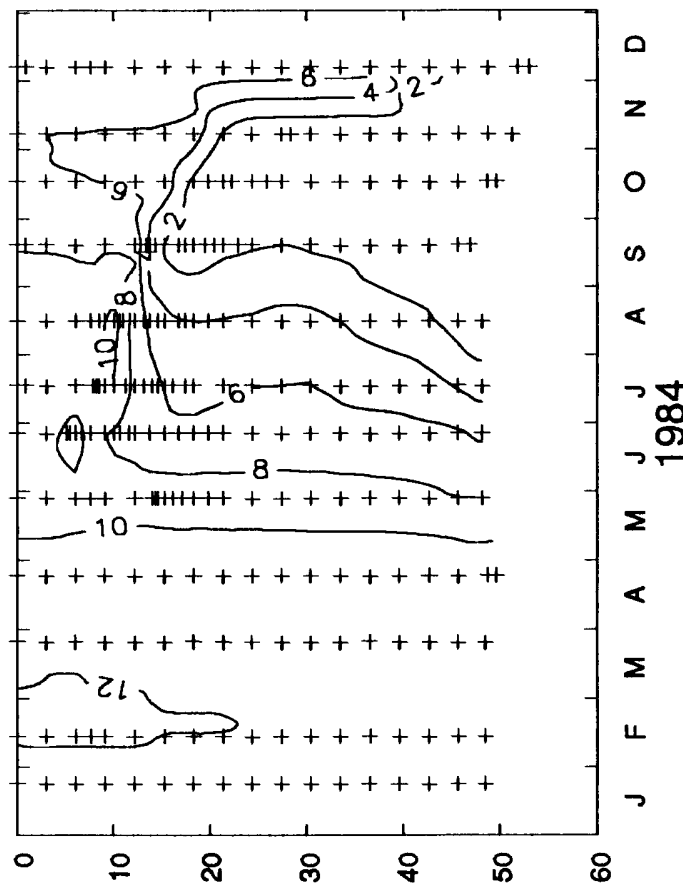

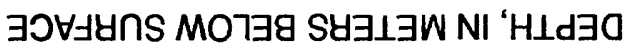



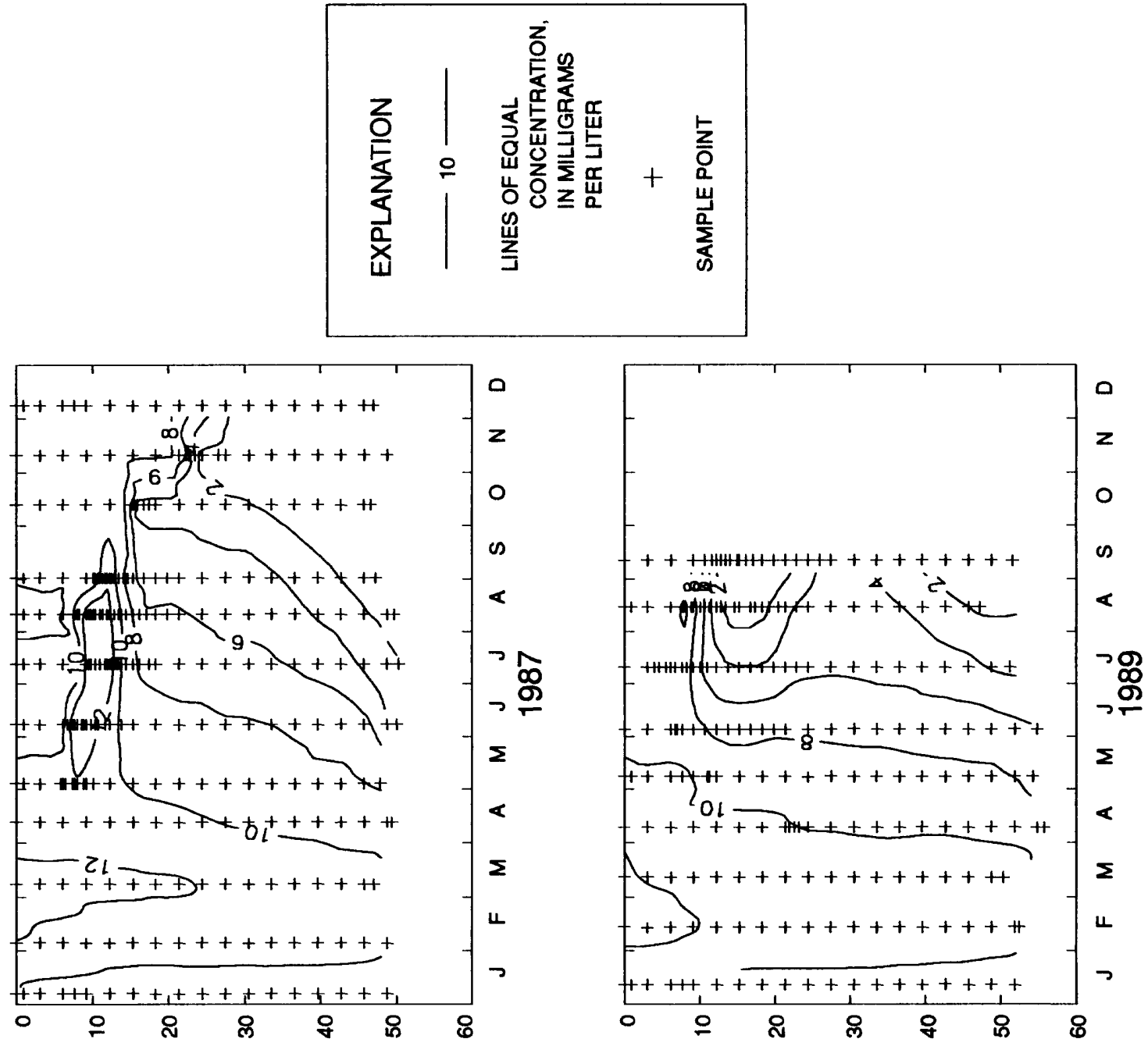

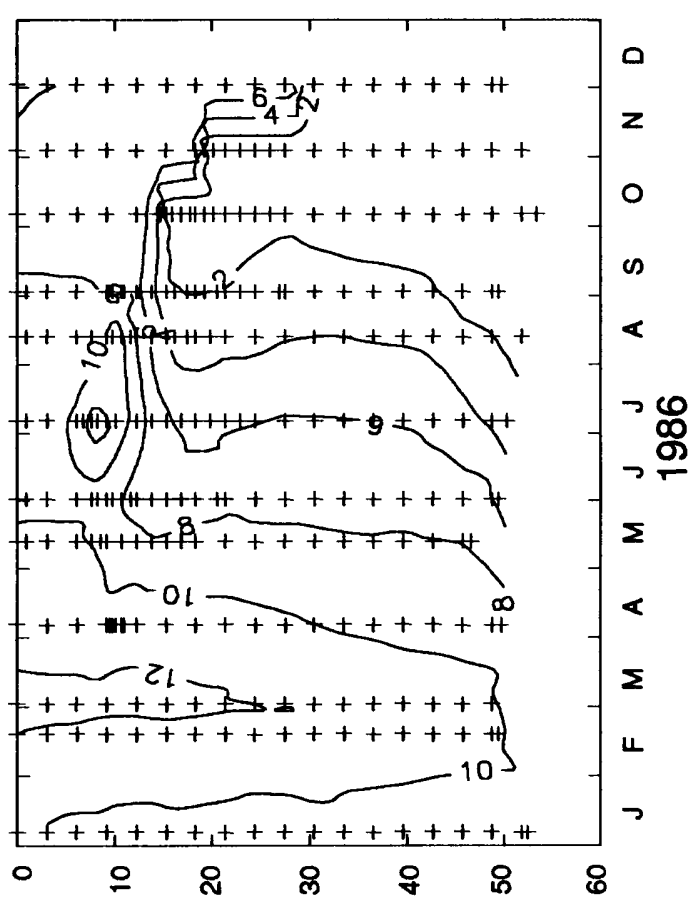

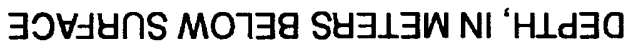

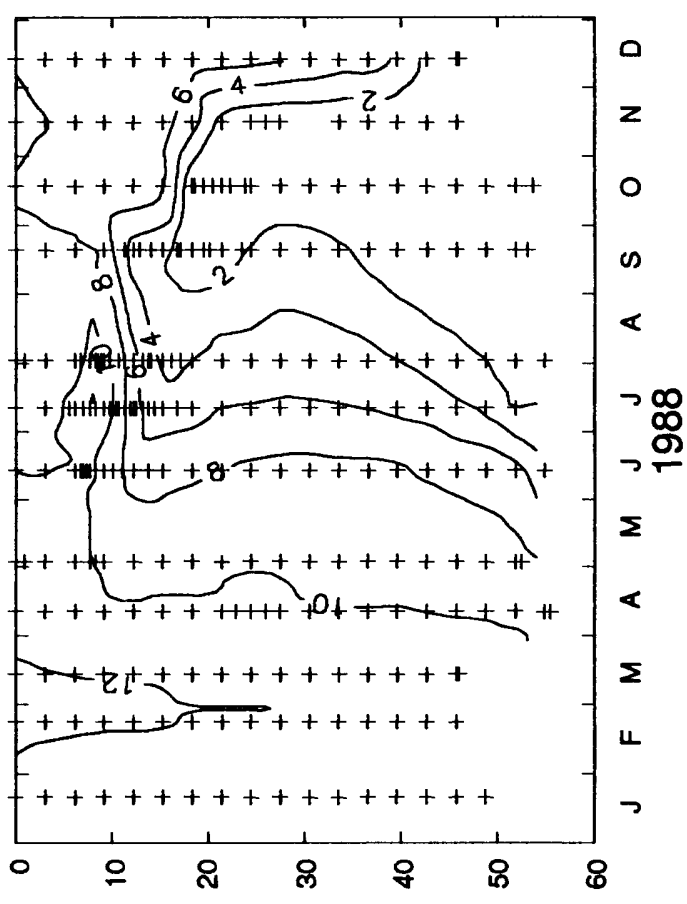

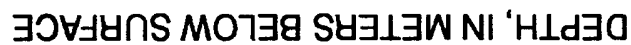




$$
\text { II In! }
$$
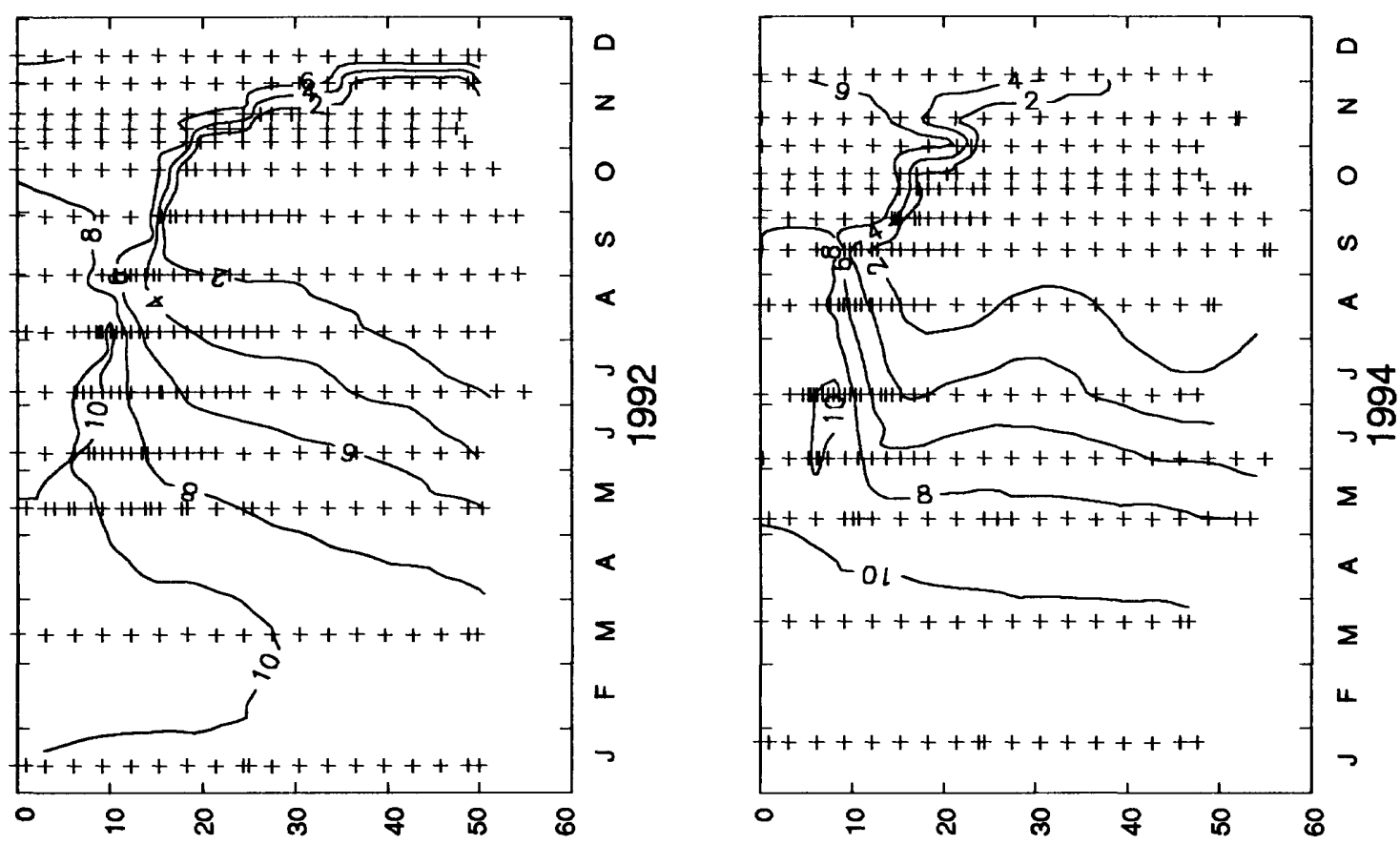

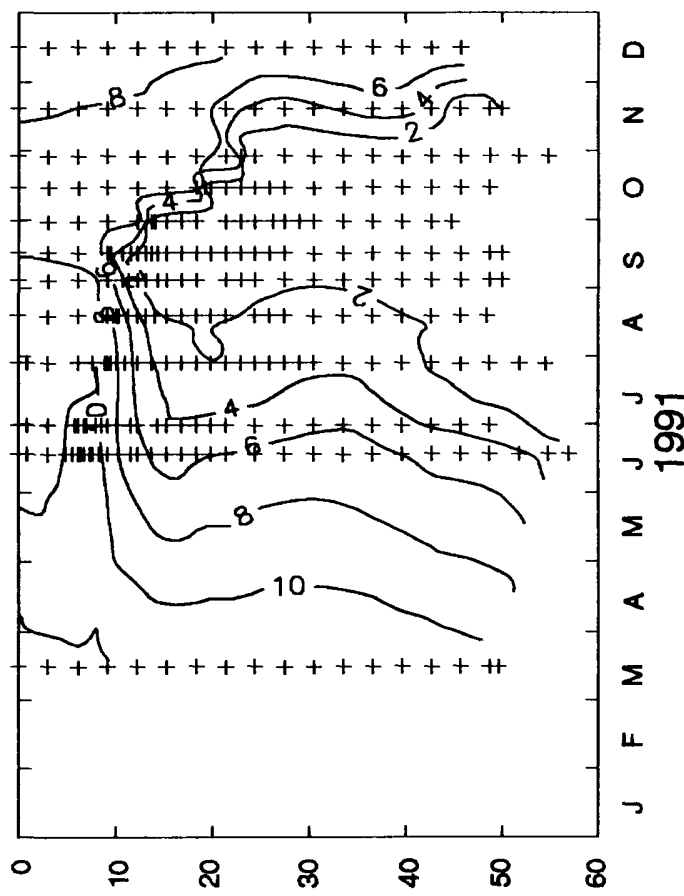

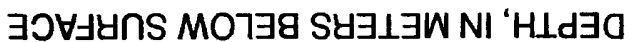

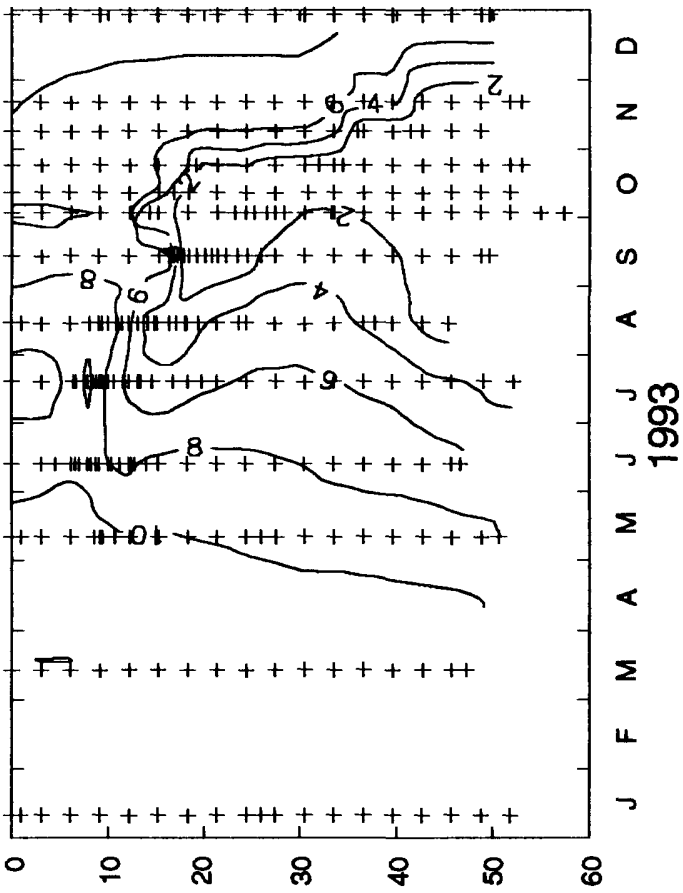

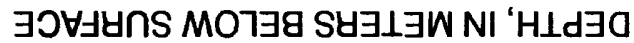

